
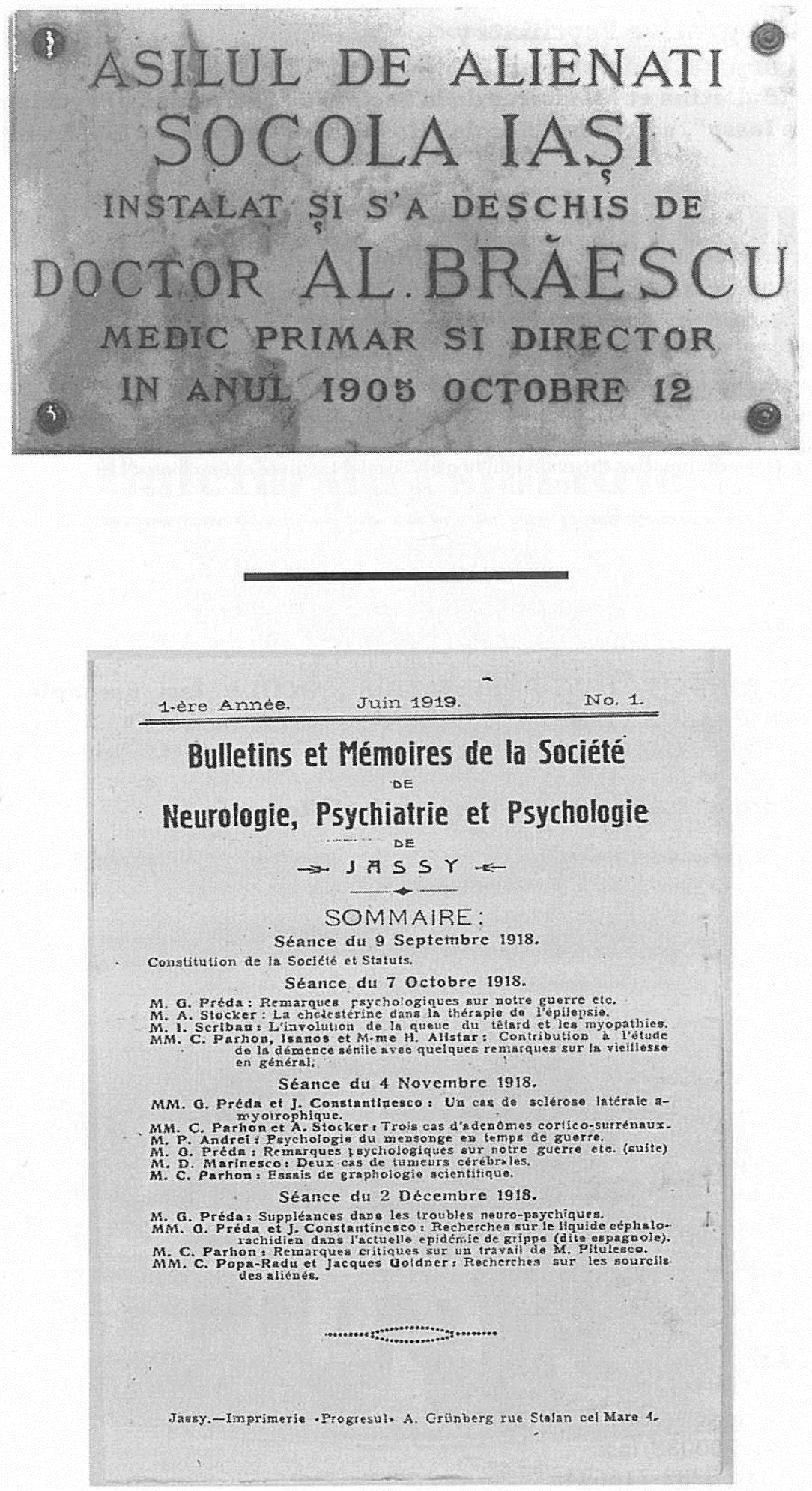


\section{Bulletin of Integrative Psychiatry}

New series of "Bulletins et Mémoires de la Société de Neurologie, Psychiatrie et Psychologie de Iassy", edited by "Socola” Hospital of Psychiatry Iaşi from 1919 to 1946

\section{Editorial Board: "Socola" Institute of Psychiatry Iaşi}

Address: Şoseaua Bucium nr. 36, cod poştal 700282, Iaşi, România

Images on the first page represent: Inaugural board of "Socola" Hospital of Psychiatry Iaşi The cover of the first number of "Bulletins et Mémoires de la Société de Neurologie, Psychiatrie et Psychologie de Iassy"

The image on the first cover represents the main building of "Socola" Institute of Psychiatry Iaşi

Free images from: httpsfreephotos.onlineitemfree-high-res-geometric-polygonbackground \& Designed by rawpixel.com / Freepik

ISSN: 1453-7257

\section{Copyright @ 2017 INSTITUTUL DE PSIHIATRIE „SOCOLA" Iaşi, România}

The papers published in "The Bulletin of Integrative Psychiatry" are protected by copyright. Their full or partial publication in other journal is allowed only with the written approval of "SOCOLA" Institute of Psychiatry Iaşi, Romania.

\section{Published by "Socola" Institute of Psychiatry Iaşi, Romania}

\section{"Gr.T. Popa" Pullisher}

University of Medicine and Pharmacy Iaşi $16^{\text {th }}$ Universităţii Str.

All rights of this work are reserved to the authors and „Gr.T. Popa" Publisher Iaşi. No part of this publication may be reproduced or transmitted by any means, electronical or mechanical, including photocopying without written permission from the authors or publisher. 


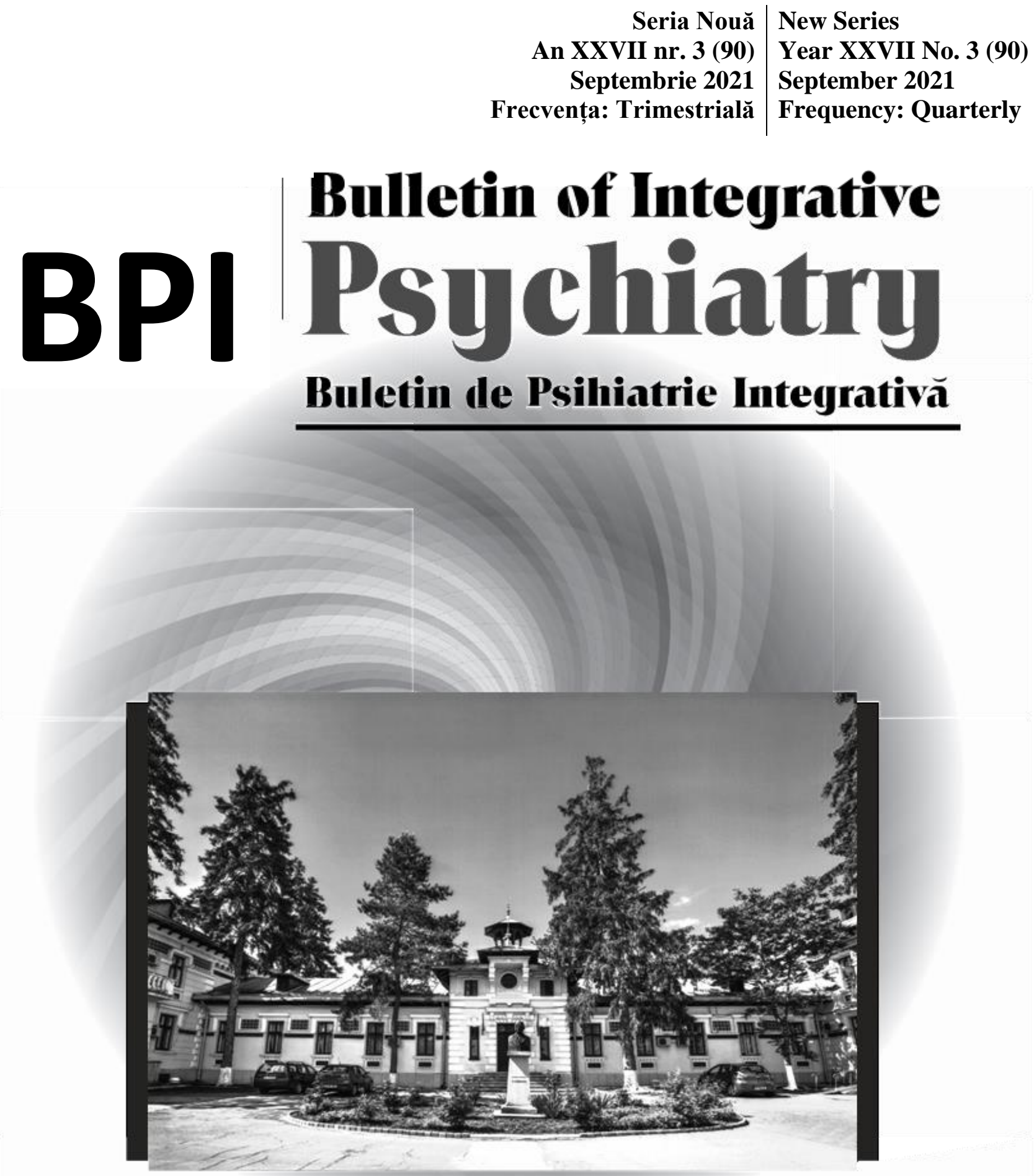

Official Publication of

"SOCOLA" INSTITUTE OF PSYCHIATRY

Iași, Romania 


\section{PUBLISHER: "SOCOLA" INSTITUTE OF PSYCHIATRY IAȘI}

\section{EDITORIAL BOARD}

Chief Editor:

Professor Roxana Chiriţă-MD, PhD

Grigore T. Popa University of Medicine and

Pharmacy, Iasi, Romania

Scientific Editor:

Professor Vasile Chiriţă-MD, PhD

Honorary Member of the Romanian Academy of Medical Science

Managing Editors:

Alexandra Boloş-MD, PhD

Grigore T. Popa University of Medicine and

Pharmacy, Iasi, Romania

Romeo P. Dobrin-MD, PhD

Grigore T. Popa University of Medicine and

Pharmacy, Iasi, Romania

Deputy editors:

Prof. Cristinel Ştefănescu-MD, PhD

Grigore T. Popa University of Medicine and

Pharmacy, Iasi, Romania

Prof. Călina Gogălniceanu

Al. I.Cuza University, Faculty of Letters, Iasi,

Romania

Laura Pricop-researcher, PhD

Al. I. Cuza University -Interdisciplinary Research in Social-Human Sciences Iasi, Romania

Alin Ciobîcă-researcher, $\mathbf{P h D}$

Al. I. Cuza University Iasi, Romania

Editors:

Radu Andrei-MD, PhD

Socola Institute of Psychiatry, Iasi, Romania

Ovidiu Eugen Alexinschi-MD, PhD

Socola Institute of Psychiatry, Iasi, Romania

Adrian Dumitru Cantemir- MD, PhD

Grigore T. Popa University of Medicine and

Pharmacy, Iasi, Romania

Gabriela Elena Chele-MD, PhD

Grigore T. Popa University of Medicine and

Pharmacy, Iasi, Romania

Oana Crețu-MD, PhD

Socola Institute of Psychiatry, Iasi, Romania

Ana Caterina Cristofor-MD, PhD

Grigore T. Popa University of Medicine and

Pharmacy, Iasi, Romania

Irina Dobrin-MD, PhD

Grigore T. Popa University of Medicine and

Pharmacy, Iasi, Romania
Tudor Florea-MD

Grigore T. Popa University of Medicine and

Pharmacy, Iasi, Romania

Anton Knieling-MD, PhD

Grigore T. Popa University of Medicine and Pharmacy, Iasi, Romania

Ioan Mihalache-MD, PhD

Socola Institute of Psychiatry, Iasi, Romania

Florin Mitu-MD, PhD

Grigore T. Popa University of Medicine and Pharmacy, Iasi, Romania

Petronela Nechita-MD, PhD

Socola Institute of Psychiatry, Iasi, Romania

Matei Palimariciuc-MD

Grigore T. Popa University of Medicine and

Pharmacy, Iasi, Romania

Elena Popescu-MD

Grigore T. Popa University of Medicine and Pharmacy, Iasi, Romania

Raluca Ioana Prepeliță-MD

Socola Institute of Psychiatry, Iasi, Romania Dania Andreea Radu-MD

Grigore T. Popa University of Medicine and Pharmacy, Iasi, Romania

Irina Săcuiu-MD, PhD

Socola Institute of Psychiatry, Iasi, Romania

Laura Gheucă Solovăstru-MD, PhD

Grigore T. Popa University of Medicine and Pharmacy, Iasi, Romania

Andreea Silvana Szalontay-MD, PhD

Grigore T. Popa University of Medicine and Pharmacy, Iasi, Romania

Șerban Turliuc-MD, PhD

Grigore T. Popa University of Medicine and Pharmacy, Iasi, Romania

Gabriela Ștefănescu- MD, PhD

Grigore T. Popa University of Medicine and

Pharmacy, Iasi, Romania

Ilinca Untu-MD

Grigore T. Popa University of Medicine and Pharmacy, Iasi, Romania

\section{Secretaries}

Vlad Iacob-MD

Socola Institute of Psychiatry, Iasi, Romania

Bianca Georgiana Secrieru -MD

Socola Institute of Psychiatry, Iasi, Romania 
ADVISORY BOARD:

\author{
ALLILAIRE J.F. (France) \\ ANDREI ELENA MIHAELA (Romania) \\ ASTĂRĂSTOAE VASILE (Romania) \\ BĂLĂCEANU-STOLNICI CONSTANTIN \\ (Romania) \\ BILD WATER (Romania) \\ BURLEA(CIUBARĂ) ANA-MARIA (Romania) \\ BURLUI VASILE (Romania) \\ CÂȘLARU DIANA (Romania) \\ COSMAN DOINA (Romania) \\ COSMOVICI NICOLAE (Romania) \\ COŞCIUG ION (Republic of Moldavia) \\ CĂRUNTU IRINA (Romania) \\ DAFINOIU ION (Romania) \\ DAVIDSON MICHAEL (Israel) \\ DEHELEAN LIANA (Romania) \\ DI FIORINO MARIO (Italy) \\ ENĂTESCU VIRGIL (Romania) \\ ENĂTESCU VIRGIL RADU (Romania) \\ FODOREANU LIANA (Romania) \\ FORNA NORINA CONSUELA (Romania) \\ GABOŞ-GRECU IOSIF (Romania) \\ GEORGESCU ȘTEFAN OCTAVIAN (Romania) \\ GOGĂLNICEANU PETRUȚ (UK) \\ HABOT SIMON (Israel)
}

HULUBAŞ ADINA (Romania)

KAMPITS PETER (Austria)

KNIGHT BERNARD (USA)

LADEA MARIA (Romania)

LAZARESCU MIRCEA (Romania)

LEPPEE MARCEL (Croatia)

MANEA MIRELA (Romania)

MARINESCU DRAGOS (Romania)

MICLUȚIA IOANA (Romania)

NACU ANATOL (Republic of Moldavia)

NIREŞTEAN AUREL (Romania)

NISHARA BRIAN (Canada)

OPREA VALENTIN (Republic of Moldavia)

PRELIPCEANU DAN (Romania)

PIANI FRANCESCO (Italy)

PRUS ELENA (Republic of Moldavia)

REVENCO MIRCEA (Republic of Moldavia)

RUJESCU DAN (Germany)

SCRIPCARIU VIOREL (Romania)

SCRIPCARU CĂLIN (Romania)

STOCKMAN RENE (Belgium)

ȘERBAN IONELA LĂCRĂMIOARA (Romania)

TĂRCOVEANU EUGEN (Romania)

TIMOFTE DANIEL (Romania)

TUDOSE CĂTĂLINA (Romania)

NUNO VIEIRA DUARDE (Portugal)

YOUNG ALLAN (UK) 

The Bulletin of Integrative Psychiatry tries to continue the tradition initiated at "Socola" Hospital in 1919, when a group of intellectuals, medical doctors and personalities from other professions founded the Society of Neurology, Psychiatry and Psychology in Iaşi. Even from its beginnings, the Society edited a journal entitled "Bulletins et Mémoires de la Société de Neurologie, Psychiatrie et Psychologie de Iassy", the first publication of the kind in Romania, which was unique also by its vision and opening towards biology, psychology, sociology and philosophy and by its prestigious board of editors: C. I. Parhon, Gh. Preda, Constantin Fedeleș, Arnold Stocker, P. Andrei, Corneliu Popa-Radu, I. A. Scriban, well known personalities, some of them being physicians of great culture and scientific qualification.

Starting from 1920, the Association and its Bulletin, born and edited at "Socola", due to their remarkable scientific activity have contributed to the organization of 18 congresses, which are mentioned in the description of "Socola" Hospital activities.

In 1947, the last number of "The Bulletin of the Society", edited in French, was banned as a result of the interdictions imposed by extremist tendencies. From its first number in 1919 and until 1947, "The Bulletin of the Society" published 2,412 articles.

The journal or "The Bulletin of the Society" has appeared under several titles: "Bulletin et Mémoires de la Société de Neurologie, Psychiatrie et Psychologie de Iassy" (between 1919 and 1922), then "Bulletin de l'Association des Psychiatres Roumains" and from 1923 it has changed its title several times.

After the year 1947, all publications at "Socola" Hospital were included in the "Medico-Surgical Journal of the Society of Physicians and Naturalists in Iaşi", another prestigious scientific journal which has been published without interruption since 1886.

Starting from 1994, Professor Dr. Tadeusz Pirozynski, Professor dr. Petru Boișteanu, Professor dr. Vasile Chiriță, Conf. dr. Radu Andrei and Dr. M. E. Berlescu have revived the tradition of publications at "Socola" Hospital, editing the new "Bulletin of Integrative Psychiatry".

At the end of 2014, "Socola" Hospital became the "Socola" Institute of Psychiatry, which has increased its responsibilities regarding medical assistance, scientific research, didactic activity, professional training and also the development of editorial activity. 
Journal B+ CNCS and Indexed IDB by Index Copernicus, DOAJ, Erih Plus, Gale Cengage, CEEOL, Crossref

Editorial contact: contact@buletindepsihiatrie.ro

Publisher contact:

„Gr. T. Popa” Publisher

University of Medicine and Pharmacy Iaşi

$16^{\text {th }}$ Universităţii Str.

Tel. 0232301678

www.umfiasi.ro 


\section{Summary}

\section{Editorial / 11}

Health management / 13

Roxana Chiriță, Elena-Rodica Popescu

\section{Articles / 15}

Diabetes, obesity and metabolic syndrome models studied in zebrafish - further relevance for the neuropsychiatric disorders-related manifestations / 17

Iuliana Simona Luca, Irina Dobrin, Alin Ciobîcă, Alexandru Ungureanu, Daniel Timofte

The psychological impact of the novel coronavirus pandemic on healthcare workers and ways to adress it / $\mathbf{3 3}$

Amira Chehab, Laura Elena Bucur, Mirona Letiţia Dobri, Codrina Moraru, Petronela Nechita

Saccharin deprivation increases depression and anxiety levels through oxidative stress biochemical mechanisms / 41

Sorin Ungurianu, Constantin Truş, Roxana-Rosmary Enciu

Medium-term religious support program applied to suicidal psychiatric patients / 51

Speranța-Giulia Herea, Roxana Chiriță, Andreea Silvana Szalontay, Gabriela Elena Chele, Cristinel Ștefänescu

Dyslexia intervention to combat specific language disorder, a consequence of economic migration / 63

Katalin Tiron

Meditation and melotherapy as adjuvant treatments of chronic dermatoses / 69

Bogdan M Tarcău, Ioana A Halip, Adriana I Pătrașcu, Laura Stătescu, Dan Vâță, Adrian Cantemir, Laura Gheucă Solovăstru

Particularity of suicide in the countries of the European Union / 77

Andrei Scripcaru, Costel Marius Frăsilă, Silvia Şpac, Mădălina Maria Diac, Călin Scripcaru 
The therapeutical role of psychedelic drugs in treatment of mental disorders / 87

Dan Cătălin Oprea, Loretta Epure, Vasile Chiriţă, Adrian Cantemir

The psychological impact of aesthetic procedures on the young patient / 97

Ioana A Halip, Laura Gheucă Solovăstru, Laura Stătescu, Ioana A Popescu, Adriana I Pătrașcu, Andra G Salahoru, Bogdan-Marian Tarcău, Alina Stîncanu, Doinița Olinici Temelie, Dan Vâță

Humanistic contributions / 107

Artificial intelligence, transhumanism and translation as a universal property of thinking) / 109

Miroslava Metleaeva (Luchianchicova)

The hypocrisy - changing the vices into virtues / 121

Iosif Tamaș

Case reports / 131

Particularities and limitations of kinesiotherapy in genetic disorders and their medical recovery - Russell-Silver Syndrome: a case report / 133

Adina Sorina Mitrică, Avram Carmen, Ada Bargau Petrache, Adrian Cantemir, Vlad Teodor Iacob

Instructions for authors / 139 


\section{Editorial}





\title{
Health management
}

\author{
Efficient people are the laziest, but they are brilliant lazy people.
}

(David Dunham)

\section{Roxana Chiriță, Elena-Rodica Popescu}

Roxana Chiriță - Professor, M.D., Ph.D., senior psychiatrist, "Grigore T. Popa” University of Medicine and Pharmacy, Iași, "Socola” Institute of Psychiatry Iaşi

Elena-Rodica Popescu - M.D., Ph.D. student, psychiatrist, assistant professor, "Grigore T. Popa" University of Medicine and Pharmacy, Iaşi, "Socola” Institute of Psychiatry Iași

Society is in continuous development and adaptation in all fields of activity, especially in the medical area, necessary to improve the quality of life. World Health Organization defines this small discipline, Public Health, the science and art of disease prevention, prolongation of life, and health promotion through the organized efforts of society to which can be added the improvement of notions of biostatistics, epidemiology over well-acquired knowledge of general medicine. All this with the aim of a good quality of life for all people, whether they are providers or providers of health services or simple beneficiaries of health services, the role and function being interchangeable.

The basic concepts of management were described in different ways for thousands of years. The first reference to management was found in the Old Testament of the Christian Bible. Some practical managerial concepts are still described today in the construction of the pyramids of Ancient Egypt; suggestions of good management can be found in the Code of Good Manners of Babylon, 3000 years ago.

Social Medicine was established for the first time in Bucharest under the leadership of Prof. Gh. Banu in 1942. In 1948, the discipline Sanitary Organization was selected for the first time in Iași, led by lecturer Dr. Ion Spinu, and currently, this discipline is called Public Health and Sanitary Management.

The specialty of Public Health and Sanitary Management is included in the terminology of medical things. The establishment of this specialization initially conceived as a 
.

discipline that would come to the aid of young doctors as a necessity of literacy in the integral medical field. For a start so that later it could be known, in the true sense of the word management, which includes the main management areas at the level of a hospital and the main management activities.

In general terms, management is a process by which work is done through others done on time and within budget, involves a series of integrated activities. Management determines a combination of means (financial-budget, human-human resource, materials) to generate socially helpful services.

The basic terms that revolve around management are effectiveness and efficiency, precisely in this order, which involves the availability of primary conceptual skills, human skills, technical skills (medical, financial, and legislative knowledge), and adaptation to change. Conceptual skills and transformation to change present together lead to good management. Change is understood as a continuous confrontation, identification, evaluation, and action determined mainly by political factors, political legislation, the government's economic policy or other countries, international regulations, wars, trade union activity, technological factors, and socio-cultural factors.

Isn't $t$ it funny how day by day nothing changes, but when you look back, everything is different.

A good organization of the entire medical system can prevent us from attributing the above expression.
Healthcare managers oversee financial initiatives; the economic field is a vital aspect of the hospital unit, designs and analyzes, evaluates, communicates, and reviews financial strategies, and recruits the appropriate human resource for the crew.

It also plays a bridge role, a link between doctors and other heads of health units, both territorial, inside the borders or outside them. All of the above require extraordinary communication skills at all hierarchical levels, of all types (internal, external), with the transmission of clear, consistent information in and for the benefit of the health unit. At the same time, managers need to ensure the quality-of-care standards that govern all facilities in the medical industry.

The biggest challenge for a hospital manager is to do things consistently and correctly every time.

We conclude by saying that a manager or management is something or someone who makes the resources of a health unit turn into results by focusing on the beneficiary of health services (patient), continuous quality improvement, teamwork. 


\section{Articles}





\title{
Diabetes, obesity and metabolic syndrome models studied in zebrafish - further relevance for the neuropsychiatric disorders-related manifestations
}

\author{
Iuliana Simona Luca, Irina Dobrin, Alin Ciobîcă \\ Alexandru Ungureanu, Daniel Timofte
}

\begin{abstract}
Iuliana Simona Luca - Department of Biology, Faculty of Biology, Alexandru Ioan Cuza University, B-dul Carol I, no11, Iasi, Romania

Irina Dobrin - MD, PhD, psychiatrist, lecturer, "Grigore T. Popa" University of Medicine and Pharmacy, Iasi, Romania

Alin Ciobîcă - PhD, Department of Biology, Faculty of Biology, Alexandru Ioan Cuza University, Iasi, Romania, Academy of Romanian Scientists, Bucuresti, Center of Biomedical Research, Romanian Academy, Iasi

Alexandru Ungureanu - Psychologist, Faculty of Psychology, Alexandru Ioan Cuza University, Iasi, Romania

Daniel Timofte - Professor, MD, PhD, "Grigore T. Popa" University of Medicine and Pharmacy, Iasi, Romania
\end{abstract}

\section{ABSTRACT}

In the recent decades, the incidence of cardiovascular diseases, as well as endocrine and metabolic diseases, which are affecting the quality of human life, is constantly increasing. Currently, given that the prevalence of metabolic diseases, obesity and diabetes is constantly increasing worldwide, there is an increased interest in developing new therapies and in creating better experimental models for mimicking the complex human symptomatology. This could result in a faster diagnosis with lower cost, as well as in advances of the so-called personalized medicine. Among the animals that could be experimental models for these diseases, there is an increased interest in the zebrafish (Danio rerio), giving that the qualities that recommend it are its small size, the need for a small living space, relatively low costs of use, high homology to the human genome, high fertility and mostly the formation of the major organs at $\mathbf{2 4}$ hours after fertilization. In this way, the presence in zebrafish of all the key organs that are important and necessary for the complex metabolic control, as well as the similarities in lipid metabolism and the adipogenic pathway between zebrafish and mammals, could make this small organism an ideal tool for the study and the better understanding of adipogenesis, diabetes, obesity and the complex pathological processes which are 


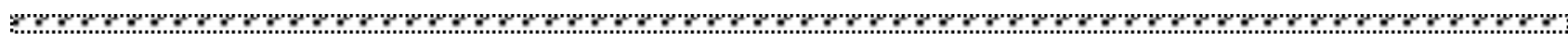
characterizing the metabolic diseases. This could have an increased relevance in the context of our previous work describing neuropsychiatric models in zebrafish (focusing for example on dementia), considering also the important connections that might exist between the general metabolic disorders and most of the neuropsychiatric-related manifestations.

\section{KEYWORDS:}

Metabolic syndrome, obesity, diabetes, zebrafish.

\section{INTRODUCTION}

The metabolic syndrome, generically called at the beginning by Gerald Reaven's, syndrome $\mathrm{X}$ in 1988, was then defined as an accumulation of abnormal disorders $(1,2)$. Syndrome $\mathrm{X}$, later becoming the subject of several researchers, was finally defined as a combination of 4 disorders (diabetes, blood pressure, obesity, hypertrigligeridemia) closely related to each other (3).

Regarding the endocrine and metabolic diseases, zebrafish is considered to have great potential in the investigation of thyroid diseases, thyroid hormones and defects related to their receptors, helped by the fact that the zebrafish, like the mammals, has molecular mechanisms and components related to thyroid axis (4). Moreover, knowing that the organ systems of zebrafish resemble those of humans, especially those related to metabolic control to regulate body energy homeostasis, which results in obesity, zebrafish has been used to study various diseases in the field of metabolic diseases such as obesity, diabetes, nonalcoholic fatty liver disease (NAFLD), nonalcoholic steatohepatitis (NASH), atherosclerosis and liver cancer (5) (6).

Thus, it was lately suggested that zebrafish can be used successfully in modeling these diseases because it has all the key organs to balance energy homeostasis and metabolism in mammals, as well as appetite regulation, insulin and lipid storage. (5) (6) (7) (8).

Diabetes, known as a syndrome with high blood glucose levels and as a consequence of metabolic imbalance, also affects the quality of human life and requires the creation of an experimental model on which this disease can be modeled. (8).

\section{METABOLIC SYNDROME}

As mentioned, the initially called Syndrome $\mathrm{X}$, went through several definitions: obesity, along with a fasting blood glucose $>100$ $\mathrm{mg} / \mathrm{dl}$, accompanied by high blood pressure, high triglycerides $>150 \mathrm{mg} / \mathrm{dl}$ and an increase in lipoproteins (Lower HDL) (9). Reaching another definition, practically an association of increased glucose with at least two other health problems: high blood pressure, increased plasma triglycerides, abdominal BMI $>30 \mathrm{~kg} / \mathrm{m}^{2}$ and microalbuminoria (9).

Finally, the European Insulin Resistance Study Group (EGIR) defined X syndrome as insulin resistance syndrome, along with 2 other factors: high plasma glucose, but not necessarily a person with diabetes, high triglycerides, low HDL, blood pressure. All definitions assigned to syndrome $\mathrm{X}$ show that the 4 disorders (diabetes, blood pressure, obesity and hypertriglyceridaemia) are related to each other (9).

Underlying the body's survival and functioning is the control of energy homeostasis between cells and tissues. When this homeostasis is disrupted in the body, the toxic accumulation of carbohydrates, proteins and lipids takes place. In diabetes, high blood sugar causes both micro- and macrovascular diseases (10), which in turn can cause strokes, heart attack, kidney failure, blindness and neuropathy (11) (12) (13). In conclusion, the metabolic syndrome must be understood at the system level precisely because of its multi-organ effects. 
Zebrafish has great potential for investigating thyroid diseases and everything related to them, because it has all the components related to the thyroid axis, similar to mammals; thus, by using transgenic lines, this model is suitable for developing new therapeutic approaches (4). It has also been observed that long-term exposure to environmental chemicals causes disorders similar to those caused by endocrine disorders. Chemicals that interfere with the components of the endocrine system are called endocrine disrupting components (EDC). Zebrafish can be used to understand related mechanisms and to detect EDC by applying biomarkers, specific genes and a transcriptomic platform (14).

The organ systems of zebrafish are similar to humans in terms of metabolic control for regulating body energy homeostasis, and for this reason zebrafish has been used to model metabolic diseases such as obesity, diabetes, NAFLD, NASH, atherosclerosis and liver cancer (5) (6). The basic metabolic mechanisms of zebrafish are similar to those of humans (15). Other similarities of zebrafish with humans consist in the development of the peripheral nervous system (16), and the development of adipose tissue takes place in both species, as well as the existence of similar genetic factors (17).

Metabolic disease is a consequence of the interaction of lifestyle, socio-economic factors and behavioral factors (18) (19) (20). Both energy metabolism by maintaining energy homeostasis and the microbiome can certainly affect metabolism (18) (19) (20). In zebrafish, organs such as the thyroid and endocrine pancreas develop within 48 hours dpf (days after fertilization) and have the role of secreting hormones essential for maintaining energy homeostasis. (21) (22) (23) (24), and the maintenance of metabolic homesostasis begins by regulating glucose. Returning to the influence of the microbiome on metabolism, a basic microbiome has been observed in zebrafish, and researchers have begun to study how infection naturally or induced alters the intestinal microbiota by disrupting carbohydrate and lipid homeostasis
(25) (26) (27) (28) (29) (30) (31) (32). Over time, zebrafish have been used in the study of many metabolic diseases, innate metabolic errors (33) (34) yper and hypothyroidism (35) (36), metabolic cancer (37), and in this review I will bring in discuss diabetes, obesity and dyslipidemia as the most common metabolic tubing (38) (39). So zebrafish can be a model for studying metabolic diseases due to functional preservation in lipid metabolism, adipose tissue biology, glucose structure and glucose homeostasis (40).

\section{OBESITY}

Obesity, a global health problem, is a disease that results from the interaction of genetic and environmental factors, characterized by increased fat storage in WAT (white adipose tissue). Causes of obesity include the quantity and quality of food consumed by individuals, as well as exposure to obesogens, a class of chemicals that disrupt the endocrine system, and their presence in early life affects adipogenesis and lipid metabolism (41) (42).

Obesity, the result of a positive balance when the energy ratio is higher than its expenditure, causes the organs involved in maintaining balance, mean the brain, liver and adipose tissue to interact to regulate this aspect. Due to the similarities with the human body, the zebrafish is used to study obesity (43) (44). Zebrafish is a suitable model to study metabolic dysfunction because it has digestive organs, adipose tissue and skeletal muscle, organs that regulate energy homeostasis and metabolism in mammals (45) (46).

In mammals there are 2 main classes of adipose tissue: brown adipose tissue (BAT) which dissipates energy and generates heat, and white adipose tissue (WAT) with the role of energy storage and regulation of energy balance (47). BAT consists of several drops of microvesicular lipids as well as many mitochondria that have the role of providing heat using lipids. WAT is a large unilocular lipid drop formed by the union of small lipid droplets that will be stored as a small energy reserve (48). Adult zebrafish contain WAT in the pancreatic, visceral, esophageal, mandibular, cranial, and tail fins (49). Being poikilothermic animals, they do not contain 
BAT, although they have been shown to have an approved coupling protein 1 (PCU 1) that can be associated with BAT in other species (50).

To better understand the physiological changes of an organism affected by obesity, zebrafish are used to monitor adipogenesis, from egg fertilization to larval stage, precisely because zebrafish larvae develop outside the mother's body and due to the optical transparency of them. Thus, with the help of appropriate tools, defects in the absorption, transport and arrangement of lipids can be detected (51) (52). Zebrafish also contain cells that specialize in the absorption and processing of lipids (eg, intestinal enterocytes, fat-storing adipocytes, liver hepatocytes, and pancreatic acinar cells) (53) (54). Adipocytes that form in fish larvae can be observed with the help of dyes: Sudanophilic dye Oil Red O (ORO), Sudan Nile Red, or Lipid Green (55), and to observe the transport of fatty acids are used BODIPY lipophilic floroflor by injection yolk, from fish food, the latter reaching the circulatory system very quickly, lasts about 3 hours (56).

Zebrafish can be considered a suitable model for human lipid metabolism because functions such as regulating appetite (by the presence in the hypothalamus of appetite circuits) of insulin (through the pancreas) and lipid storage are well preserved (57) (58) ( 59). Excess nutrients increase plasma TGL levels and the appearance of hepatic steatosis (60) as well as the presence in zebrafish of horses that regulate lipid metabolism: SREBF 1, P PAR S, NR 1 N 3, LEP (60) make it a suitable model .

The preservation of these metabolic pathways that intervene in the differentiation of adipocytes energy homeostasis (61) and cholesterol metabolism make zebrafish an ideal model for human lipid metabolism (62). Obesity caused by the creation of a prolonged imbalance between calories entered and insufficient energy expenditure, is characterized by adipose tissue hypertrophy and hyperplasia. Obesity occurs practically when the excess energy, stored in the form of lipid droplets, is deposited in both adipose and non-adipose tissues (63) (64).

Excess nutrients cause adipocyte hypertrophy and hyperplasia in adipose tissue; Among the cells that inflame adipose tissue are macrophages and pro-inflammatory molecules: tumor necrosis factor (TNF- $\alpha$ ), interleukin-6 (IL-6), monocytic chemoattractant protein (MCP-1) (65) (66) (67). Adipocytes and macrophages interact and thus inflammatory adipocytokines decrease, leading to complications associated with obesity. In many organs it all causes some metabolic disorders, insulin resistance, diabetes, cardiovascular disease, stroke and even some cancers (68) (69). It has been shown that in order to assess the development of comorbidities related to obesity, the distribution of fat in a body is more important than the total amount of fat (70) (71). When adipose tissue grows, plasma free fatty acids (FAA) are released and in obese patients it forms a link between obesity and metabolic syndrome by promoting lipotoxicity in the liver and muscles, by altering the action of insulin and causing non-alcoholic fatty liver disease (NAFLD) (72).

Knowing that the hypothalamus is the site of appetite circuits (73), leptin receptors and melanocortin system proteins (74) (75) we can highlight the similarities of fish with humans in this regard. Intracerebroventricular administration of neuroactive peptides (NPY) has also been shown to definitely stimulate food intake, and administration of CART (regulated cocaine and amphetaminetranscription) of melanocortin peptides and CRF (corticotropin-releasing factor) inhibits feeding (76). A zebrafish model for obesity can be created by chromosomal translocation, which suppresses central melanocortin receptors, knowing that the central melanocortin system (CMS) controls and regulates energy homeostasis. It contains propriomelanocortin (POMC), peptides and agouti-bound peptide (AgRP). Zebrafish following this chromosomal translocation increase in weight due to the high content of triglycerides (TGL), due to increased expression of AgRP, an endogenous 
antagonist of melanocortin and due to visceral fat accumulation (36) (77).

Leptin, the main adipostatic factor, is a hormone that informs the brain about the total energy stored as TGL in fat cells; and by regulating the amount of adipose tissue in the body, by inhibiting food intake, by stimulating energy expenditure, reducing body weight and fat percentage intervenes to maintain euglycemic status (78). Leptin leads to the onset of hepatic steatosis and the onset of insulin resistance (79). Deficiency of this hormone causes the onset of deep hyperphagia and obesity, infertility and diabetes. The difference is that in zebrafish the leptin receptor is expressed in the liver and other tissues, and not in adipose tissue as in humans, and the deficiency of receptors in zebrafish larvae causes an increase in the number of beta cells and insulin mRNA levels, and larval zebrafish in response to a fatty diet may have beta cell hyperplasia or peripheral insulin resistance, so it can be said that leptin has a major role in maintaining glucose homeostasis and a secondary role as an adipostatic factor (80).

Zebrafish, like mammals, have white adipose tissue, initially made up of several small drops of lipids, and as they develop, they turn into a single large drop of lipids (81). Visceral adiposity is considered to be a critical risk factor for other metabolic diseases and T2DM (82). Zebrafish contain lipid deposits in visceral, intramuscular and subcutaneous adipocytes (83) and can assess the degree of metabolic disorders related to obesity. In humans, these quantitative measures consist of the calculation of body mass index and quantitative computed tomography (CT), and in fish lipophilic dyes are used: red Nile, oil Red O and Sudan Black B (84) (85). With zebra larvae having optical transparency, the researchers developed screens based on live imaging and fluorescence to study digestive physiology or lipid metabolism. Nile red has been used to quantify intracellular neutral lipid droplets and for vivid imaging (86) as well as to purify adipose tissue (87). In addition, a variety of fatty acid analogs and fluorescent lipid tracers are available, including BODIPY cholesterol analogs and fluorescence reports such as PED 6 for monitoring the metabolism and distribution of exogenous lipids in live zebrafish (88) (89). Micro CT 3D is also available for this small animal and allows the measurement of total adipocyte tissue volume as well as various fat deposits (90). Recently, Landgrof et al., compared the methodology for quantifying the body fat mass of zebrafish using MR imaging (MRI) and 4 in 1 Echo MRI (Echo MRI tm) (91). These methods provide accurate measurements of zebrafish adiposition and provide means for longitudinal monitoring.

It was also showed that a high-fat diet given to zebrafish larvae increases adiposity, and in adult zebrafish it causes hepatosteatosis, hypertriglyceridemia, and high BMI (39) (92). One of the methods of inducing obesity is to administer excess fat immediately after 5 days after fertilization. Early larvae do not have WAT (93), in which case lipid droplets accumulate in the bloodstream, and the amount of whole larval triacylglycerol is used as an indicator to quantify the progression of obesity (94) (95). A high-fat diet consists of administering egg yolk (95).

Zebrafish larvae begin to eat 5 days after fertilization (dpf), until then they absorb the essential fats, cholesterol and triacylglycerol provided by a sac of maternal yolk (96). At 5 dpf the lipids become visible in several tissues, with the formation of a small deposit in hepatocytes; instead, the first signs of adipogenesis can be seen at $8 \mathrm{dpf}$ in the visceral cavity, close to the pancreas. Adipocytes appear in the pancreas of larvae at 12 dpf (96). To highlight adipocytes, at 15 dpf, red Nile dye is used; $15 \mathrm{dpf}$ being the day when the adipocytes in the visceral area (internal intra-abdominal and surrounding organs become visible (97); a location associated in humans with risk factors for the development of type 2 diabetes mellitus (T2DM) (98) (99). The number of adipocytes correlates with the size of the larvae, rather than with their age; thus, it was observed that at $17 \mathrm{dpf}$ the larvae have WAT in the pancreatic and visceral area, and at 20-22 dpf, 
\%

subcutaneous and cranial adipocytes develop, depending on the size (93).

There is also an increase in microsomal triglyceride transfer protein (MTP) mRNA levels in the proximal intestine and liver, following a high-fat diet (90). MTP has a $54 \%$ identity with human MTP and is involved in the breakdown of lipoproteins in the born ApoB, and these ApoB-MTP complexes can prevent lipid degradation by proteasomes and increase plasma lipid levels. ApoB levels increased in response to overeating (100) (101).

The high degree of conservation in the distribution and formation of adipose tissue in zebrafish compared to mammals make it a suitable model to study obesity.

\section{DIABETES}

Diabetes is a syndrome characterized by elevated blood glucose levels (hyperglycemia) and metabolic imbalance (102).

Chronic blood glucose is the major biochemical diagnostic parameter observed in the two major forms of diabetes: type 1 or insulin-dependent diabetes, caused by autoimmune destruction of insulin-producing pancreatic beta cells, and T2DM or noninsulin-dependent characterized by insulin insensitivity (102).

The development of the pancreas in the organs of vertebrates often involves a twostage process. First, the formation of a functionally immature organ during embryogenesis, which is followed by differentiation into mature form (103) (104). The second step most often occurs during the postembryonic / postnatal period, when the concentration of plasma thyroid hormone (TH) becomes high. In addition, mammalian weaning, frog metamorphosis, and the larvaljuvenile transition of the zebrafish have been proposed to be functionally equivalent events during postembryonic development, based on cellular and molecular events in their digestive organs, including the pancreas, and increase in plasma $\mathrm{TH}$ concentration during these periods (103) (104).
To understand exactly when and where $\mathrm{TH}$ works in the pancreas, the thyroid is ablated when treated with metronidazole. Thyroid ablation leads to loss of endogenous TH (105). A transgenic line can be used to perform conditioned $\mathrm{TH}$ during the transition from larvae to the juvenile transition. After thyroid ablation, insulin expression was decreased and glucagon expression was loaded, followed by increased blood glucose during the transition from larval to juvenile. Decreased insulin secretion and increased glucagon secretion and the resulting increase in blood glucose continued in adult fish. The TH treatment of adult thyroid fish increased insulin secretion and reduced glucagon secretion and reduced blood glucose levels. These results suggest that $\mathrm{TH}$ is important to generate $\alpha$ and $\beta$ cells and to maintain their maturation. In addition, glucose sensitivity was found to be improved in both $\alpha$ and $\beta$ cells after T3 treatment (106). Thus, TH can regulate $\alpha$ and $\beta$ cells in cell maturation by increasing glucose sensitivity (105).

The pancreas is an organ with two sets of functions: those related to the digestive system (acinar cells and ductal cells), and those of the endocrine system (islets). Several phylogenetic analyzes suggest that the digestive system and the endocrine system evolved differently (107) and that the single unified pancreas developed as a new organ through the fusion of endocrine and digestive parts during fish evolution (107).

The zebrafish pancreas comes from two progenitor domains called the dorsal bud (DB) and the ventral bud (VB). However, unlike dorsal and ventral pancreatic buds in mammals, DB and VB in zebrafish have distinct differentiation potentials (108). DB is formed within 24 hours after fertilization (HPF) and consists of early endocrine cells grouped to form the main islet. VB arises from the intestinal tract after $34 \mathrm{dpf}$ and these cells migrate to swallow the main islet (108). The endocrine compartment consists of alpha cells that secrete glucagon, beta cells that produce insulin, gamma cells that produce somatostatin, epsilon cells that produce ghrelin, and pancreatic polypeptides that 
produce PP (109) (110). In addition to the pancreas, the development and function of other organ systems involved in glucose homeostasis, including the brain, liver, adipose tissue and skeletal muscle are also preserved (111). Preservation of pancreatic structure and system glucose homeostasis makes zebrafish useful for identifying new targets in pancreatic-related diseases such as diabetes.

Pancreatic $\beta$ cells secrete insulin in response to high glucose levels. In $\beta$ cells in mammals under high glucose conditions, this one moves into $\beta$ cells through the glucose transporter, GLUT2. Beta cells then produce more ATP, which increases the ATP / ADP ratio through glucose metabolism. Increasing the ATP / ADP ratio stimulates the closure of the ATPdependent potassium channel (KAtp), subsequently evoking the depolarization of $\beta$ cells that leads to the activation of $2+$ channels that stimulate insulin secretion. Like mammals, GLUT 2 is expressed in pancreatic zebrafish $\beta$ cells. In addition, KAtp and $\mathrm{Ca} 2+$ channels regulate insulin secretion according to blood glucose levels (112),(113). These indicate that the pancreatic $\beta$ cells of zebrafish function in the same way as other vertebrates. On the other hand, these investigations were performed using main islets, but not with secondary islets. The molecular mechanisms underlying the secondary development of islets in zebrafish is similar to that of the development of mammalian islets. Thus, determining the functional differences between the main islets and the secondary islets could become important to understand how vertebrates acquired functional islets.

T1DM is an organ-specific autoimmune disease caused by the destruction of insulinproducing pancreatic beta cells by $\mathrm{T}$ cells (114). T2 DM is a metabolic disease associated with insulin resistance. Hyperglycemia in T2DM is initially accompanied by compensatory hyperinsulinemia, but as the disease progresses oxidative stress triggers beta cell apoptosis, and the amount of insulin produced by the pancreas gradually decreases (115). T2 DM is an often associated lifestyle disease. with obesity and considered part of the metabolic syndrome (116). T2DM is accompanied by chronic inflammation and oxidative stress (117) and patients often develop non-alcoholic fatty liver disease (118). Insulin is the cause of hyperglycemia in T1 DM. The most common treatment for this form of the disease is insulin injection. Antidiabetic drugs for T2DM can directly target hyperglycemia by promoting the release of insulin from beta cells in the early stages of the disease by improving the insulin sensitivity of target cells in various ways or by slowing the digestion of carbohydrates after meals. T2DM patients can also improve their health by reducing obesity, inflammation and oxidative stress.

Deficiency of glucose, the main fuel of the brain, leads to coma, convulsions causing permanent damage to the brain. Glucose reaches the brain through $\mathrm{CBF}$ (119) cerebral blood flow through endothelial cells, to the blood-brain barrier (BBB) (120) and eventually to glial cells through facilitated diffusion. Glucose is transported to glial cells and neurons by GLUT 7 carriers. Although insulin alters glucose metabolism in the CNS (121) it is not the main mechanism in the brain for neuronal absorption. But insulin influences activities such as neuronal growth and survival, synaptic plasticity, neurotransmitter release, tubulin activity, cognitive improvement of memory, learning (123).

Destruction of pancreatic beta cells is the leading cause of T1 DM and a consequence of T2DM progression. The toxic glucose analogue of alloxan is well known for its use in rodent diabetes models and has been used successfully in wild zebrafish larvae along with staining of the fluorescent analog 2NBDG for one hour and using a fluorescent microscope (124) a green fluorescence is obtained. For wild-type larvae, an alternative method of visualizing the pancreas is to use fluorescent conjugated antibodies against insulin or glucagon (125).

Glucose transporters (GLUT) in zebrafish have a structure and tissue distribution similar 
r

to that of mammals (126) (127). Fluorescent analogues of glucose 2-NBDG and GB-2 Cy 3 are both substrates known for GLUT and have been used to monitor glucose uptake in zebrafish larvae. Increased uptake of 2 NBDG could be inhibited by the glucose transporter inhibitor () and reduced in the presence of excess D-Glucose to illustrate that uptake of 2 NBDG in zebrafish occurs through GLUTs in similar to that of mammalian glucose (129).

The pancreas of the zebrafish is very similar to that of humans in terms of cell types, as well as the secretion of hormones and digestive enzymes. Regulation of zebrafish genes for insulin, glucagon, and other proteins involved in glucose metabolism has also been shown to be similar in the two species (130). Increased endogenous glucose levels in zebrafish larvae are associated with a increased expression of the gluconeogenic regulatory enzyme PEPCK (131). The major regulatory mechanism for this enzyme is the activation of expression by cortisone and glucagon and inhibition of glucagon receptor signaling lead to a reduction in PEPCK which in turn improved insulin sensitivity and reduced blood glucose in models with severe insulin resistance (132). In addition, hyperglycemia and excessive gluconeogenesis are present in all forms of diabetes. (133).

Direct measurement of in vivo glucose levels in larvae can also be used as an indicator of glucose homeostasis reflecting the net activity of glycolysis and gluconeogenesis (134). Inflammation is triggered by numerous stimuli (microbiological, physical and chemical) which activates the immune system and recruits immune cells. It is accompanied by the production of inflammatory mediators such as proinflammatory cytokines (interleukin -6, IL-6, IL-8, IL-1beta, macrophage granulocyte colony stimulating factor and tumor necrosis factor alpha (135).

Inflammation and oxidative pathways are interconnected to form a positive feedback loop. Immune cell recruitment and the secretion of cytokines and chemokines lead to the production of reactive oxygen species (ROS) and reactive nitrogen species (NOS).
During diabetes, inflammation in wild zebrafish larvae was achieved by exposure to high concentrations of glucose or fructose (136).

In fact, this mini-review of ours could open the discussion on the obvious connections that might exist between the digestive and gastrointestinal-metabolic component that is associated with the neuropsychiatric one (137, 138), considering the latest expertise of our group in this area (139), as well as the social implications in this context $(140,141)$, and of course the neurological and psychiatric manifestations related to the general metabolic disorders, in the context of the oxidative stress (another important expertise and perspective of our group -142) or not (143-146).

We could also mention in this context, the developing of the techniques for glucose homeostasis in zebrafish, as many transgenic strains of zebrafish with fluorescent protein expression have been used to study pancreatic development and glucose homeostasis in living vertebrates (148).

Thus, methods for zebrafish pancreatic function have been established, including postprandial blood glucose measurement and glucose tolerance tests as well as pancreatic dissection techniques and islet cell culture (150).

In larvae, blood collection for glucose measurement is not a viable methodology, but free glucose in whole larvae can be measured by a coupled enzyme fluorescent test (151). For adult zebrafish, the small size $(3-4 \mathrm{~cm})$ makes blood collection difficult. However, several protocols have been developed for blood collection: lateral incision in the dorsal aorta, decapitation and tail ablation, although these methods require animal sacrifice (153).

Measuring insulin function was a major challenge in this context. As surrogate indicators, insulin mRNA levels can be determined directly by qPCR and insulin promoter activity can be determined indirectly by measuring EGFP signal strength in Tg (- 
\% \%

1.oins.EGFP) over zebra (154). Insulin sensitivity can also be assessed by intraperitoneal injection of insulin into hyperglycemic zebrafish (156). Also, young fish (4-11 months) acclimatize more easily to the glucose exposure protocol compared to older fish (1-3 years) so they showed a transient hyperglycemia, but persistent hyperglycemia can be achieved in young zebrafish by gradually increasing glucose concentration (157).

\section{CONCLUSIONS}

In this way, the presence in zebrafish of all the key organs that are important and necessary for the complex metabolic control, as well as the similarities in lipid metabolism and the adipogenic pathway between zebrafish and mammals, could make this small organism an ideal tool for the study and the better understanding of adipogenesis, diabetes, obesity and the complex pathological processes which are characterizing the metabolic diseases. This could have an increased relevance in the context of our previous work describing neuropsychiatric models in zebrafish (focusing for example on dementia), considering also the important connections that might exist between the general metabolic disorders and most of the neuropsychiatric-related manifestations.

\section{ACKNOWLEDGEMENTS AND DISCLOSURES}

The authors state that there are no declared conflicts of interest regarding this paper.

\section{REFERENCES}

1. Chakraborty C, Hsu CH, Wen ZH, Lin CS, Agoramoorthy G. Zebrafish: a complete animal model for in vivo drug discovery and development. Curr Drug Metab. (2009) 10:116-24.

2 Gerald, M. R. 2001. Syndrome X: A Short History. Ochsner. J. 3: 124- 125.

3. Vancampfort D., Stubbs B., Mitchell, A.J., De Hert, M, Wampers, M., Ward v, P.B., Rosenbaum, S. and Corell, C.U. 2015. Risk of metabolic syndrome and its components in people with schizophrenia and related psychotic disorders, bipolar disorder and major depressive disorder: a systematic review and meta-analysis. World Psichiatry 14: 339-47.

4. Ding Y, Liu W, Deng Y, Jomok B, Yang J, Huang W, Clark KJ, Zhong TP, Lin X,Ekker SC, Xu X. Trapping cardiac recessive mutants via expression-based insertional mutagenesis screening. Circ Res 112: 606-617, 2013.

5. Cox AG, Hwang KL, Brown KK, Evason KJ, Beltz S, Tsomides A, O’Connor K, GalliGG, Yimlamai D, Chhangawala S, Yuan M, Lien EC, Wucherpfennig J, Nissim S,Minami A, Cohen DE, Camargo FD, Asara JM, Houvras Y, Stainier DY, Goessling W.Yap reprograms glutamine metabolism to increase nucleotide biosynthesis and enableliver growth. Nat Cell Biol 18: 886-896, 2016.

6. Ding Y, Sun X, Huang W, Hoage T, Redfield M, Kushwaha S, Sivasubbu S, Lin X, Ekker S,Xu X. Haploinsufficiency of target of rapamycin attenuates cardiomyopathies in adult zebrafish. Circ Res 109: 658 - 669, 2011.

7. Arjmand B, Goodarzi P, Mohamadi-Jahani F, Falahzadeh K, Larijani B. Personalized regenerative medicine. Acta medica Iranica. (2017) 55:144-9.

8. Oku H, Umino T. Molecular characterization of peroxisome proliferator- activated receptors (PPARs) gene expression in the differentiating adipocytes of red sea bream Pagrus major. Comp Biochem Physiol B Biochem Mol Biol. 2008;151:268-277.

9. Khosravi-Boroujeni, H., Ahmed, F., Sadeghi, M., Roohafza, H., Talaei, M., 15 Dianatkhah, M., Pourmogaddas, A. and Sarrafzadegan, N. 2015. Does the impact of 16 metabolic syndrome on cardiovascular events vary by using different definitions? 17 BMC Public Health 15: 1313.

10. Lozano R, Naghavi M, Foreman K, Lim S, Shibuya K, Aboyans V, Abraham J, Adair T, et al. Global and regional mortality from 235 causes of death for 20 age groups in 1990 and 2010: a systematic analysis for the Global Burden of Disease Study 2010. Lancet 380: 2095-2128.

11. Collaborators GBD, Forouzanfar MH, Afshin A, Alexander LT, Anderson HR, BhuttaZA, Biryukov S, Brauer M, et al. Global, regional, and national comparative risk assessment of 79 behavioural, environmental and occupational, and metabolic risks or clusters of risks, 1990-2015: a systematic analysis for the Global Burden of Disease Study 2015. Lancet 388: 1659-1724, 2016.

12. Murray CJ, Vos T, Lozano R, Naghavi M, Flaxman AD, Michaud C, Ezzati M, ShibuyaK, et al. Disability-adjusted life years (DALYs) for 291 diseases and injuries in 21 regions, 1990-2010: a systematical analysis for the Global Burden of Disease Study 2010. Lancet 380: 2197-2223. 


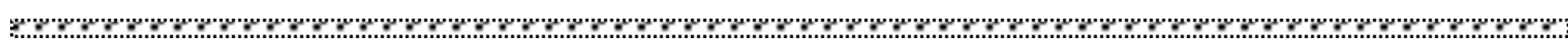
13. Vos T, Flaxman AD, Naghavi M, Lozano R, Michaud C, Ezzati M, Shibuya K, SalomonJA, et al. Years lived with disability (YLDs) for 1160 sequelae of 289 diseases and injuries 1990-2010: a systematic analysis for the Global Burden of Disease Study2010. Lancet 380: 2163-2196.

14. Ding Y, Long PA, Bos JM, Shih YH, Ma X, Sundsbak RS, Chen J, Jiang Y, Zhao L, Hu X,Wang J, Shi Y, Ackerman MJ, Lin X, Ekker SC, Redfield MM, Olson TM, Xu X. A modifier screen identifies DNAJB6 as a cardiomyopathy susceptibility gene. JCI Insight 1: 14, 2016.

15. Dong PD, Munson CA, Norton W, Crosnier C, Pan X, Gong Z, Neumann CJ, StainierDY. Fgf10 regulates hepatopancreatic ductal system patterning and differentiation. Nat Genet 39: 397- 402, 2007.

16. Dooley K, Zon LI. Zebrafish: a model system for the study of human disease. Curr Opin Genet Dev 10: 252-256, 2000 .

17. Doyle EL, Booher NJ, Standage DS, Voytas DF, Brendel VP, Vandyk JK, Bogdanove AJ.TAL Effector-Nucleotide Targeter (TALE-NT) 2.0: tools for TAL effector design and target prediction. Nucleic Acids Res 40: W117-W122, 2012.

18. Eames SC, Philipson LH, Prince VE, Kinkel MD. Blood sugar measurement in zebrafish reveals dynamics of glucose homeostasis. Zebrafish 7: 205-213, 2010

19. Kinkel MD, Eames SC, Philipson LH, Prince VE. Intraperitoneal injection into adult zebrafish. J Vis Exp 42: 2126 , 2010.

20. Marín-Juez R, Jong-Raadsen S, Yang S, Spaink HP. Hyperinsulinemia induces insulin resistance and immune suppression via Ptpn6/Shp1 in zebrafish. J Endocrinol 222:229-241, 2014.

21. Houbrechts AM, Delarue J, Gabriëls IJ, Sourbron J, Darras VM. Permanent de iodinase type 2 deficiency strongly perturbs zebrafish development, growth, and fertility. Endocrinology 157: 3668-3681, 2016.

22. Jurczyk A, Roy N, Bajwa R, Gut P, Lipson K, Yang C, Covassin L, Racki WJ, RossiniAA, Phillips N, Stainier DY, Greiner DL, Brehm MA, Bortell R, diIorio P. Dynamic glucoregulation and mammalian-like responses to metabolic and developmenta ldisruption in zebrafish. Gen Comp Endocrinol 170: 334-345, 2011.

23. Ober EA, Field HA, Stainier DY. From endoderm formation to liver and pancreas development in zebrafish. Mech Dev 120: 5-18, 2003.

24. Opitz R, Maquet E, Huisken J, Antonica F, Trubiroha A, Pottier G, Janssens V, Costagliola S. Transgenic zebrafish illuminate the dynamics of thyroid morphogenesis and its relationship to cardiovascular development. Dev Biol 372 : 203-216, 2012

25. Bates JM, Akerlund J, Mittge E, Guillemin K. Intestinal alkaline phosphatase detoxifieslipopolysaccharide and prevents inflammation in zebrafish in response to the gutmicrobiota. Cell Host Microbe 2: 371-382, 2007.

26. Falcinelli S, Picchietti S, Rodiles A, Cossignani L, Merrifield DL, Taddei AR, MaradonnaF, Olivotto I, Gioacchini G, Carnevali O. Lactobacillus rhamnosus lowers zebrafish lipid content by changing gut microbiota and host transcription of genes involved in lipid metabolism. Sci Rep 5: 9336, 2015.

27. Falcinelli S, Rodiles A, Unniappan S, Picchietti S, Gioacchini G, Merrifield DL, CarnevaliO. Probiotic treatment reduces appetite and glucose level in the zebrafish model. SciRep 6: 18061, 2016.

28. Hill JH, Franzosa EA, Huttenhower C, Guillemin K. A conserved bacterial protein induces pancreatic beta cell expansion during zebrafish development. eLife 5: e20145,2016.

29. Pham LN, Kanther M, Semova I, Rawls JF. Methods for generating and colonizing notobiotic zebrafish. Nat Protoc 3: 1862-1875, 2008.

30. Rawls JF, Mahowald MA, Ley RE, Gordon JI. Reciprocal gut microbiota transplants from zebrafish and mice to germ-free recipients reveal host habitat selection. Cell127: 423-433, 2006.

31. Rawls JF, Samuel BS, Gordon JI. Gnotobiotic zebrafish reveal evolutionarily conservedresponses to the gut microbiota. Proc Natl Acad Sci USA 101: 4596-4601, 2004.

32. Wong S, Stephens WZ, Burns AR, Stagaman K, David LA, Bohannan BJ, Guillemin K, Rawls JF. Ontogenetic differences in dietary fat influence microbiota assembly in thezebrafish gut. MBio 6: e00687-e15, 2015.

33. Matthews RP, Lorent K, Mañoral-Mobias R, Huang Y, Gong W, Murray IV, Blair IA,Pack M. TNFalpha-dependent hepatic steatosis and liver degeneration caused $\mathrm{b}$ mutation of zebrafish S-adenosylhomocysteine hydrolase. Development 136: 865-875, 2009.

34. Paardekooper Overman J, Yi JS, Bonetti M, Soulsby M, Preisinger C, Stokes MP, HuiL, Silva JC, Overvoorde J, Giansanti P, Heck AJ, Kontaridis MI, den Hertog J, BennettAM. PZR coordinates Shp2 Noonan and LEOPARD syndrome signaling in zebrafish and mice. Mol Cell Biol 34: 2874-2889, 2014.

35. Houbrechts AM, Delarue J, Gabriëls IJ, Sourbron J, Darras VM. Permanent deiodinase type 2 deficiency strongly perturbs zebrafish development, growth, and fertility. Endocrinology 157: 3668-3681, 2016.

36. Zada D, Tovin A, Lerer-Goldshtein T, Appelbaum L. Pharmacological treatment and BBB-targeted genetic therapy for MCT8-dependent hypomyelination in zebrafish. DisModel Mech 9: 1339-1348, 2016.

37. Cox AG, Hwang KL, Brown KK, Evason KJ, Beltz S, Tsomides A, O’Connor K, GalliGG, Yimlamai D, Chhangawala S, Yuan M, Lien EC, Wucherpfennig J, Nissim S,Minami A, Cohen DE, Camargo FD, Asara JM, Houvras Y, Stainier DY, Goessling W.Yap reprograms glutamine metabolism to increase nucleotide biosynthesis and enableliver growth. Nat Cell Biol 18: 886 - 896, 2016.

38. Collaborators GBD, Forouzanfar MH, Afshin A, Alexander LT, Anderson HR, BhuttaZA, Biryukov S, Brauer M, et al. Global, regional, and national comparative risk assessment of 79 behavioural, environmental and occupational, and 


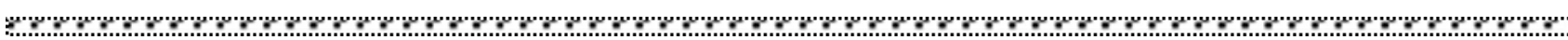
metabolic risks or clusters of risks, 1990-2015: a systematic analysis for the Global Burden of Disease Study 2015. Lancet 388: 1659-1724, 2016

39. Wang G, Rajpurohit SK, Delaspre F, Walker SL, White DT, Ceasrine A, Kuruvilla R, LiRJ, Shim JS, Liu JO, Parsons MJ, Mumm JS. First quantitative high-throughput screen in zebrafish identifies novel pathways for increasing pancreatic cell mass. eLife 4:08261, 2015.

40. Zang L, Maddison LA, Chen W. Zebrafish as a model for obesity and diabetes. Front Cell Dev Biol. (2018) 6:91.

41.Tingaud-Sequeira, A.; Ouadah, N.; Babin, P.J. Zebrafish obesogenic test: A tool for screening molecules that target adiposity. J.Lipid Res. 2011, 52, 1765-1772.

42. den Broeder, M.J.; Moester, M.J.B.; Kamstra, J.H.; Cenijn, P.H.; Davidoiu, V.; Kamminga, L.M.; Ariese, F.; de Boer, J.F.; Legler, J.Altered Adipogenesis in Zebrafish Larvae Following High Fat Diet and Chemical Exposure Is Visualised by Stimulated Raman Scattering Microscopy. Int. J. Mol. Sci. 2017, 18, 894.

43. Kleinert, M.; Clemmensen, C.; Hofmann, S.M.; Moore, M.C.; Renner, S.; Woods, S.C.; Huypens, P.; Beckers, J.; de Angelis, M.H.;Schurmann, A.; et al. Animal models of obesity and diabetes mellitus. Nat. Rev. Endocrinol. 2018, 14, $140-162$.

44. Khneizer, G.; Rizvi, S.; Gawrieh, S. Non-alcoholic Fatty Liver Disease and Diabetes Mellitus. In Advances in Experimental Medicine and Biology; Springer: New York, NY, USA, 2020; pp. 1-24.

45. Lieschke, G. J., and Currie, P. D. (2007). Animal models of human disease:zebrafish swim into view. Nat. Rev. Genet. 8, 353-367.

46. Schlegel, A., and Stainier, D. Y. (2007). Lessons from "lower" organisms: what worms, flies, and zebrafish can teach us about human energy metabolism. PLoSGenet. 3:e199.

47. Minchin JE, Rawls JF. In vivo analysis of white adipose tissue in zebrafish. Methods Cell Biol. 2011;105:63-86

48. Gesta, S.; Tseng, Y.H.; Kahn, C.R. Developmental origin of fat: Tracking obesity to its source. Cell 2007, 131, 242256.

49. Imrie, D.; Sadler, K.C. White adipose tissue development in zebrafish is regulated by both developmental time and fish size. Dev.Dyn. 2010, 239, 3013-3023.

50. Minchin, J.E.; Rawls, J.F. In vivo analysis of white adipose tissue in zebrafish. Methods Cell Biol. 2011, 105, 63-86 51. Brand M, Granato M, Nüsslein-Volhard C. Keeping and raising zeb-rafish. In: Nüsslein-Volhard C, Dahm R, eds.Zebrafish. Oxford, UK:Oxford University Press; 2002:7-37

52. Anderson JL, Carten JD, Farber SA. Zebrafish lipid metabolism:from mediating early patterning to the metabolism of dietary fat and cholesterol. Methods Cell Biol. 2011;101:111-141

53. Hölttä-Vuori M, Salo VT, Nyberg L, et al. Zebrafish: gaining popularity in lipid research. Biochem J. 2010;429:235-242.

54. Wallace KN, Akhter S, Smith EM, Lorent K, Pack M. Intestinal growth and differentiation in zebrafish. Mech Dev. 2005; $122: 157-173$

55. Flynn EJ, Trent CM, Rawls JF. Ontogeny and nutritional control of adipogenesis in zebrafish (Danio rerio). J Lipid Res. 2009;50:1641-1652.

56. Lee JH, So JH, Jeon JH, et al. Synthesis of a new fluorescent small molecule probe and its use for in vivo lipid imaging. Chem Commun(Camb). 2011;47:7500-7502

57. Elo, B., Villano, C. M., Govorko, D., and White, L. A. (2007 ). Larval zebrafish as a model for glucose metabolism: expression of phosphoenolpyruvatecarboxykinase as a marker for exposure to anti-diabetic compounds. $J$. Mol.Endocrinol. 38, 433-440.

58. Flynn, E. J. III, Trent, C. M., and Rawls, J. F. (2009). Ontogeny and nutritional control of adipogenesis in zebrafish (Danio rerio). J. Lipid Res. 50, 1641-1652.

59. Nishio, S., Gibert, Y., Berekelya, L., Bernard, L., Brunet, F., Guillot, E., et al. (2012).Fasting induces CART downregulation in the zebrafish nervous system in a cannabinoid receptor 1-dependent manner. Mol. Endocrinol. 26, 13161326.

60. Oka, T., Nishimura, Y., Zang, L., Hirano, M., Shimada, Y., Wang, Z., et al. (2010).Diet-induced obesity in zebrafish shares common pathophysiological path ways with mammalian obesity. BMC Physiol. 10:21.

61. Den Broeder, M. J., Kopylova, V. A., Kamminga, L. M., and Legler, J.(2015). Zebrafish as a model to study the role of peroxisome proliferating-activated receptors in adipogenesis and obesity. PPAR Res. 2015:358029.

62. Schlombs, K., Wagner, T., and Scheel, J. (20 0 3). Site-1 protease is required for cartilage development in zebrafish. Proc. Natl. Acad. Sci. U.S.A. 100,14024-14029.

63. Milani GP, Silano M, Pietrobelli A, Agostoni C. Junk food concep t:seconds out. Int J Obes (Lond) . 2017;41:669671

64. Kopelman P. Health risks associated with overweight and obesity. Obes Rev. 2007;8:13-17

65. Kang YE, Kim JM, Joung KH, et al. The Roles of adipokines, proinflammatory cytokines, and adipose tissue macrophages in obesity-associated insulin resistance in modest obesity and early metabolic dysfunction. PLoS One. 2016;11:e0154003.

66. Hotamisligil GS. Inflammation and metabolic disorders. Nature.2006;444:860-867.

67. Weisberg SP, McCann D, Desai M, Rosenbaum M, Leibel RL, Fer-rante AW Jr. Obesity is associated with macrophage accumulationin adipose tissue. J Clin Invest . 2003;112:1796-1808

68. Rocha VZ, Libby P. Obesity, inflammation, and atherosclerosis. NatRev Cardiol. 2009;6:399-409. 


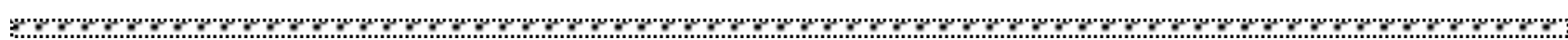
69. Mokdad AH, Ford ES, Bowman BA, et al. Prevalence of obesity, diabetes, and obesity-related health risk factors, 2001. JAMA.2003;289:76-79.

70. Anate M, Olatinwo A, Omesina A. Obesity - an overview. West AfrJ Med. 1998;17:248-254.

71. Després JP, Lemieux I, Bergeron J, et al. Abdominal obesity and the metabolic syndrome: contribution to global cardiometabolic risk. Arterioscler Thromb Vasc Biol. 2008;28:1039-1049.

72. Kopelman P. Health risks associated with overweight and obesity. Obes Rev. 2007;8:13-17.

73. Overton, J. M. (2010). Phenotyping small animals as models for the human metabolicsyndrome: thermoneutrality matters. Int. J Obes. 34 Suppl. 2, S53-S58.

74. Liu, Q., Chen, Y., Copeland, D., Ball, H., Duff, R. J., Rockich, B. and Londraville, R. L.(2010). Expression of leptin receptor gene in developing and adult zebrafish. Gen.Comp. Endocrinol. 166, 346-355.

75. Zhang, C., Forlano, P. M. and Cone, R. D. (2012). AgRP and POMC neurons are hypophysiotropic and coordinately regulate multiple endocrine axes in a larval teleost. Cell Metab. 15, 256-264.

76. Kawauchi, H. (2006). Functions of melanin-concentrating hormone in fish. J. Exp. Zool.305A, 751-760.

77. Song Y, Cone RD. Creation of a genetic model of obesity in a teleost. FASEB J. (2007) 21:2042-9.

78. Poordad, F. Fred MD. The Role of Leptin in NAFLD: Contender or Pretender? Journal of Clinical Gastroenterology: November/December 2004, Volume 38 - Issue 10 - pp 841-843

79. Ekstedt M., Franzén L.E., Mathiesen U.L., et al., Long-term follow-up of patients with NAFLD and elevated liver enzymes, Hepatology, vol. 44, no. 4, pp. 865-873, 2006.

80. Michel, M., Page-McCaw, P. S., Chen, W., and Cone, R. D. (2016). Leptin signaling regulates glucose homeostasis, but not adipostasis, in the zebrafish. Proc. Natl.Acad. Sci. U.S.A. 113, $3084-3089$

81. Flynn, E. J., III, Trent, C. M. and Rawls, J. F. (2009). Ontogeny and nutritional control of adipogenesis in zebrafish (Danio rerio). J. Lipid Res. 50, 1641-1652.

82. Ahima, R. S., and Lazar, M. A. (2013). Physiology. The health risk of obesity better metrics imperative. Science 341, 856-858

83. Song, Y., and Cone, R. D. (2007). Creation of a genetic model of obesity in a teleost. FASEB J. 21, $2042-2049$.

84. Marza, E., Barthe, C., André, M., Villeneuve, L., Hélou, C., and Babin, P. J.(2005). Developmental expression and nutritional regulation of a zebrafish gene homologous to mammalian microsomal triglyceride transfer protein large subunit. Dev. Dyn. 232 , 506-518.

85. Schlegel, A., and Stainier, D. Y. (2006). Microsomal triglyceride transfer protein is required for yolk lipid utilization and absorption of dietary lipids in zebrafish larvae. Biochemistry 45, 15179-15187

86. Greenspan, P., Mayer, E. P., and Fowler, S. D. (1985). Nile red: a selective fluorescent stain for intracellular lipid droplets. J. Cell Biol. 100, 965-973.

87. Jones, K. S., Alimov, A. P., Rilo, H. L., Jandacek, R. J., Woollett, L. A.,and Penberthy, W. T. (2008). A high throughput live transparent animal bioassay to identify non-toxic small molecules or genes that regulate vertebrate fat metabolism for obesity drug development. Nutr. Metab. 5:23.

88. Hölttä-Vuori, M., Salo, V. T., Nyberg, L., Brackmann, C., Enejder, A., Panula, P.,et al. (2010). Zebrafish: gaining popularity in lipid research. Biochem. J. 429,235-242.

89. Anderson, J. L., Carten, J. D., and Farber, S. A. (2011). Zebrafish lipid metabolism: from mediating early patterning to the metabolism of dietary fat and cholesterol. Methods Cell Biol. 101, 111-141.

90. Hasumura, T., Shimada, Y., Kuroyanagi, J., Nishimura, Y., Meguro, S., Takema, Y.,et al. (2012). Green tea extract suppresses adiposity and affects the expression of lipid metabolism genes in diet-induced obese zebrafish. Nutr. Metab. 9:73.

91. Landgraf, K., Schuster, S., Meusel, A., Garten, A., Riemer, T., Schleinitz,D., et al. (2017). Short-term overfeeding of zebrafish with normal orhigh-fat diet as a model for the development of metabolically healthy versus unhealthy obesity. BMC. Physiol.17.4.

92. Zang L, Maddison LA, Chen W. Zebrafish as a model for obesity and diabetes. Front Cell Dev Biol. (2018) 6:91.

93. Imrie, D. and Sadler, K.C. (2010). White adipose tissue development in zebrafish is regulated by both developmental time and fish size. Dev. Dyn. 239, 3013-3023.

94. Schlegel, A., and Stainier, D. Y. (2006). Microsomal triglyceride transfer protein is required for yolk lipid utilization and absorption of dietary lipids in zebrafish larvae. Biochemistry 45, 15179-15187.

95. Tingaud-Sequeira, A., Ouadah, N., and Babin, P. J. (2011 ). Zebrafish obesogenic test: a tool for screening molecules that target adiposity. J. Lipid Res. 52,1765-1772.

96. Miyares RL, de Rezende VB, Farber SA. Zebrafish yolk lipid processing: a tractable tool for the study of vertebrate lipid transport and metabolism. Dis Model Mech. 2014;7:915-927.

97. Minchin JE, Rawls JF. In vivo analysis of white adipose tissue in zebrafish. Methods Cell Biol. 2011;105:63-86.

98. Després JP. The insulin resistance-dyslipidemic syndrome of visceral obesity: effect on patients risk. Obes Res. 1998;6:8S-17S.

99. Fox KR, Hillsdon M. Physical activity and obesity. Obes Rev.2007;8:115-121.

100. Gordon DA, Jamil H. Progress towards understanding the role of microsomal triglyceride transfer protein in apolipoprotein-B lipoprotein assembly. Biochim Biophys Acta. 2000;1486:72-83.

101. Hussain MM, Shi J, Dreizen P. Microsomal triglyceride transfer protein and its role in apoB-lipoprotein assembly. J Lipid Res. 2003;44:22-32. 


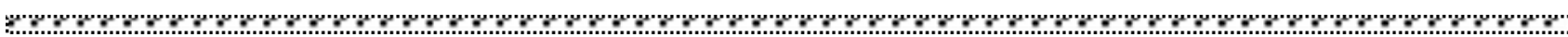
102. Kahn, S.E. The relative contributions of insulin resistance and beta-cell dysfunction to the pathophysiology of Type 2 diabetes. Diabetologia 2003, 46, 3-19.

103. Matsuda, H., \& Shi, Y. B. (2010). An essential and evolutionarily conserved role of protein arginine methyltransferase 1 for adult intestinal stem cells during postembryonic development. Stem Cells, 28, $2073-2083$.

104. Shi, Y. B. (1999). Amphibian metamorphosis: From morphology to molecular biology. New York, NY: John Wiley \& Sons Inc.

105. McMenamin, S. K., Bain, E. J., McCann, A. E., Patterson, L. B., Eom, D. S., Waller, Z. P., Parichy, D. M. (2014). Thyroid hormone-dependent adult pigment cell lineage and pattern in zebrafish. Science, 345, 1358-1361.

106. Matsuda, H., Mullapudi, S. T., Zhang, Y., Hesselson, D., \& Stainier, D. Y. R. (2017). Thyroid hormone coordinates pancreatic islet function during the zebrafish larval to juvenile transition to maintain glucose homeostasis. Diabetes, 66, 2623-2635.

107. Youson, J. H., \& Al-Mahrouki, A. A. (1999). Ontogenetic and phylogenetic development of the endocrine pancreas (islet organ) in fish. General and Comparative Endocrinology, 116, 303-335.

108. Filed, H. A., Dong, P. D., Beis, D., \& Stainier, D. Y. (2003). Formation of the digestive system in zebrafish. II. Pancreas morphogenesis. Developmental Biology, 261, 197-208.

109. Argenton, F., Zecchin, E., \& Bortolussi, M. (1999). Early appearance of pancreatic hormone-expressing cells in the zebrafish embryo. Mechanisms of Development, 87, 217-221.

110. Biemar, F., Argenton, F., Schmidtke, R., Epperlein, S., Peers, B., \& Driever, W. (2001). Pancreas development in zebrafish: Early dispersed appearance of endocrine hormone expressing cells and their convergence to form the definitive islet. Developmental Biology, 230, 189-203.

111. Maddison, L. A., \& Chen, W. (2017). Modeling pancreatic endocrine cell adaptation and diabetes in the zebrafish. Frontiers in Endocrinology, 8, 1-6.

112. Emfinger, C. H., Welscher, A., Yan, Z., Wang, Y., Conway, H., Moss, J. B., Nichols, C. G. (2017). Expression and function of ATP-dependent potassium channels in zebrafish islet $\beta$-cells. Royal Society Open Science, 4, 160808.

113. Singh, S. P., Janjuha, S., Hartmann, T., Kayisoglu, O., Konantz, J., Birke, S., Ninov, N. (2017). Different developmental histories of beta-cells generate functional and proliferative heterogeneity during islet growth. Nature Communications, 8, 664 .

114.Wang, Z.; Xie, Z.; Lu, Q.; Chang, C.; Zhou, Z. Beyond Genetics: What Causes Type 1 Diabetes. Clin. Rev. Allergy Immunol.2017,52, 273-286.

115. Hollander, P.A.; Kushner, P. Type 2 Diabetes Comorbidities and Treatment Challenges Rationale for DPP-4 Inhibitors. Postgrad.Med. 2010, 122, 71-80

116. DeFronzo, R.A.; Ferrannini, E.; Groop, L.; Henry, R.R.; Herman, W.H.; Holst, J.J.; Hu, F.B.; Kahn, C.R.; Raz, I.; Shulman, G.I.; et al.Type 2 diabetes mellitus. Nat. Rev. Dis. Primers 2015, 1, 15019.

117. Defronzo, R.A. Banting Lecture. From the triumvirate to the ominous octet: A new paradigm for the treatment of type 2 diabetes mellitus. Diabetes 2009, 58, 773-795.

118. Khneizer, G.; Rizvi, S.; Gawrieh, S. Non-alcoholic Fatty Liver Disease and Diabetes Mellitus. In Advances in Experimental Medicine and Biology; Springer: New York, NY, USA, 2020; pp. 1-24.

119. A. Kumar, A. Singh, Ekavali, A review on Alzheimer's disease pathophysiology and its management: an update. Pharmacological Reports: PR 67 (2) (2015) 195-203.

120. A. Alexander, S. Saraf, Nose-to-brain drug delivery approach: a key to easily accessing the brain for the treatment of Alzheimer's disease, Neural Regeneration Research 13 (12) (2018) 2102.

121. G.S. Watson, S. Craft, Modulation of memory by insulin and glucose: neuropsychological observations in Alzheimer's disease, Eur J Pharmacol 490 (1-3) (2004) 97-113.

122. K.F. Neumann, L. Rojo, L.P. Navarrete, G. Farias, P. Reyes, R.B. Maccioni, Insulin resistance and Alzheimer's disease: molecular links \& clinical implications, Current Alzheimer Research 5 (5) (2008) 438-447.

123. S.M. de la Monte, Intranasal insulin therapy for cognitive impairment and neurodegeneration: current state of the art, Expert Opinion on Drug Delivery 10 (12) (2013) 1699-1709.

124. Nam, Y.H.; Hong, B.N.; Rodriguez, I.; Ji, M.G.; Kim, K.; Kim, U.J.; Kang, T.H. Synergistic Potentials of Coffee on Injured PancreaticIslets and Insulin Action via KATP Channel Blocking in Zebrafish. J. Agric. Food Chem. 2015, 63, 5612-5621.

125. Kulkarni, A.A.; Conteh, A.M.; Sorrell, C.A.; Mirmira, A.; Tersey, S.A.; Mirmira, R.G.; Linnemann, A.K.; Anderson, R.M. An InVivo Zebrafish Model for Interrogating ROS-Mediated Pancreatic beta-Cell Injury, Response, and Prevention. Oxid. Med. Cell.Longev. 2018, 2018, 1324739.

126.Tseng, Y.C.; Chen, R.D.; Lee, J.R.; Liu, S.T.; Lee, S.J.; Hwang, P.P. Specific expression and regulation of glucose transporters in zebrafish ionocytes. Am. J. Physiol. Regul. Integr. Comp. Physiol. 2009, 297, R275-R290.

127. Jimenez-Amilburu, V.; Jong-Raadsen, S.; Bakkers, J.; Spaink, H.P.; Marin-Juez, R. GLUT12 deficiency during early developmentresults in heart failure and a diabetic phenotype in zebrafish. J. Endocrinol. 2015, $224,1-15$.

128. Blaslov, K.; Naranda, F.S.; Kruljac, I.; Renar, I.P. Treatment approach to type 2 diabetes: Past, present and future. World J. Diabetes 2018, 9, 209-219.

129. Lee, J.; Jung, D.W.; Kim, W.H.; Um, J.I.; Yim, S.H.; Oh, W.K.; Williams, D.R. Development of a highly visual, simple, and rapid testfor the discovery of novel insulin mimetics in living vertebrates. ACS Chem. Biol. 2013, 8, 18031814. 


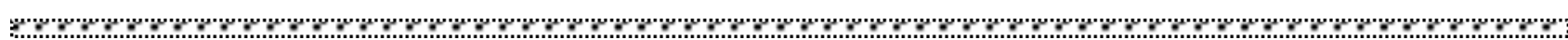
130. Elo, B.; Villano, C.M.; Govorko, D.; White, L.A. Larval zebrafish as a model for glucose metabolism: Expression of phospho-enolpyruvate carboxykinase as a marker for exposure to anti-diabetic compounds. J. Mol. Endocrinol.2007, 38, 433-440.

131. Jurczyk, A.; Roy, N.; Bajwa, R.; Gut, P.; Lipson, K.; Yang, C.; Covassin, L.; Racki, W.J.; Rossini, A.A.; Phillips, N.; et al. Dynamic glucoregulation and mammalian-like responses to metabolic and developmental disruption in zebrafish. Gen. Comp. Endocrinol.2011, 170, 334-345.

132. Okamoto, H.; Cavino, K.; Na, E.; Krumm, E.; Kim, S.Y.; Cheng, X.; Murphy, A.J.; Yancopoulos, G.D.; Gromada, J. Glucagonreceptor inhibition normalizes blood glucose in severe insulin-resistant mice. Proc. Natl. Acad. Sci. USA 2017, 114, 2753-2758.

133. Lee, Y.H.; Wang, M.Y.; Yu, X.X.; Unger, R.H. Glucagon is the key factor in the development of diabetes. Diabetologia 2016, 59,1372-1375.

134. Gut, P.; Baeza-Raja, B.; Andersson, O.; Hasenkamp, L.; Hsiao, J.; Hesselson, D.; Akassoglou, K.; Verdin, E.; Hirschey, M.D.;Stainier, D.Y. Whole-organism screening for gluconeogenesis identifies activators of fasting metabolism. Nat. Chem. Biol.2013, 9,97-104.

135. Gutierrez, R.M.P.; Flores, J.M.M.; Gonzalez, A.M.N. Anti-inflammatory effect of procumbenoside B from Justicia spicigera onlipopolysaccharide-stimulated RAW 264.7 macrophages and zebrafish model. Pharmacogn. Res. 2018, 10, 218-224.

136. Kim, E.-A.; Kang, M.-C.; Lee, J.-H.; Kang, N.; Lee, W.; Oh, J.-Y.; Yang, H.-W.; Lee, J.-S.; Jeon, Y.-J. Protective effect of marine brown algal polyphenols against oxidative stressed zebrafish with high glucose. RSC Adv. 2015, 5, 25738-25746.

137. Statescu C, Honceriu C, Trus C, Does Magnesium Deficient Diet and its Associated Metabolic Dysfunctions Induces Anxiety-like Symptoms Further cardiovascular relevance. Revista de Chimie , 2019; 70: 3579-3581.

138. Kinda P, Guenné S, Basile T, Ouédraogo N, Compaoré M, Bayala B, Bild W, Dobrin R, et al. Brain protection and anti-amnesic effects assessment of Datura Innoxia Mill. aqueous extracts. Farmacia 2020, 68; 2: 261-268.

139. Massaoudi Y, Ciobica A, Dobrin I, Hassouni M. Halophilic bacteria - a potential therapeutical approach for autism? Romanian Biotechnological Letters 2019; 24, 826-836.

140. Prepelita R. Cristofor AC, Dobrin R, Trus C, Ciobica A, Chirita R. The Serotonin-Dopamine Relationship on the Aggression-Suicidal Risk Axis in Patients with Major Depression Disorder: Describing Some Social Implications. Revista de Cercetare si Interventie Sociala 2019; 65: 111-130.

141. Dobrin I. Chirita R. Dobrin R. Birsan M. Stefanescu C. Trus C. Cristofor A.C. Social Intervention as an Adjuvant Therapy for Patients with Schizophrenia. Revista de Cercetare si Interventie Sociala 2020; 68: 261-270.

142. Luca M, Di Mauro M, Perry G. Neuropsychiatric Disturbances and Diabetes Mellitus: The Role of Oxidative Stress. Oxid Med Cell Longev 2019 Jul 4;2019:5698132.

143. Foley DL, Mackinnon A, Morgan VA, Castle DJ, Waterreus A, Galletly CA. Comorbid Diabetes and Depression in a National Sample of Adults With Psychosis. Schizophr Bull 2018 Jan 13;44(1):84-92.

144. Martins LB, Monteze NM, Calarge C, Ferreira AVM, Teixeira AL. Pathways linking obesity to neuropsychiatric disorders. Nutrition 2019 Oct;66:16-21.

145. Ogrodnik M, Zhu Y, Langhi LGP, Tchkonia T, Krüger P, Fielder E, Victorelli S, Ruswhandi RA, Giorgadze N, Pirtskhalava T, Podgorni O, Enikolopov G, Johnson KO, Xu M, Inman C, Palmer AK, Schafer M, Weigl M, Ikeno Y, Burns TC, Passos JF, von Zglinicki T, Kirkland JL, Jurk D. Obesity-Induced Cellular Senescence Drives Anxiety and Impairs Neurogenesis. Cell Metab 2019 May 7;29(5):1061-1077.e8.

146. Seabrook LT, Borgland SL. The orbitofrontal cortex, food intake and obesity. J Psychiatry Neurosci 2020 Sep 1;45(5):304-312.

147. Kinkel, M. D., and Prince, V. E. (2009). On the diabetic menu: zebrafish a sa model for pancreas development and function. Bioessays 31, 139-152.

148. Tiso, N., Moro, E., and Argenton, F. (2009). Zebrafish pancreas development. Mol.Cell. Endocrinol. 312, 24-30.

149. Eames, S. C., Philipson, L. H., Prince, V. E., and Kinkel, M. D. (2010). Blood sugarmeasurement in zebrafish reve als dynamics of glucose homeostasis. Zebrafish 7, 205-213.

150. Eames Nalle, S. C., Franse, K. F., and Kinkel, M. D. (2017). Analysis of pancreatic disease in zebrafish. Method Cell Biol. 138, 271-295.

151. Jurczyk, A., Roy, N., Bajwa, R., Gut, P., Lipson, K., Yang, C., et al. (2011). Dynamic glucoregulation and mammalian-like responses to metabolic and developmental disruption in zebrafish. Gen. Comp. Endocrinol. 170, 334345 .

152. Jagadeeswaran, P., Sheehan, J. P., Craig, F. E., and Troyer, D. (1999). Identification and characterization of zebrafish thrombocytes. Br. J. Haematol. 107, 731- 738.

153. Velasco-Santamaría, Y. M., Korsgaard, B., Madsen, S. S., and Bjerregaard, P.(2011). Bezafibrate, a lipid-lowering pharmaceutical, as a potential endocrine disruptor in male zebrafish (Danio rerio). Aquat. Toxicol. 105, $107-118$.

154. Zang, L., Shimada, Y., and Nishimura, N. (2017). Development of a novel zebrafish model for type 2 diabetes mellitus. Sci. Rep. 7:1461.

155. Capiotti, K. M., Antonioli, R. Jr., Kist, L. W., Bogo, M. R., Bonan, C. D., and Da Silva, R. S. (2014). Persistent impaired glucose metabolism in a zebrafish hyperglycemia model. Comp. Biochem. Physiol. B Biochem. Mol. Biol. $171,58-65$. 
Bulletin of Integrative Psychiatry $\bigcirc$ New Series OSeptember 2021 Year XXVII ONo. 3(90)/31

20. 156. Maddison, L. A., Joest, K. E., Kammeyer, R. M., and Chen, W. (2015). Skeletal muscle insulin resistance in zebrafish induces alterations in be ta-cell numberand glucose tolerance in an age- and diet-dependent manner. Am. J. Physiol. Endocrinol. Metab. 308, E662-E669.

157. V.Connaughton, C. Baker, L.Fande et al., Altrnate Immersion in an External Glucose Solution Differentially Affects Blood Sugar Values in Older Versus Younger Zebrafish Adults. Zebrafish. 2016;13

\section{Correspondence}

Irina Dobrin,

MD, PhD, lecturer, psychiatrist, "Grigore T. Popa" University of Medicine and Pharmacy, 16, Universitatii Street, 700115, Iasi, Romania, irinadobrin2002@gmail.com

Submission: 15 jul 2021

Acceptance: 28 aug 2021 



\title{
The psychological impact of the novel coronavirus pandemic on healthcare workers and ways to adress it
}

\author{
Amira Chehab, Laura Elena Bucur, Mirona Letiția Dobri, \\ Codrina Moraru, Petronela Nechita
}

\begin{abstract}
Amira Chehab - Second year Medical Resident in psychiatry, "Socola" Psychiatry Institute, Iasi, Romania

Laura Elena Bucur - Second year Medical Resident in psychiatry, "Socola" Psychiatry Institute, Iasi, Romania

Mirona Letiția Dobri - Fourth year Medical Resident in psychiatry, " Socola” Psychiatry Institute, Iasi, Romania

Codrina Moraru - Third year Medical Resident in psychiatry," Socola" Psychiatry Institute, Iasi, Romania

Petronela Nechita - MD, PhD, Senior psychiatrist, "Socola" Institute, Iasi, Romania
\end{abstract}

\begin{abstract}
The spread of COVID 19 across the globe is challenging the capacity of response of all healthcare systems. The uncertainty and the newness af this pandemic provoked a generalized wariness and stress among all categories of population, but mainly among healthcare professionals. Due to the lack of knowledge of the disease, the excessive amount of work, poor resources and depletion of personal protection equipment, the huge media pressure and many other difficulties, healthcare workers $(\mathrm{HCW})$ are at high risk of developing many mental health issues such as anxiety, depression, burnout, post-traumatic stress disorder, sleep disorders, all of which could have a negative long-term psychological impact. In this context, it is important to research and to have an real-time view on this topic, in order to find ways of improving the psycological distress $\mathrm{HCW}$ are facing.
\end{abstract}

\section{KEYWORDS:}

Distress, anxiety, PTSD, burnout. 


\section{INTRODUCTION}

The novel Coronavirus disease started in December 2019 in Wuhan, China and since then, it is spreading rapidly all around the world. In just months it was considered a world health emergency and it was declared a pandemic by the World Health Organization (WHO) in March 2020 (1). As in any pandemic situation, this global crisis requires intense and immediate response of medical system, with thousands of professionals delivering services to pacients, adressing the challenges posed to healthcare system by the huge number (over 60 million) of pacients infected by the time we are writing (2).

Previous viral outbreaks have shown that healthcare professionals are at high risk of infection and other adverse physical health outcomes. Furthermore, HCW reported mental health problems associated with their ocupational activities during and years after the epidemics. In order to have an idea of the effects of this pandemic in the following years, it is helpful to analize the outcome of other epidemics/ pandemics that the world has faced. In a study done by Lee et al., performed after the SARS (Severe Acute Respiratory Syndrome- associated coronavirus) pandemic in 2015, for the hospital workers, the post-traumatic stress and depression symptoms associated to the quarantine, can last up to three years after the crisis finalizes. In addition, the healthcare workers placed in quarantine show greater symptoms of post-traumatic stress than the average population. Similar concerns now have been voiced out about the psychological well-being of HCWs in facing the SARSCoV-2 outbreak. The number of COVID-19 patients is increasing dramatically. This leads to a heavier workload in life-threatening situations disturbing the psychological health of hospitals' workforces. As studies done by Huang et al., shows, the rate of psychiatric morbidities in HCWs in the result of SARS-

COV2 was three times higher than the general public $(3,4)$.

\section{WORK-RELATED STRESS FACTORS}

Work and personal-life stressors can compromise physical, mental and emotional wellbeing of people. Studies done by Xiu et al. showed that there are many factors that have contributed to the development of mental issues among $\mathrm{HCW}$. The strict contact with infected pacients and the risk of getting infected themselves, the possibility to take the virus at home and infect their families and other people, not having rapid acces to testing if needed were some of the difficulties faced by HCW. Also, organizational factors, such as depletion of personal protection equipment, concerns of not being able to provide competent care if deployed to new area, lack of treatments, the limited number of beds and the shortage of of ventilators so much needed by the increased number of critically ill pacients who require intubation, high volume workload, lack of both material and human resources could be triggers for distress. The feeling of unknown and social stigmatization are also important to mention. A preliminary study on trauma done by Lee et al. during COVID 19 pandemic showed that HCW may experience traumatization due to frequent experience of seeing pacients dying alone, with no possible contact with their loved ones. In addition to all the labor conditions, the quarantine implemented to stop the expansion of epidemic has also have consequences ont HCW's mental health.

On the other side, Covid 19 provided also positive elements that should be disscused. The public response towards HCWs was a very heartening one. Reports showed that the population expressed a worldwide gratitude and closeness to medical staff. This pandemic has put the health system once again in the 
spotlight, and for some, it has been an important positive reinforcement (5).

\section{INDIVIDUAL STRESS FACTORS}

It is important to mention that there are some individual factors, such as: gender, age, family background, history of psychiatric disorders that influence the mental health impact of this pandemic. A review on six studies conducted in India and Canada by Cai et al. analized the demographic variables that influence the mental impact. Findings indicate that woman reported statistically significant higher score in developing posttraumatic stress disorder, anxiety and depression. As in age, young medical staff (age <30 years old) had higher self-related depression scores compared with those with older age, but the difference wasn't statistically significant. The same article compared the subject matter of worry and concluded that the younger staff was concerned about infecting their families, whereas HCW over 50 years old worried about their own safety.

Findings that compared front-line workers (those working in Covid-departments) and professionals working in other departments suggest differences in self-rated anxiety and depression scores. Being at the high-risk of contagion in such environments will increase the psychological problems, including fear, anxiety, stress, depression. Moreover, being quarantined as a result of working in high-risk wards was another source of mental disorders. The same study reported that nurses are facing the highest level of anxiety and distress among all HCW. Nurses are the largest occupational group that directly and intensively are in constant contact with their patients (6).

\section{PSYCHOLOGICAL IMPACT}

It is still too soon to determine the ultimate psychological and physical impact of Covid19 pandemic outbreak, but distress and anxiety are normal reaction to a situation as threatening and unpredictible as this. The main symptoms developed by HCW since the Covid 19 crisis were anxiety, depression, insomnia, post-traumatic stress disorder and burnout.

Burnout, a state of emotional, physical and mental exhaustion caused by excessive and prolong stress, was one of the major concerns in HCW. The long- term consequences of this syndrome include job dissatisfaction, abandonment and family deterioration, as well as health issues. At a organizational level, workers with burnout syndrome have a smaller capacity to give their patients the healthcare they need, they are more likely to make mistakes, therefore getting the quality of healthcare services even worse. Burnout Syndrome is declared by WHO as a labor risk , with negative influence uppon life quality, compromising individual's mental and physical health. Tendency to social isolation,fear, depression, anxiety, mood changes, addictions, eating disoders and weight fluctuations, memory loss, sleep disorders could suggest presence of burnout syndrome. Studies showed that younger respondands (age 21-30 years old) and especially woman had higher personal and work-related burnout. In the light of this informations and the effects caused by burnout in $\mathrm{HCW}$ at an individual level, as well as the repercussion on health system, the prevention and treatment of burnout syndrome would be essential $(6,7)$.

Mild to moderate and severe anxiety was another common issue found among healthcare staff. Anxiety and fear of falling sick could amplify the sense of helplessness, hopelessness, exhaustion and burnout. These 
s

could also lead to depression, focusing problems at work, self- depreciation, insomnia, health problems and an overall low quality of life $(6,8)$.

If it is not treated in time, the disorder or the episode of acute stress could become a chronic posttraumatic stress disorder (PTSD). Acordig to ICD-10, PTSD is a disorder characterized by flashbacks or nightmares about the traumatic event, which produce terror and strong physiological reactions, avoidance of memories or thoughts related to the event, or to avoid activities, situations or persons related to, and a lasting perception of a current noticeable threat. Due to these symptoms, professionals working in intensive care units (ICU) may consider the possibility of quitting their jobs. If these individuals develop post-traumatic stress, as a selfprotection strategy either being aware or unaware, they may not want to return to where it was produced. Therefore, the psychological consequences derived from the social situation to which the healthcare workers are exposed could not only have implications at individual level, but also increase the burnout already mentioned and may help degrade the health system institution $(6,9)$.

Studies and reviews, like this one, that describe, asses and compare the psychological symptoms $\mathrm{HCW}$ are facing during coronavirus pandemic can offer service planners, strategies and methods on how to mitigate mental health risks and preserve the wellbeing of this essential workers. Eventually, such reasearch can help protect health system, a key sector in this society in all times, but especially during this crisis. Unfortunatelly, existing evidence reguarding the mental health and well-being of people emerging early in the COVID-19 pandemic shows that adequate resources to limit negative psychological effects are almost invariably lacking (as can be proven to be during other pandemics and global crises). Attention to mental health and well-being is commonly superseded by urgent physical and public health needs during an emergency. However, as we disscused in the present review, the long-term mental damages that can result from this pandemic are not to be ignored and actions to help and support should be implemented as soon as possible $(10,11)$.

\section{COPING MECHANISMS}

In these framework, we considerate important to mention some of the coping mechanisms and solutions that had positive outcome during other epidemics that humanrace had faced. In 2012, after SARS, medical professionals reported that clear directiveness and support from the supervisors, adequate training, social and family support were the most effective support mechanisms. Moreover, after MERS (Middle East respiratory syndrome-related coronavirus), medical staff sustained that strict protective measures and guidance, an cohesive team, optimistic and an overall positive attitude in the work enviroment and the recognition of their efforts by the hospial help them to overcome the situation (12).

Having several informations and taking the history as an exemple, several studies reported on the implementation of interventions to prevent or reduce psychological trauma caused by Covid-19 pandemic among HCW. WHO recognised the extremely high burden on health care workers and asked for action to adress the immmediate needs in order to save lifes and prevent the serios mental health and physical impact of $\operatorname{HCW}(13,14)$. 
One help-strategy implemented already in many countries is a thelephone-based hotline set up to provide immediate psychological support, allowing $\mathrm{HCW}$ to speak to trained psychiatrists or psychologists. Although, several studies reported a low level of interest in proffesional psychological support. In two studies performed by Ho et al., participants specified that there is a greater need of a personal protective equipment than psychological help $(15,16)$. So, an important role in reducing stress in this group of workers belongs to hospital managers. Providing adequate and effective protective equipment, addressing HCWs physical needs, such as access to healthy meals and hydration, considering regular rest breaks, designing a safe place for their rest, considering shorter working hours and rotating shifts especially for those working in high-risk departments (working in two or three weeks shifts, followed by 2 weeks quarantine) could be a solution in order to protect medical staff and their pacients. Accommodation and lodging for staff working in high-risk areas and those who are on rapid-cycle shifts that don't live in close proximity to the hospital, providing support for childcare needs, dispatching fresh medical teams from other areas with less number of patients, keep monitoring and check on HCWs' physical and mental wellbeing, teamwork, identifying staff who are exhausted or have psychological distress, taking all necessary measures to limit infections are some key factors in preventing direct and indirect negative effects of this pandemic $(17,18)$.

Lack of family and social support leads to higher rates of depression and hopelessness.A way of solving the distress is rechead with the help of friends and family. Many people turn to mindfullness, meditation, exercise and self-distraction in order to cope with stress. Others, consider that family support or talking to friends is more efficient $(19,20)$.

Regardless of the method used, health care workers should seek help and take action in timely manner in order to prevent and treat any psychological side effect of this pandemic.

\section{CONCLUSIONS}

In conclusion, healthcare workers battling the COVID-19 epidemic are facing a major physical and mental stress which could have severe long-term consequences. Anxiety, depression, burnout, as well as post-traumatic stress disorder are the main psyhological issues that medical teams are dealing with during this pandemic. Various factors, both individual and work-related, are contributing to the mental-health impact among HCW. Prevention and timely treatment of these conditions is recomended in order to preserve the professional's health. The wellbeing of the health workers ensure a better quality of medical service, therefore being beneficial not only for HCW themselves, but also for the pacients and the entire medical system. This review adds to our understanding of mental health needs during this pandemic. However, further research is required to understand and confirm in more detail the potential effects of a given outbreak.

\section{ACKNOWLEDGEMENTS AND DISCLOSURES}

The authors declare no conflicts of interest regarding this paper. 


\section{REFERENCES}

1. 1. Spoorthy MS, Pratapa SK, Mahant S. Mental health problems faced by healthcare workers due to the COVID19 pandemic-A review. Asian J Psychiatr. 2020;51:102119.

2. Chen Q, Liang M, Li Y, et al. Mental health care for medical staff in China during the COVID-19 outbreak [published correction appears in Lancet Psychiatry. 2020 May;7(5):e27]. Lancet Psychiatry. 2020;7(4):e15-e16.

3. Giusti E. M., Pedroli E., D’Anielo G. E., Badiale C. S.,Pietrabissa G.,Manna C., Badiale M. S.,Riva G., Castelnuovo G., Molinari E., The Psychological Impact of the COVID-19 Outbreak on Health Professionals: A CrossSectional Study,Front Psychol,2020;11:1684.

4. Xiang YT, Yang Y, Li W, et al. Timely mental health care for the 2019 novel coronavirus outbreak is urgently needed. Lancet Psychiatry. 2020;7(3):228-229. doi:10.1016/S2215-0366(20)30046-8.

5. El-Hage W., Hingray C., Lemogne C., Yrondi A., Brunault O., Bienvenu T., Etain B., Paquet C., Gohier B. Bennabi D., Brimes P., Savuget A., Fakra E., Prieto N., Bulteau S., Vidaihey P., Camus V., Leboyer M., Krebs M. O., Aouizerate B., , Les professionnels de santé face à la pandémie de la maladie à coronavirus (COVID-19) : quels risques pour leur santé mentale ?, L'Encephale, 2020,Vol. 46, Issue 3;S73-S80.

6. Cai W, Lian B, Song X, Hou T, Deng G, Li H. A cross-sectional study on mental health among health care workers during the outbreak of Corona Virus Disease 2019. Asian J Psychiatr. 2020;51:102111.

7. Chua S.E., Cheung V., Cheung C., McAlonan G.M., Wong J.W., Cheung E.P.,Tsang K.W. Psychological effects of the SARS outbreak in Hong Kong on high-risk health care workers., Can. J. Psychiatry. 2004;49(6):391-393.

8. Cai Q. , Feng H. , Huang J., Wang M., Wang Q.,Lu X. , Xie Y., Wang X., Liu Z. , Hou B., Ouyang K., Pan J. , Li Q. , Fu B., Deng Y., Liu Y., The mental health of frontline and non-frontline medical workers during the coronavirus disease 2019 (COVID-19) outbreak in China: A case-control study, J Affect Disord.,2020, 1;275:210-215.

9. Stuijfzand S. , Deforges C. , Sandoz V., Sajin C-T., Jaques C., Elmers J.,Horsch A., Psychological impact of an epidemic/pandemic on the mental health of healthcare professionals: a rapid review, BMC Public Health, $2020,1230$.

10. Buselli R., Corsi M.,Baldanzi S.,Chiumiento M., Del Lupo E.,Dell'Oste V., Bertelloni C. A., Massimetti G., Dell'Osso L.,Cristaudo A.,Carmassi C., Professional Quality of Life and Mental Health Outcomes among Health Care Workers Exposed to Sars-Cov-2 (Covid-19), Int. J. Environ. Res. Public Health, 2020,17(17), 6180.

11. Mrklas K., Shalaby R., Hrabok M., Gusnowski A.,Vuong W.,Surood S.,Urichuk L., Li D.,Li X-M., Greenshaw A. J., Agyapong V. I. O., Prevalence of Perceived Stress, Anxiety, Depression, and Obsessive-Compulsive Symptoms in Health Care Workers and Other Workers in Alberta During the COVID-19 Pandemic: Cross-Sectional Survey,JMIR Ment Health, 2020,7(9): e22408.

12. Chew Q.H., Chia F.L.A., Ng W.K., Lee W.C.I., Tan P.L.L., Wong C.S., Puah S.H., Shelat V.G., Seah E.J.D., Huey C.W.T., et al., Psychological and coping responses to COVID-19 amongst residents in training across ACGME-I accredited specialties in Singapore. Psychiatr. Res.,2020,290:113146.

13. Muller A. E.,Hafstad E. V., Himmels J-P, W., Smedslund G., Flottorp S., Stensland S. O., Stroobants S., Van de Velde S., Vist G. E., The mental health impact of the covid-19 pandemic on healthcare workers, and interventions to help them: A rapid systematic review,Psychiatr. research, 2020, 293:113441.

14. Chew Q. H., Chia F. L-A., Ng W. K., Lee W. C. I.,Tan P. L. L.,Wong C. S.,Puah S. H., Shelat V. G., Seah E-J. D., Huey C. W. T.,Phua E. J.,Sim K., Perceived Stress, Stigma, Traumatic Stress Levels and Coping Responses amongst Residents in Training across Multiple Specialties during COVID-19 Pandemic-A Longitudinal Study, Int J Environ Res Public Healt,2020, 17(18):6572.

15. Mukhtar S., Mental health and emotional impact of COVID-19: Applying Health Belief Model for medical staff to general public of Pakistan,Brain Behav. Imun.,2020,82:28-29.

16. Blake H. , Bermingham F., Johnson G., Tabner A., Mitigating the Psychological Impact of COVID-19 on Healthcare Workers: A Digital Learning Package, Int J Environ Res Public Healtth,2020, 17(9):2997.

17. Cabarkapa S., Nadjidai S. E.,Murgier J.,Ng C. H., The psychological impact of COVID-19 and other viral epidemics on frontline healthcare workers and ways to address it: A rapid systematic review, Brain Behav Immun Health,2020, 8:100144.

18. Moazzami B., Razavi-Khorasani N., Moghadam A.D., Farokhi E., Rezaeia N. COVID-19 and telemedicine: Immediate action required for maintaining healthcare providers well-being, J. Clin. Virol. ,2020;126:104345.

19. Rodríguez BO, Sánchez TL. The Psychosocial Impact of COVID-19 on health care workers. Int Braz J Urol. 2020;46(suppl.1):195-200.

20. Pollock A., Campbell P., Cheyne J., Cowie J., Davis B., McCallum J., McGill K., Elders A. , Hagen S. , McClurg D., Torrens C. , Maxwell M., Interventions to support the resilience and mental health of frontline health and social care 
Bulletin of Integrative Psychiatry $\bigcirc$ New Series OSeptember 2021 Year XXVII ONo. 3(90)/39 . professionals during and after a disease outbreak, epidemic or pandemic: a mixed methods systematic review, Cochrane Database Syst. Rev., 2020,5;11:CD013779.

\section{Correspondence:}

Petronela Nechita,

MD, $\mathrm{PhD}$, senior psychiatrist Socola Institute of Psychiatry Iași, România, no. 36 Str. Bucium craciunpetronela@yahoo.com

Submission: 29 mar 2021

Acceptance: 29 may 2021 



\title{
Saccharin deprivation increases depression and anxiety levels through oxidative stress biochemical mechanisms
}

\author{
Sorin Ungurianu, Constantin Truş, \\ Roxana-Rosmary Enciu
}

\begin{abstract}
Sorin Ungurianu - Faculty of Medicine, Dunărea de Jos University, Galaţi, România
Constantin Truş - Department of Morphological and Functional Sciences, Faculty of Medicine, Dunărea de Jos University, Galaţi, Romania
\end{abstract}

Roxana-Rosmary Enciu - Sf. Apostol Andrei, Emergency Clinical Hospital

\begin{abstract}
Saccharin is a low-calorie artificial sweetener that has been extensively used in food products since 1879. It has been proven in various studies that saccharin can stimulate the brain centers of pleasure and reward centers in the brain. These brain centers are also proven to be active in alcohol and drug abuse. Therefore, we wanted to study in the present paper the repercussions of saccharin withdrawal on oxidative stress levels and then on depression and anxiety-like behavior of rats. Our experimental design included 40 lab rats divided into two groups, 20 rats in each group. The first group of rats had unlimited access to water and saccharin bottles. The second group was considered the control group and had access only to water. After 4 weeks, the rats in the saccharin group were deprived of saccharin for 14 days to allow sufficient time for deprivation episodes to occur. Our statistical analysis revealed that saccharin withdrawal produced a decrease in catalase activity and as a result an increase in oxidative stress level. Furthermore, saccharin deprivation was associated with an increase in the duration of immobility time in the popular forced swim test and a decrease in the time the rats spent exploring the central area of the open field test. Therefore, saccharin deprivation seems to produce high levels of oxidative stress which may lead to depression-like and anxiety-like behaviors in rats. In conclusion, deprivation from the non-drug reinforcer saccharin produces anxiety and depression-like effects on rats by decreasing the level of certain antioxidant enzymes, such as catalase. These effects are often seen in withdrawn models of abused drugs or alcohol.
\end{abstract}


KEYWORDS:

Oxidative stress, saccharin, catalase, depression, anxiety, deprivation.

\section{INTRODUCTION}

It has been proven in various studies that sugar can stimulate the brain centers of pleasure and reward centers in the brain. These brain centers are also proven to be active in alcohol and drug abuse (1). Interestingly, the same brain centers' activation has been associated with depressive disorders (2,3). Furthermore, withdrawal behaviors following excessive sugar consumption were demonstrated to be similar to those induced by addictive narcotics $(4,5)$. While there are many studies on addictive drug withdrawal, relatively few authors aimed to discover the underlying mechanisms behind the motivation, reward, and addiction of sugar or other artificial sweeteners. (6).

Regarding the available literature, a study that directly compared sugars to cocaine and nicotine have reported that their results proved that sugars are more rewarding than these well-known very addictive substances (7). Other studies proved that mice preferred a sucrose dosage to direct stimulation of dopamine neurons $(8,9)$. Besides, it has also been shown in diabetes mellitus rats that sugar overeating accentuates sugar craving behavior (10). The mechanism behind this addiction suggests that consuming hyperpalatable foods like artificial sweeteners produces changes in dopamine, serotonin, and glutamate levels. These changes in the neurotransmitters pathways lead to the observed, pronounced psychological alterations $(11,12)$.

Furthermore, some literature indicates insulin dysfunction as a plausible underlying mechanism behind sugar addiction (13). This theory that insulin dysfunction may cause brain serotonin levels to decrease suggests that a low level of serotonin will induce a condition in which sugar craving may cause depressive symptoms (14). Another molecular way in which sugar may increase serotonin levels is through an elevation in the serotonin precursor tryptophan $(15,16)$. By the same mechanism, pharmacological treatments that are designed to restore serotonin-mediated neurotransmission to a normal level may also decrease the level of sugar cravings (14). Therefore, eating an excess of sugars, sugar withdrawal, or psychological sugar cravings may cause neurotransmission dysfunctions and negatively alter various brain processes.

Besides the before - mentioned neurotransmission alteration, sugars may also worsen symptoms of various psychiatric disorders. For example, a study on ADHD children showed that patients who received sugar presented higher levels of inattention and aggressive behavior compared to the control group (12). Another example is represented by studies conducted on obese individuals. A study on obese children showed that the subjects who exhibited sugar craving also exhibited an increase in depressive symptoms (17). In regards to sugar replacements, such as saccharin, it has been shown that they also may have positive effects. For example, a meta-analysis study showed that saccharin can moderately lower the body weight in obese individuals by regulating glucose levels (18).

Saccharin is a virtually zero calories artificial sweetener which is approved by USFDA. The history of this product shows that it has been extensively used in food products since 1879 . However, individuals who suffer from diabetes, obesity, or metabolic syndrome are the most popular consumers of saccharin (19). Saccharin is considered safe in low amounts and several studies presented results that suggested that no significant adverse effects occur after consuming low doses of this artificial sweetener $(20,21)$.

But perhaps the most important biochemical effect that saccharin might have is its negative impact on oxidative stress level. It has been established that saccharin induces oxidative stress on brain cells through two distinct biochemical mechanisms. The first mechanism refers to the observed decrease in catalase activity after saccharin ingestion. The 
second biochemical mechanism is related to the decline in the total antioxidant concentration in a sanguine fluid that is detected post saccharin consumption (22). Furthermore, other studies on various rats models, found that saccharin harmfully influences brain tissues and alters oxidative stress markers, on both low and high doses (23).

Therefore, given the increasing demand for the use of saccharin to control the body weight and the blood glucose level and its' possible negative effects on specific biochemical markers of oxidative stress, we wanted to study in the present paper the repercussions of saccharin withdrawal on catalase activity, as a biochemical marker of oxidative stress. Furthermore, we also wanted to determine if catalase activity might act as a possible predictor of depression and anxietylike behavior in a rat model.

\section{MATERIALS AND METHODS}

Our experimental design was simple. We had 40 lab rats divided into two groups, 20 rats in each group. The first group of rats had unlimited access to water and saccharin bottles. The second group was considered the control group and had access only to water.

After 4 weeks, the rats in the saccharin group were deprived of saccharin for 14 days to allow sufficient time for deprivation episodes to occur.

\section{Experiment 1: Forced Swim Test}

The experiment was conducted similarly to the previously developed model. Rats from both groups $(n=40)$ were placed individually into a plastic water tank filled with $30 \mathrm{~cm}$ of tap water. This initial phase of the model lasted for $15 \mathrm{~min}$. Later a 5-min test was conducted in the same plastic water tank with the immobility time measured with a stopwatch by a blind investigator. The stopwatch was started when the rats remained immobile and made no attempts to escape, with no hind limb movement, just floating on the water.

\section{Experiment 2: Open field test}

The open-field test was constructed in a plastic box. The open field was divided into two areas: a central zone and a surrounding margin zone. The rats from both groups $(n=40)$ were positioned one at a time into the margin zone. They were allowed to explore the open field for $10 \mathrm{~min}$. A blind investigator recorded the following parameter: the time each rat spent in the central zone.

\section{Biochemical measurements:}

The activity of catalase in the brain of the animals was measured with the previously demonstrated method of Hadwan and Abeds (24). Therefore, the activity of this antioxidant enzyme was measured as an absorbance variance of 0.01 as units/min.

\section{RESULTS AND DISCUSSIONS}

Saccharin withdrawal and catalase:

The first analysis of our data showed that the saccharin deprived group was significantly different regarding the catalase level when compared to the control group $\mathrm{F}(1,38)=$ $25.539, \mathrm{p}<0.001$.

Specifically, the rats in the saccharin deprived group had a significantly lower level of catalase (mean $=6.75 \mathrm{u} / \mathrm{min}$, standard deviation $=1.650$ ) when compared with the rats that did not receive saccharin at all - the control group $($ mean $=10.6 \mathrm{u} / \mathrm{min}$, standard deviation $=2.981$ ). A better perspective of the two groups can be seen in figure 1 . 


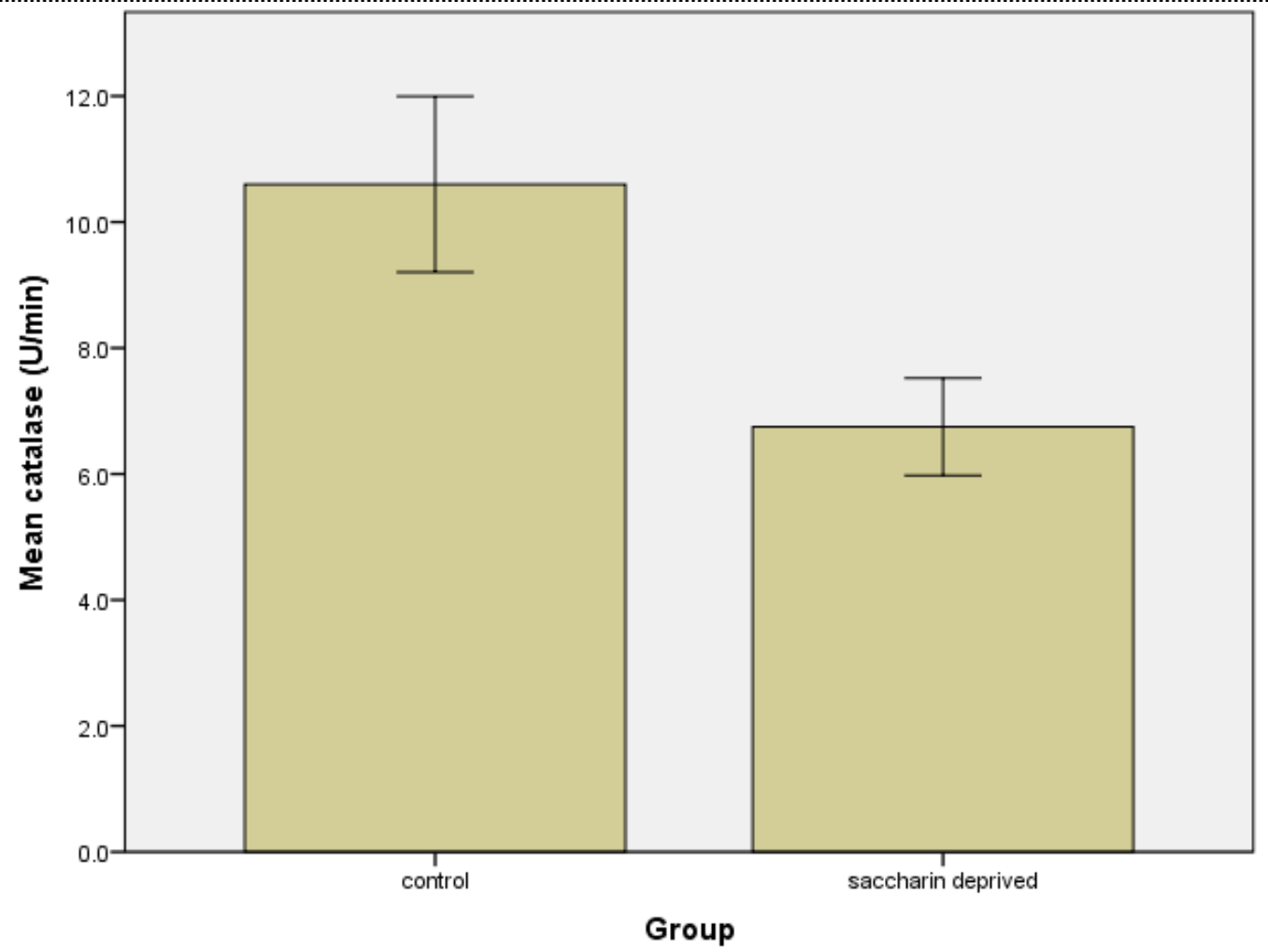

Error Bars: $95 \% \mathrm{Cl}$

Fig 1. The level of catalase activity for each experimental group

Saccharin withdrawal and depression:

The second analysis of our results proved that the saccharin deprived group was significantly different regarding the time the rats spent being immobile when compared to the control group: $\mathrm{F}(1,38)=16.018, \mathrm{p}<$ 0.001 .
To be more precise, the rats in the saccharin deprived group had a significantly higher time spent in immobility (mean $=103.95$ seconds, standard deviation $=2.488)$ when compared with the rats from the control group (mean $=$ 88.65 seconds, standard deviation $=2.902$ ). A better perspective of the two groups can be seen in figure 2 . 


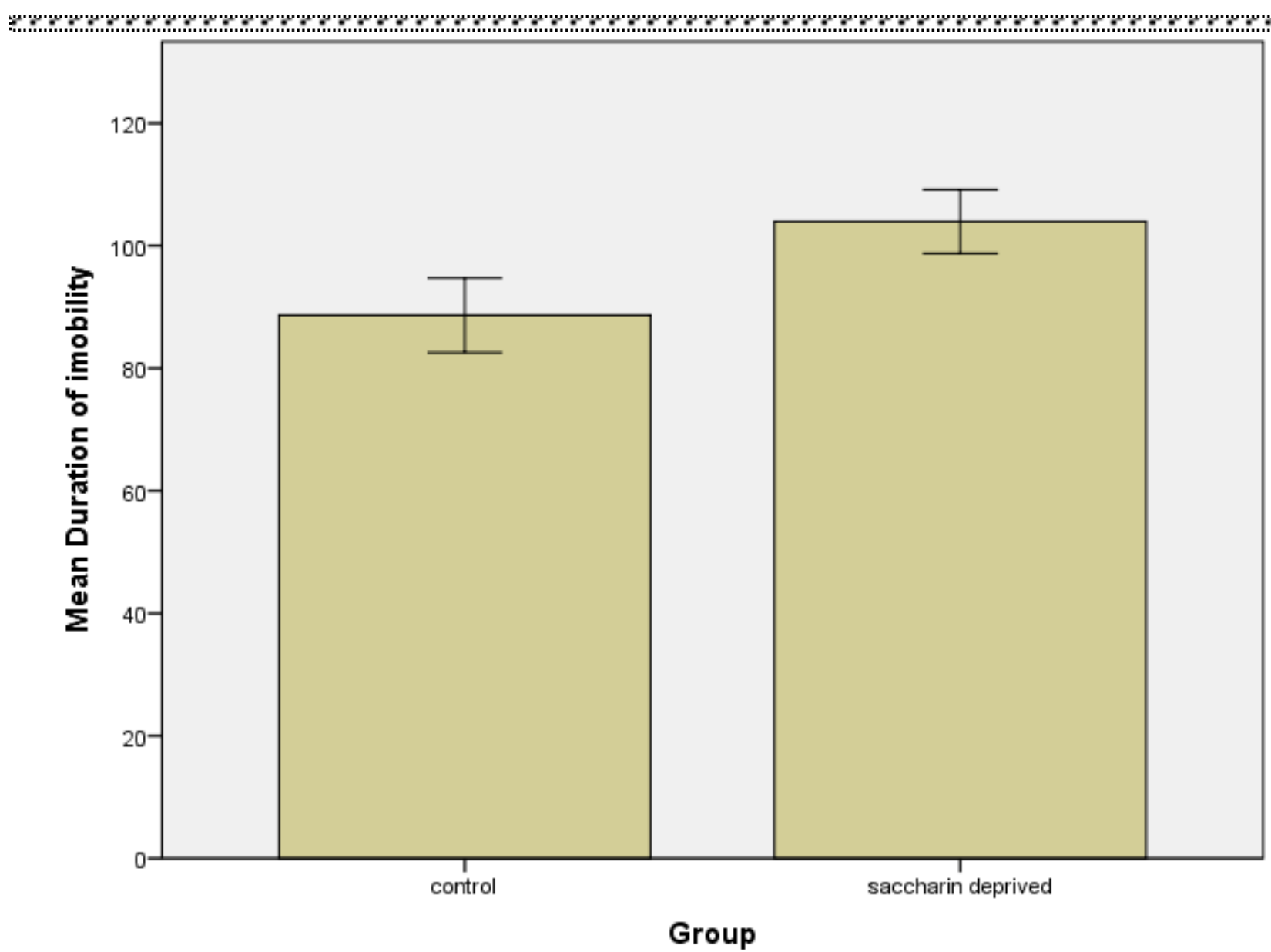

Error Bars: $95 \% \mathrm{Cl}$

Fig 2. The time spent being immobile in the water tank for each experimental group Saccharin withdrawal and anxiety:

The third analysis of our input, regarding the anxiety-like behavior, showed that the saccharin deprived group spent significantly different time in the center of the open field test compared to the control rats $\mathrm{F}(1,38)=$ 5.393, $\mathrm{p}=0.026$.

Specifically, the rats in the control group explored more time the center of the Open
Test Field $($ mean $=76.45$ seconds, standard deviation $=19.667)$ in comparison with the rats which were saccharin deprived (mean $=$ 62.35 seconds, standard deviation $=18.723$ ) . A better perspective of the significant differences between groups can be seen in figure 3 . 


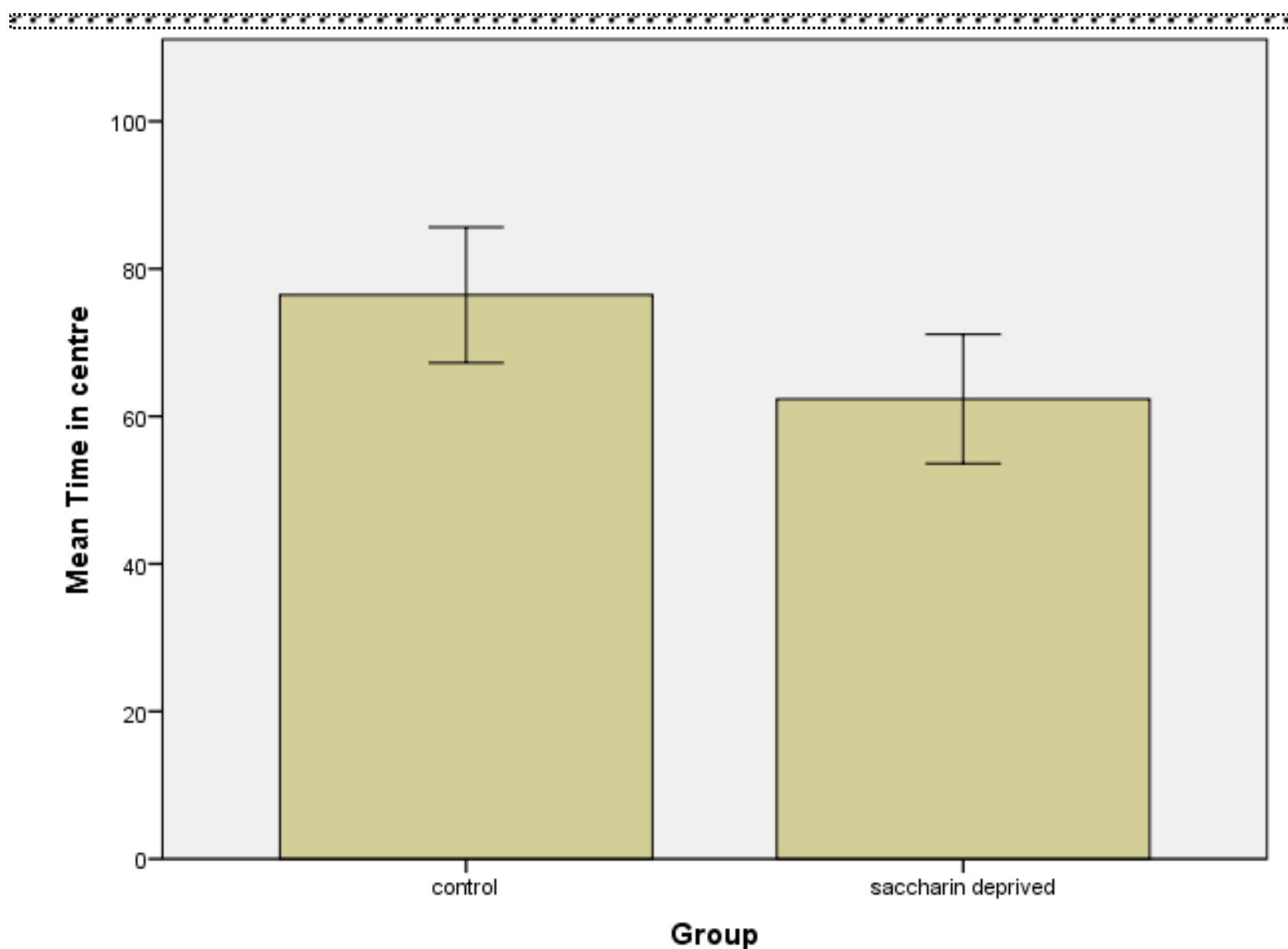

Error Bars: $95 \% \mathrm{Cl}$

Fig 3. The time spent exploring the center of the field for each experimental group

The results of our study demonstrate a positive relationship between saccharin withdrawal and oxidative stress, measured in our experiment by catalase activity in the brain. The rats in the saccharin withdrawal group had a significantly lower catalase activity compared to control rats. The biochemical explanation of these results may be related to the release of reactive oxygen species (ROS). To be more precise, saccharin withdrawal could produce a release of ROS. The body will respond with its' ability to generate antioxidants, such as catalase, superoxide dismutase, or glutathione peroxidase, as a result of cellular defense against ROS. When the initial release of ROS will overcome the production of antioxidants, high levels of oxidative stress will result $(25,26)$. Besides, if the deprivation persists, an increase in free radical production will occur, which will further overwhelm the defense antioxidant mechanisms and lead to an even more pronounced decline in catalase activity.

Furthermore, we also wanted to evaluate the behavioral outcomes of saccharin deprivation on depression and anxiety levels. Such results can be used to measure anxiety and depression-like changes to help in the process of screening for antidepressant drugs. Our statistical analysis revealed that saccharin deprivation was associated with an increase in the duration of immobility time in the popular forced swim test and a decrease in the time the rats spent exploring the central area of the open field test. Therefore, saccharin deprivation seems to produce depression-like and anxiety-like behaviors in rats.

These results are not in contrast with those we found in the available literature. Drug deprivation has been repeatedly shown to result in high levels of oxidative stress, anxiety, and depression-like behaviors (27). 


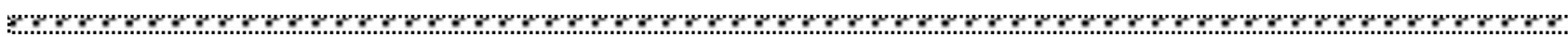

The symptoms of withdrawal lead to a decrease in motivation to gain any other common reinforcer besides the initial drug (28). All these symptoms are translated to an observed increase in the immobility time measured in the forced swim test (29). Much of the before mentioned data refers to serious drug administration, like cocaine or nicotine, but there is also evidence suggesting that artificial sweeteners are not that different in regards to the withdrawal period (30). Even if these anxiety and depression symptoms were observed in rats that received various drugs of abuse, it is yet to be demonstrated if the observed elevation in the withdrawal-induced symptoms is explained by random behavioral aspects or by the specific mechanism of each drug. For example, studies have shown that alcohol withdrawal was correlated with elevated ICSS thresholds. Some authors have stated that this effect may be interpreted as a decrease in the function of the brain connected with the reward system (31). Interestingly, other studies have found that acute administration of alcohol ethanol can have similar effects to antidepressants to rats tested in the forced swim test (32). Furthermore, alcohol high dose administration is shown to lower the ICSS thresholds (33). Therefore, like every drug of abuse, alcohol withdrawal symptoms are expected to be exactly contrary to the acute administration. Therefore, it is expected that saccharin acute administration will lead to a decrease in anxiety and depression-like behaviors; however, the withdrawals of saccharine will increase these behaviors. In this regard, a previous study demonstrated exactly the previously mention theory: ethanol administration presented an antidepressantlike effect and was correlated with a decrease in the immobility of rats in the forced swim test (34).

The present study generated similar results to the available literature on the correlation between saccharin deprivation oxidative stress, anxiety, and depression. In the present study, the increased immobility time, compared to the control rats, was detected after 14 days of saccharin deprivation. Regarding the deprivation time, this period varies from study to study, with some data suggesting that some drug withdrawal effects typically diminish after 3-5 days (34). However, studies on the effects of ethanol or saccharin deprivation typically use longer periods of drug deprivation (35).

\section{CONCLUSIONS}

In conclusion, deprivation from the non-drug reinforcer saccharin produces high levels of oxidative stress which leads to anxiety and depression-like effects on rats. These effects are often seen in withdrawn models of abused drugs or alcohol. However, it is important to mention that the present study has used very high doses of saccharin, doses that do not apply to daily human consumption of saccharin.

\section{CONFLICT OF INTEREST}

None to disclose.

\section{REFERENCES}

1. Lustig, R. Fructose: metabolic, hedonic, and societal parallels with ethanol, J. Am. Diet Assoc., 110(9), 2010, 13071321.

2. Jastreboff, A., Sinha, R., Arora, J., Giannini, C., Kubat, J., Altered brain response to drinking glucose and fructose in obese adolescents, Diabetes, 65(7), 2016, 1929- 1939.

3. Page, K.A., Chan, O, Arora, J., Deaguiar, R.B., Dzuira, J., Roemhholdt, B., Effects of fructose vs glucose on regional cerebral blood flow in brain regions involved with appetite and reward pathways, JAMA, 309(1), 2013, 63-70. 4. Avena, N.M., Rada, P., Hoebel, B.G., Evidence for sugar addiction: behavioral and neurochemical effects of intermittent, excessive sugar intake, Neurosci. Biobehav. Rev., 32(1), 2008, 20-39.

5. Drewnowski, A., Krahn, D.D., Demitrack, M.A., Nairn, K., Gosnell, B.A., Naloxone, an opiate blocker, reduces the consumption of sweet high-fat foods in obese and lean female binge eaters, Am. J. Clin. Nutr., 61(6), 1995, 1206-1212. 
. 6. Berridge, K.C., Ho, C.Y., Richard, J.M., Difeliceantonio, A.G., The tempted brain eats: pleasure and desire circuits in obesity and eating disorders, Brain Res., 1350, 2010, 43-64.

7. Lenoir, M., Serre, F., Cantin, L., Ahmed, S.H., Intense sweetness surpasses cocaine reward. PLoS One, 2, 2007, e698.

8. Domingos, A.I., Vaynshteyn, J., Voss, H.U., Ren, X., Gradinaru, V., Zang, F, Leptin regulates the reward value of nutrient, Nat. Neurosci., 14, 2011, 1562-1568.

9. Adamantidis, A.R., Tsai, H.C., Boutrel, B., Zhang, F., Stuber, G.D., Budygin, E.A., Tourino, C., Bonci, A., Optogenetic interrogation of dopaminergic modulation of the multiple phases of reward-seeking behavior, J. Neurosci., 31(30), 2011, 10829-10835.

10. Belzer, L.M., Smulian, J.C., Lu, S.E., Tepper, B.J., Food cravings and intake of sweet foods in healthy pregnancy and mild gestational diabetes mellitus. A prospective study, Appetite, 55(3), 2010, 609-615.

11. Ahmed, S.H., Guillem, K., Vandaele, Y., Sugar addiction: pushing the drug-sugar analogy to the limit. Curr. Opin. Clin. Nutr. Metab. Care., 16(4), 2013, 434-439.

12. Wender, E.H., Solanto, M.V., Effects of sugar on aggressive and inattentive behavior in children with attention deficit disorder with hyperactivity and normal children, Pediatrics, 88(5), 1991, 960-966

13. Naicker, K., Johnson, J.A., Skogen, J.C., Manuel, D., Overland, S., Sivertsen, B., Colman, I., Type 2 diabetes and comorbid symptoms of depression and anxiety: longitudinal associations with mortality risk, Diabetes Care, 40(3), 2017, 352-358.

14. Wurtman, R.J., Wurtman, J.J., Carbohydrate craving, obesity and brain serotonin, Appetite, 7, 1986, 99-103.

15. Wurtman, R.J., Wurtman, J.J., Do carbohydrates affect food intake via neurotransmitter activity?, Appetite, 11(1), 1988, 42-47.

16. Wurtman, R.J., Wurtman, J.J., Brain serotonin, carbohydrate-craving, obesity and depression, Obes. Res., 3(4), 1995, 477-480.

17. Drewnowski, A., Menella, J.A., Johnson, S.L., Bellisle, F., Sweetness and food preference, J. Nutr., 142(6), 2012, $1142-1148$.

18. Olivier, B., Serge, A.H., Catherine, A, Belegaud, J., Bortolotti, M., Review of the nutritional benefits and risks related to intense sweeteners, Arch. Public Health, 73(41), 2015, 41.

19. Chattopadhyay, S., Raychaudhuri, U., Chakraborty, R., Artificial sweeteners - a review, J. Food Sci. Technol., 51(4), 2011, 611-621.

20. Chappel, C.I., A review and biological risk assessment of sodium saccharin, Regul. Toxicol. Pharmacol., 15(3), 1992, 253-270.

21. Ellwein, L.B., Cohen, S.M., The health risks of saccharin revisited, Crit. Rev. Toxicol., 20(5), 1990, 311-326

22. Alkafafy, M.E.S., Ibrahim, Z.S., Ahmed, M.M., El-Shazly, S.A., Impact of aspartame and saccharin on the rat liver: Biochemical, molecular, and histological approach, Int. J. Immunopathol. Pharmacol., 28, 2015, $247-255$.

23. Amin, K.A., Al-Mufazar, H.M., Abd Elstarr, A.H., Effect of sweetener and flavoring agent on oxidative indices, liver and kidney function levels in rats, Indian J. Exp. Biol., 54, 2016, 56-63.

24. Hadwan, M.H., Abed, H.N., Data supporting the spectrophotometric method for the estimation of catalase activity, Data Brief, 6, 2016, 194-199.

25. Fridovich, I., Superoxide dismutases. An adaptation to a paramagnetic gas, J. Biol. Chem., 264, 1989, $7761-7764$.

26. Sies, H., Strategies of antioxidant defense, Eur. J. Biochem., 215, 1993, 213-219.

27. Markou, A., Kenny, J.P., Neuroadaptations to chronic exposure to drugs of abuse: Relevance to depressive symptomatology seen across psychiatric diagnostic categories. Neurotox. Res., 4, 2002, 297-313.

28. Barr, A.M., Philips, A.G., Withdrawal following repeated exposure to d-amphetamine decreases responding for a sucrose solution as measured by a progressive ratio schedule of reinforcement. Psychopharmacology (Berl.), 141, 1999, 99-106.

29. Kokkinidis, L., Zacharko, R.M., Anisman, H., Amphetamine withdrawal: A behavioral evaluation, Life Sci., 38, 1986, 1617-1623.

30. Ahmed, S.H., Kenny, P.J., Koob, G.F., Markou, A., Neurobiological evidence for hedonic allostasis associated with escalating cocaine use, Nat. Neurosci., 5, 2002, 625-626.

31. Schulteis, G., Markou, A., Cole, M., Koob, G.F., Decreased brain reward produced by ethanol withdrawal, PNAS, USA, 92, 1995, 5880-5884.

32. Ciccocioppo, R., Panocka, I., Froldi, R., Colombo, G., Gessa, G. L., Massi, M., Antidepressant-like effect of ethanol revealed in the forced swimming test in Sardinian alcohol-preferring rats. Psychopharmacology (Berl.), 144, 1999, 151157. 
Bulletin of Integrative Psychiatry $\bigcirc$ New Series OSeptember 2021 Year XXVII ONo. 3(90)/49

(n) 33. Bespalov, A., Lebedev, A., Panchenko, G., Zvartau, E., Effects of abused drugs on thresholds and breaking points of intracranial self-stimulation in rats. European Neuropsychopharmacology, 9, 1999, 377-383.

34. Spanagel, R., Holter, S.M., Long-term alcohol selfadministration with repeated alcohol deprivation phases: An animal model of alcoholism? Alcohol Alcohol, 34, 1999, 231-243.

35. Kornet, M., Goosen, C., Van Ree, J.M., The effect of interrupted alcohol supply on spontaneous alcohol consumption by rhesus monkeys. Alcohol Alcohol, 25, 1990, 407-412.

\section{Correspondence:}

\section{Constantin Trus,}

Department of Morphological and Functional Sciences, Faculty of Medicine, Dunărea de Jos University, Galaţi, Romania, dilconstantin@yahoo.com

Submission: 10 jun 2021

Acceptance: 19 aug 2021 



\title{
Medium-term religious support program applied to suicidal psychiatric patients
}

\author{
Speranța-Giulia Herea, Roxana Chiriță, Andreea Silvana Szalontay, \\ Gabriela Elena Chele, Cristinel Ștefănescu
}

\begin{abstract}
Speranța-Giulia Herea - PhD stud, "Grigore T. Popa" University of Medicine and Pharmacy, "Socola" Institute of Psychiatry, Iasi, Romania

Roxana Chiriță - MD, PhD, professor, psychiatrist, "Grigore T. Popa" University of Medicine and Pharmacy

Andreea Silvana Szalontay - MD, PhD, lecturer, psychiatrist, "Grigore T. Popa" University of Medicine and Pharmacy

Gabriela Elena Chele - Assistant of professor, MD, PhD, psychiatrist, "Grigore T. Popa" University of Medicine and Pharmacy

Cristinel Ștefănescu - Professor, MD, PhD, psychiatrist, "Grigore T. Popa" University of Medicine and Pharmacy, 16 Strada Universității, 700115 Iasi, Romania
\end{abstract}

\begin{abstract}
Psychiatric literature generally recognizes the importance of religion and spirituality in the care of religious psychiatric patients. In this work we aimed to investigate the influence of a supportive religious program on religious patients with suicidal ideation. The results confirmed the theoretical predictions of the psychiatric literature regarding the broad positive value of a complementary religious support applied to religious psychiatric patients. A potential negative effect of the most influential Christian Orthodox religious practices used in the therapy of suicidal patients was also noted. These findings may have significant implications for medium and long-term psychiatric interventions in faith-based settings.
\end{abstract}

\section{KEYWORDS:}

Suicide, religious support, depression, spiritual/religious care practice.

\section{INTRODUCTION}

The psychiatric literature recognizes largely the importance of religion and spirituality in the care of religious psychiatric patients, recommending collaborative professional spiritual/religious approaches to support them. Moreover, a majority of clinicians acknowledged their responsibility to address the religious/spiritual needs of patients. D'Souza et al. emphasized the need for psychiatrists to take into account the spiritual and religious dimension of their patients since it leads to the strengthening of the patientphysician relationship and the increase of the therapeutic impact of interventions.(1) Shin et al. showed that physicians of higher religiosity/spirituality were more willing to believe that medically unexplained symptoms of their patients, accounting for $20-30 \%$ of primary care consultations, result from a 
spiritual issue, underlining the importance of paying attention to the patients' spiritual life.(2) Furthermore, in another study, the majority of German psychiatric staff members expressed their willingness to deal with patients' religiosity/spirituality in therapeutic settings, while clinical chaplains, even if they agreed to the psychiatrists' opening, offered however a different general perception, a result that recommended an increase in collaboration between psychiatrists and clinical chaplains by changing their views on religious/spiritual issues for clinical practice.(3) Also, Judge showed that nurse practitioners should take into account the patients' spirituality needs, especially for chronic cases.(4) Such studies prove that religion and/or spirituality - as important components of people's lives(5) - are largely considered by the psychiatrists to be important in therapy, at least at a functional level.(6) For this reason, the World Psychiatric Association recommended a more direct and close partnership between psychiatry and religion/spirituality at institutional level.(7) Moreover, because religion can help religious psychiatric patients to cope with the stressful circumstances of an illness, psychiatrists are advised to consider the spiritual history of their patients, to support healthy religious beliefs, to pray with patients (if appropriate), and to consult or do joint therapy with the trained clergy.(8) Nevertheless, it is warned that even if praying with religious patients could induce positive effects and increase therapeutic success, the practice may still have some risky features and should only occur if the psychiatrist would demonstrate a good understanding of patients' religious beliefs and if they have good knowledge of and experience with religion.(9)

A series of reports emphasized the key role of the religious factors in reducing the incident depression and suicide rates. An extended study performed on about 50,000 nurses in U.S. found an inverse relationship of the risk of incident depression with the attendance of religious service.(9) Likewise, religious social support was positively associated with the decrease of depressive symptoms, while its lack predicted an increase of the depressive symptoms and emotional disturbances.(10) Other results have suggested that religious support may not be automatically the result of simple religious attendance, but can however afford exclusive benefits to religious persons, distinctly from social support.(11) In addition, Robinson et al. showed that relationship between religious attendance and mental health differs when evaluated across ethnic groups, infrequent religious attendance being associated with anxiety and suicidal ideation in Whites and Hispanics.(12) Moreover, Koenig et al. found that while baseline religiosity does not moderate the optimism of the persons with major depressive disorder and chronic medical illness, religiosity predicts however increases in optimism over time.(13)

Religion can as well protect against suicide attempts, regardless of social functioning, psychopathology and substance use. $(5,14)$ Religion acts as a protective factor both at the individual and societal levels.15 For example, the frequent attendance of religious services significantly reduces the suicide risk(16) while weekly attendance may lead to a $42 \%$ reduction in suicide ideation.(17) In another study performed on about 90,000 women in the United States, the suicide rate for attending at least one religious service once a week was about 5 times lower than when never attending.(18) Hence, it seems that even if simple religious affiliation might not automatically protect against suicidal ideation, it does reduce suicide attempts.(19) Similarly, people who were not involved in religious activities had four times higher suicide rates than those with high participation.(20) As a result, religious support is positively associated with recovery from severe mental illness(21) while, more specifically, religious attendance is considered an important independent protection factor against suicide attempts and depression.(22) The reported findings have significant implications for psychiatric interventions in faith-based settings and have emphasized the importance of considering religious practices as influential protective factors against suicide, depression, and psychiatric illness, in 
\% \% \% \% \% \% \% \% \%

general.(10,23) Hence, given the reported positive impact of religious practices on religious patients, psychiatrists were advised to be willing to work with members of faith communities, chaplains and pastoral workers, and to encourage all fellow psychiatrists to do the same, as religion and spirituality should be seen as essential components of psychiatric training and professional development.(24) In addition, clinicians who are familiar with the faith traditions regarding suicide are better prepared to address crisis situations by religious means as well, and are better prepared for consultation with religious professionals, when considered.(5)

However, despite consistent findings and recommendations on the benefits of religious support for religious suicide patients, the specific content of such a religious supportive program is neither detailed nor applied effectively. Therefore, in this paper, we have designed a consistent and highly flexible religious supportive program containing a series of influential religious activities which were applied to a number of patients with suicidal ideation. The obtained data were analyzed using a dedicated psychological/psychiatric evaluation scale and a religious assessment questionnaire.

\section{METHODS}

Study population and data collection. For this study, sixty-seven religious Caucasian patients with suicidal ideation were randomly divided into two groups (34 and 33 patients, each), the first group receiving continuous religious support for about 6 months between 2018 and the beginning of 2020. A religiously-supported patient withdrew in the middle of the study. The patients were diagnosed with schizophrenia, depression, bipolar disorder, organic personality disorder, anxiety disorder, alcohol withdrawal syndrome. Patients with dementia and oligophrenia were excluded.

The religiously-supported patients (RSP) benefited from religious support both during hospitalization and after discharging. Patients' religious level was evaluated using a religious questionnaire (Table 1), partially inspired from Curlin et. al.(25), while the efficiency of the religious program was assessed through a 21-item Hamilton Depression Rating Scale (HAM-D) that estimates depressed mood, guilt feeling, suicidal ideation, and somatic, vegetative and cognitive symptoms of depression.(26) A high score is an indication of increased mental (and somatic) degradation. Ratings were performed at baseline and at the end of the study. Some of the final interviews were conducted by phone. Participation in this study was done exclusively on a voluntary basis and no reward or favor was offered to patients. Patients were allowed to completely stop the religious support at any time.

Table 1. Religious questionnaire applied for both admission in the study and general evaluation of the religious level

\begin{tabular}{ll}
\hline Do you consider yourself a practicing & a). Yes. \\
believer? & b). Not. \\
& c). Only in part \\
\hline
\end{tabular}

\begin{tabular}{ll}
\hline & a). Twice a month or more. \\
How often do you attend religious & b). Once a month or less. \\
services? & c). Rarely. \\
& d). Never.
\end{tabular}

a). I believe in God;

What are your religious beliefs?

b). I only believe in the afterlife, but I don't believe in God.

c). I believe in God and in the afterlife.

d). I have no religious beliefs. 
How religious do you consider yourself to be?

a). Very religious.

b). My religiosity is average.

c). My religiosity is low.

d). I'm not religious at all

a). I ask God for help;

b). I do not ask for God's help;

If you encounter difficult situations in life:

c). I only ask for God's help if there is no other way to solve problems

d). I believe that I can solve my problems only on my own.

a). No, never.

b). Yes, to encourage me.

In case of more difficult medical problems, would you agree to have a priest to help you along with the doctors?

c). Yes, because I believe that through prayer, confession and other works of the Church I can be healed or I can more easily overcome my suffering.

d). I don't know what to do.

Assuming you know that one doctor
believes in God and another does not
believe in God, who would you choose to
take care of you?

a). The one who believes in God.

b). The one who does not believe in God.

c). I don't know, my choice would depend on other factors.

a). I had no regrets.

If you ever tried to leave this world, what were your thoughts in those moments?

b). I was sorry for what I was doing.

c). I was afraid of God's judgment.

e). I don't know what I was thinking at the time.

a). No, I wanted to die.

Did you want to be saved when you b). Yes, I wish I were saved, no matter by whom. decided to leave this world?

c). I prayed to the Lord to be saved.

d). I didn't care if I lived or died.

a). Family, friends.

Who do you think could help you stop making such attempts?

b). The Church (God).

c). The society.

d). No one.

a). Nothing, everything is the same as before.

After going through this difficult b). Yes, I would never try to repeat such a gesture. situation, did you learn anything?

c). Yes, I pray more and go to church.

d). Yes. I think only God saved me.

a). I think so.

Do you think that these dark thoughts occur because of a sin of yours or of some ancestors in your family?

b). No.

c). I do not know.

d). Yes, and I believe that God can solve all these problems.

Ethical approval. The patients were informed about the subject of the study and offered their informed consent. The institutional ethics committee approved the study.

Descriptive statistic. To examine the differences between the two groups, the Pearson Chi square test and $t$-student test were used. Reported $p$ values for $t$-student test were two-tailed. Means and standard deviations were calculated for quantitative variables. The confidence intervals, CI, for proportions were calculated through Microsoft Excel 2007. Significance was set at standard 0.05 . 


\section{RESULTS AND DISCUSSIONS}

Characteristics of the patients are shown in Table 2. The two groups were almost identically structured, with an over unity women-to-men ratio. There was no significant difference with respect to the mean age. The religiously-supported group included more patients living in rural areas, but the difference is statistically non-significant $(\mathrm{p}=0.459, \mathrm{CI}=0.41-0.65)$. There were more patients married or living in cohabitation in both groups, but the statistical difference was also non-significant. The patients of both groups, with a mean age near fifty, declared a mean monthly income of about 160 euro. For both groups, the education was primarily secondary, with no statistical significant difference.

Table 2. Characteristics of the psychiatric patients

\begin{tabular}{|c|c|c|c|c|c|c|c|}
\hline \multirow[t]{2}{*}{ Defining characteristics } & \multicolumn{3}{|l|}{ RSP } & \multicolumn{2}{|c|}{$\begin{array}{l}\text { Control } \\
\text { patients }\end{array}$} & \multirow{2}{*}{$\begin{array}{l}\text { Statistic } \\
\text { significance } \\
p^{*}\end{array}$} & \multirow{2}{*}{$\begin{array}{l}\text { Confidence } \\
\text { interval (CI) } \\
95 \%\end{array}$} \\
\hline & $N$ & $\%$ & & $N$ & $\%$ & & \\
\hline \multicolumn{8}{|l|}{ Sex } \\
\hline Women & 20 & 60 & & 18 & 54.5 & \multirow{2}{*}{0.618} & $0.45-0.68$ \\
\hline Men & 13 & 40 & & 15 & 45.5 & & $0.31-0.54$ \\
\hline \multicolumn{8}{|l|}{ Place of residence } \\
\hline Urban & 14 & 42 & & 17 & 51.5 & \multirow{2}{*}{0.459} & $0.35-0.59$ \\
\hline Rural & 19 & 58 & & 16 & 48.5 & & $0.41-0.65$ \\
\hline \multicolumn{8}{|l|}{ Marital status } \\
\hline $\begin{array}{l}\text { Married or living in } \\
\text { cohabitation }\end{array}$ & 21 & 64 & & 25 & 76 & \multirow{2}{*}{0.284} & $0.58-0.79$ \\
\hline Single & 12 & 36 & & 8 & 24 & & $0.34-0.57$ \\
\hline \multirow{3}{*}{$\begin{array}{l}\text { Age }(\mathrm{M} \pm \mathrm{S} \\
\text { Women } \\
\text { Men }\end{array}$} & \multirow{3}{*}{\multicolumn{3}{|c|}{$\begin{array}{l}52.9 \pm 10.2 \\
52.1 \pm 10.4 \\
54.3 \pm 10.1\end{array}$}} & \multicolumn{2}{|c|}{$52.2 \pm 10.1$} & \multirow{3}{*}{0.743} & \\
\hline & & & & 49.1 & \pm 12.5 & & \\
\hline & & & & $56=$ & 3.7 & & \\
\hline $\begin{array}{l}\text { Declared } \\
\text { (euro/month) }\end{array}$ & $\begin{array}{l}160( \pm 70.8) \\
\text { (declared } \\
\text { persons) }\end{array}$ & by & 21 & \multicolumn{2}{|c|}{$\begin{array}{l}159( \pm 92.3) \\
(\text { declared by } \\
17 \text { persons })\end{array}$} & & \\
\hline \multicolumn{8}{|l|}{ Education } \\
\hline Higher & 2 & & & 3 & & & $0.03-0.17$ \\
\hline Secondary & 29 & & & 30 & & 0.694 & $0.8-0.95$ \\
\hline
\end{tabular}

* by Chi square test for $5 \%$ level of significance

From Table 2, the most notable characteristics of patients are related to their income and level of education. The extremely declared low earnings could represent their pension which, in a favorable scenario, might be part of a larger family budged, given that $70 \%$ of the patients were not living alone. However, such a personal low income might impact highly negatively on the social living standards, and even affect the physical existence of the patients. Hence, poverty itself can be one of the main causes of their suicide ideation as a way to get rid of mental pain and, perhaps, to save dignity. Undoubtedly, by lacking the basic financial resources to live decently and, further, to treat their illness, they have a highly increased stress level. In such cases, they may find a viable refuge in God.

The results showed a statistical significant difference between HAMD scores (Table 3) for both groups $(p<<0.05$ for RSP, and $\mathrm{p}=0.0031$ for control group). However, while for RSP there is a positive difference $(16 \%)$ between the mean scores obtained at the beginning and the end of the study, a negative difference $(-6.2 \%)$ was found for the control group. This divergence highlights a mental state destabilization of control outpatients in the medium term compared to those who 
received religious support. This result suggests that even if the mental state of the control patients is stabilized at discharge, it slightly degrades several months after. Overall, analyzing the percentages, there is a significant difference between the variations of HMAD means for the two groups, indicating a clear positive role of religious support applied to RSP in the medium term.

Table 3. Statistical evaluation of the scores obtained by RSP using the HAMD scale and a religious questionnaire

\begin{tabular}{|c|c|c|c|c|}
\hline \multirow[t]{2}{*}{ Statistical parameters } & \multicolumn{2}{|c|}{ HAMD } & \multicolumn{2}{|c|}{ Religious level } \\
\hline & RSP & $\begin{array}{l}\text { Control } \\
\text { group }\end{array}$ & RSP & $\begin{array}{l}\text { Control } \\
\text { group }\end{array}$ \\
\hline $\mathrm{p}$ (two-tail) & $\begin{array}{l}<< \\
0.05 \\
\end{array}$ & 0.0031 & $\begin{array}{l}<< \\
0.05\end{array}$ & 0.12 \\
\hline Pearson Correlation & 0.65 & 0.73 & 0.85 & 0.90 \\
\hline $\begin{array}{l}\text { Difference between means obtained by using } t \text {-student test at } \\
\text { baseline and at the end of the study }(\%)\end{array}$ & 16 & -6.2 & 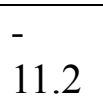 & 1.2 \\
\hline
\end{tabular}

The religious level improved significantly only for RSP $(\mathrm{p}<<0.05)$, with a negative difference $(-11.2 \%)$ between the mean scores obtained at the beginning and the end of the study. In other words, for this group, the religious score was higher at the end of the study. On the contrary, there is no statistically significant difference between the religious scores obtained by control patients $(\mathrm{p}<<0.12)$ even if a slight decrease of religiosity $(1.2 \%)$ was noted. The results are highly correlated (Pearson correlation $>50 \%$ ) for both groups and for both types of evaluations.

The religious supportive program (Table 4) was split into two main sections: (a) personal program based on personal prayer, religious reading, attendance of religious services, including those dedicated to the healing of the sick, consultation of specific religious materials in audio/video format, religious pilgrimages and (b) program conducted jointly with the therapist with theological training and the spiritual priest, respectively, which included common-offered prayers, discussions, confession, Holy Communion, and specific religious services in the patients' home. Both the personal and the common supportive program were adjusted according to the degree of religiosity of the patients and their current psycho-mental state. The supportive program included different series of activities agreed separately with each patient.

Table 4. Detailed, flexible religious supportive program of the RSP

\section{a. Personal program}

\begin{tabular}{lll}
\hline Activities at the patients' choice & $\begin{array}{c}\text { Recommended } \\
\text { frequency }\end{array}$ & $\begin{array}{l}\text { Recommended } \\
\text { allotted time }\end{array}$ \\
\hline $\begin{array}{l}\text { Prayers specific to the Christian-Orthodox ritual: } \\
\text { morning and evening prayers }\end{array}$ & times a day & $15(+15) \mathrm{min}$ \\
\hline $\begin{array}{l}\text { Prayers addressed to the Lord Jesus Christ, the Mother once a day } \\
\text { of God or a patient's favorite saint (akathist) }\end{array}$ & $15-30 \mathrm{~min}$ \\
\hline $\begin{array}{l}\text { Reading some chapters from the Bible (Gospel) } \\
\text { regarding the healing of the sick }\end{array}$ & 5 min \\
$\begin{array}{l}\text { Reading specific Psalms (from Old Testament) } \\
\text { recommended by the Church for finding inner peace once a day } \\
\text { and strong support in God }\end{array}$ & $5-15 \mathrm{~min}$ \\
\hline \begin{tabular}{l} 
Reading religious books which describe various good once a day \\
\hline
\end{tabular} & $10 \mathrm{~min}-1 \mathrm{~h}$ \\
\hline
\end{tabular}




\begin{tabular}{|c|c|c|}
\hline $\begin{array}{l}\text { Participation in the Holy Anointing - a specific } \\
\text { religious ritual dedicated to the healing of diseases }\end{array}$ & once a week & $1-2 \mathrm{~h}$ \\
\hline Participation in the Holy Mass & once a week & $1-2 \mathrm{~h}$ \\
\hline $\begin{array}{l}\text { Listening to religious songs that convey hopeful } \\
\text { messages }\end{array}$ & $1-2$ times a day & $10-20 \mathrm{~min}$ \\
\hline $\begin{array}{l}\text { Listening to some spiritual advice and parables of } \\
\text { contemporary spiritual Fathers }\end{array}$ & $1-2$ & $15 \mathrm{~min}$ \\
\hline $\begin{array}{l}\text { Watching/listening to religious shows on a religious } \\
\text { (radio) television, including online attendance of } \\
\text { religious services }\end{array}$ & & $30-60 \mathrm{~min}$ \\
\hline Practicing the so-called "prayer of the mind"* & $\begin{array}{l}\text { whenever } \\
\text { patient feels } \\
\text { need }\end{array}$ & \\
\hline Pilgrimages to monasteries & $\begin{array}{lll}\text { twice } & \text { every } & 6 \\
\text { months } & & \\
\end{array}$ & 1-4 days \\
\hline
\end{tabular}

b. Joint program

\section{Made jointly with the therapist}

Prayers offered by the therapist for the patient $* * \quad$ once a day $5 \mathrm{~min}$

Prayers offered by the patient to other patients experiencing a similar difficult life situation*** once a day

Supportive religious discussions with hospitalized patients

once a day

$5 \mathrm{~min}$

Maintaining a telephone connection between therapist and patient for supportive religious discussions

once a week $\quad 30 \mathrm{~min}$

\section{Made jointly with the spiritual priest}

Discussions with the spiritual priest, including through twice a month confession

Prayers offered by the clergyman for the patient
$\begin{aligned} & \text { Communion with the body and blood of the Lord, at the } \\ & \text { recommendation of the priest (Holy Communion) }\end{aligned}$
$\begin{aligned} & \text { Specific church services performed by the clergyman or once every } \\ & \text { months }\end{aligned}$
other minister priest at the patient's home
* The consecrated formula of the "prayer of the mind" in the Christian-Orthodox ritual is as
follows: "Lord Jesus Christ, Son of God, have mercy on me, a sinner." However, patients were
able to use modified variants; instead of "have mercy on me," and "sinner" they could use any
other expressions they felt were more appropriate for them, e.g., "help me", "give me peace",
"protect me", "the suffering," "the helpless" or "the grieving". Patients could repeat the prayer
for a period of time of their choice depending on their inner mood. The form of addressing the
prayer was at the patient's choice.
** Patients were told that the therapist would pray for them at a certain time in the evening,
possibly simultaneously with them.
*** This is a method described in the spiritual-religious literature. Praying out of compassion
for another, the person in need prays or learns to pray in fact for himself.

The religious program sought, first of all, to induce a positive and balanced change of the mental state of religious patients by increasing the level of trust, hope, reconciliation with himself, acceptance of suffering, and by exercising the associated religious practices with increased faith in God, but letting God decide what is best for him. Secondly, the program sought to increase 
the level of religious and social interaction within their religious community, through pilgrimages and attendance to religious services of the Church, including healing ones, with direct influence on the mental comfort of the patients. This two-pronged approach could provide the patient with the means for mental rebalancing by deepening the knowledge and experiences of a religious nature regarding the significance and transfiguring value of the suffering, the obligation to fight suicidal thoughts as a moral duty to God, the belief that the endured suffering will be rewarded in the eternal life, and the fact that Christians, be they sick, must be joyful, confident, active, seeing in every event of their life a pedagogy of God for them.

Much of the above religious teachings and recommendations are well known to religious patients. Therefore, they were only recalled, supplemented, consolidated and suggested to be implemented in a more systematic and consistent way through a higher community religious integration that would provide patients with moral, psycho-emotional, possibly material support for difficult cases, a support offered under the spectrum of Church teachings in a sacramental setting.

Taken hierarchically, the personal prayer, as a means of direct relationship with God, was considered a main instrument of the supportive program, given the relative ease of practicing it and the ability to generate positive emotions and living relationships with God or Saints. Patients were asked to follow as much as possible the prayer program which they chose, but they were suggested to pray freely, simply, without any restrictions, without formalities, to speak with God as they speak with the best friend or parent, generating positive emotions in any discussion they have with the Divine. Moreover, if during a usual, traditional prayer, which they read or say according to the chosen program, they will be feeling the need to deprive themselves of the written words in order to express themselves freely to God, in their own words, being animated in those moments of positive emotions, then they were advised to stop reading the prayer and to engage simply and calmly in a balanced living prayer of request and thanksgiving addressed directly to God. Most patients told they preferred this approach, confessing that the free and simple prayer, addressed with hope and emotion to God, made them feel liberated, relieved, comforted in their hearts, and confident that God would support and will help them to accept and overcome the difficulties that have arisen in their lives, also forgiving those they consider guilty to a certain extent for their troubles.

A key role in improving the mental state of religious patients with suicidal ideation may be the practice of a very short prayer as often as possible (in our case, "the prayer of the mind") in a repetitive manner to keep the mind constantly filled with protective, positive, optimistic impressions. Fighting in such a way against the mental state induced by suicidal thoughts, the mind might be trained to quickly switch from a suicidal state to a stable state (of prayer). Over time, through experience, the method can begin to operate spontaneously as a reaction to any suicidal thought or even as a reaction to other different negative mental states, other than suicidal ones. However, most patients reported that they were unable to practice this prayer constantly and consistently due to the fact that they only could focus on the words of the prayer and its message for a very short time. Even though they felt at ease, other supportive activities seemed easier to put into practice. Probably this type of supportive religious activity would find its utility only in the long-term, backed by a more reliable psychological motivation and only with wellstabilized patients under uninterrupted psychiatric supervision and psychiatric medication intake.

The religious books, afforded to patients from the library of the clinic throughout the study, included various stories with happy ending, parables and wonders, all rendered in simple, accessible language, with the potential to induce a positive emotional effect on their mental state. Religious reading had the largest share during hospitalization, with patients 
testifying however that, after discharge, they have unfortunately allocated less time to religious readings due to lack of time and socio-familial problems to which they were exposed. In the case of most patients readmitted in hospital during the study, there was a strong desire to continue the same type of simple religious readings, with happy ending events, in which God or various saints miraculously intervened in solving family, health or social problems of people who believed in God and asked for His help in great faith.

Even though this type of religious support is built on an extreme simplicity in approach and content, the message that was conveyed to patients and the associated effects were likely to move positively, to encourage, to increase confidence, hope and even resignation, leaving in God's care all the insurmountable problems that appeared or will appear in their lives seemingly without a logic of causality. In fact, it is in the human nature to overcome the hard times of life by accessing simple things, easily disconnecting activities and uncomplicated readings with positive and motivating emotional messages that may quickly rebalance mentally even the healthy and highly educated people.

During the study, it was observed that under the pressure of their major health problems, patients paid no attention to the theoretical, theological, or philosophical aspects that the religious support program might involve, being more open to the faith-related discussions based on practical examples, suggestions, and proposals for the purpose of immediate help. This could also be related to their education, mostly secondary, which allowed them to receive faith more naturally, without any further inquiry, conditionality and reluctance. Therefore, many religious people who have not had the opportunity to pursue certain university education might probably have the advantage of being protected from academic dilemmas and theoretical complex analyzes, while maintaining their authentic, unquestionable faith. And whether or not the belief in the healing power of the prayer and relationship with God might induce a placebo effect is a secondary topic that concerns specialists more than patients.

As regarding the reading of some recommended chapters in the Bible, some patients needed guidance, the biblical message needing some simplification and clarification to be understood undistorted. During hospitalization, religious patients who wished to be told of illustrative stories and events described in the Bible related to their suffering, the example of Job, an Old Testament character famous for his suffering, was considered the most appropriate. From the New Testament, religious patients were told about Jesus Christ's unconditional love for the sick, briefly describing some of the miraculous healings of the sick people obtained through faith.

Attendance of religious services and pilgrimages did not suffer interference from the therapist, being considered particular acts related to the privacy of patients. In fact, the patients' particular religious reflections and feelings were not an object of investigation in this study, the focus being only on the final effect of supportive activities on the psychomental state of patients.

As regarding the relationship between therapist and patients, an important aspect that strengthened it was the friendly proposal that the therapist pray for them. Patients accepted and confessed they would feel better knowing that someone was thinking of their own good, praying for them. Hence, prayer, while maintaining its intrinsic religious value, was also a mediator and catalyst for building a trusting relationship between therapist and suicidal patients by conveying a message of affection to them. In addition, patients agreed to pray unconditionally for other patients, known or unknown, for their well-being and health.

Discussions with patients were generally conducted individually, the allotted time differing from case to case. To normalize the psycho-affective state, the therapist used examples from the religious field in which through prayer, patience, resignation, 
forgiveness, mercy, love and trust in God, a suffering person can overcome difficult situations, as was the paradigmatic case of Job. In addition, patients with increased religiosity were told about the cathartic or even missionary valences of suffering, as was the case with St. Paul.

As previously pointed out, due to the general and religious education of the patients, it was considered that a religious support plan built on basic and easy-to-understand theological knowledge would be better suited to the purpose of the study. However, we have to add that a psycho-social interference of religious support simply could not be banned due to the specificity of the support actions. Thus, since religion teaches about love and good deeds that should be offered unconditionally to fellow sufferers, 2-3 psychiatric patients in each group were helped, at their request, to solve some of their problems, by facilitating their access to medical services, other than psychiatric, clarification of medical documents required by medical commissions, listening to their acute problems when they called urgently during an emotional crisis asking for psychoemotional support, encouraging them to socialize more within their close community, not necessarily a religious one, or referring them to some NGOs that might afford immediate help. Therefore, a pure religious support is difficult to provide and manage because at least a minimal psychosocial influence will always have to be associated to implement it successfully.

In order to increase the success rate, the program needs to be attractive, balanced, very flexible, both in content and development, without interfering with the strong beliefs of patients, even if such beliefs might be theologically wrong. Any kind of obligation or coercion imposed on patients in their state of advanced psycho-emotional fragility would nullify the positive effect of religious support. Likewise, the discussions and guidance must be conducted with great pedagogical tact by the therapist who, by definition, starts from the premise that patients who have declared themselves religious tell the truth and act with sincerity. Even so, they need to be careful and aware of the specific type of patients they support and that things can evolve in a completely unexpected way. For instance, there may be cases in which psychiatric patients might enter the program by fabricating the answers to the religious questionnaire, while actually not sharing the traditional religious values expressed by the main teaching body of the state-recognized religions. This is however a tolerable action simply because suicide patients may consider such a program a good possibility or opportunity to be helped. Hence, a false failure may be part of the end result.

In the end, it is worth noting the particular case in which one of the declared highly religious patients, belonging to the RSP, withdrew from the study after rejecting God and accepted the "demon". As a child born out a rape, divorced, recovered from cancer, and with multiple suicide attempts, she manifested intense hatred against her mother, while being simultaneously subjected to similar hatred by her own fully-aged daughter. Submitted continuously to an intense psychic pressure, she declared she had a high expectation to solve her problems, but since God didn't respond to her prayers, psychiatry couldn't solve the problem, family and society couldn't come with a viable solution, she chose as an alternative the demonic way. Therefore, a double-edged potential of religion to improve the recovery of psychiatric patients from a mental illness or to accentuate its symptoms ${ }^{27}$ is confirmed as well by this case. Therefore, religious support must be conducted with high diligence, taking into account the fragile mental condition of patients, even after their discharging, and the possibility that some may no longer follow the prescribed psychiatric drug therapy. Also, religious patients who ask for such support should not be given high expectations for the immediate resolution of their problems, but rather be reminded that the chosen religious supportive program could only help them in the long run along with psychiatric treatment, the latter remaining essential. 


\section{LIMITATIONS OF THE STUDY}

Since the religious supportive program was very permissive, the patients were free to choose and change, during the study, the activities they considered most appropriate for them. The side effect was that the study suffered from the lack of homogeneity of the applied supportive activities. Therefore, it was not possible to perform a quantitative assessment of the weight and influence of some supportive activities to the detriment of others, due to the unequal time allocated by different patients for the same supportive activity, and the subjectivity introduced by patients in the implementation of a chosen activity. Also, larger groups of religious psychiatric patients would be needed to increase the accuracy of the results.

\section{CONCLUSIONS}

In this work, a detailed supportive religious plan comprising influential religious activities was conceived and applied for approximately six months to a number of Orthodox Christian patients with suicidal ideation. The results showed a statistically significant improvement of the patients' mental state and a slight, but still statistically significant, mental degradation of the control group. The level of religiosity has also improved significantly for the religiously supported patients. By practicing personal or commonly-offered prayer, religious readings, attendance of religious services, consultation of specific religious material, religious pilgrimages, religious discussions, confession to the priest, Holy Communion, or specific religious services performed in the patients' home, all based on the patients' faith in God, the mental state of religious psychiatric patients positively changed in the medium term.

During the study, a declared highly religious patient lost her faith in God and declared she accepted the "demonic" way. Therefore, the predicted risk that religious practices may also accentuate the symptoms of a mental illness is confirmed as well by this particular case. For this reason, religious support should be conducted with caution, taking into account the possibility that some patients may place very high hopes in such a supportive program and even stop following the prescribed psychiatric drug therapy during the program.

Overall, the obtained data confirmed practically the theoretical predictions and expectations of the psychiatric literature regarding the broad positive value of a complementary religious support applied to religious psychiatric patients. These findings may have significant implications for longterm psychiatric interventions in faith-based settings, emphasizing the protective role of influential religious practices against mental illness, in general, and suicide, in particular.

\section{ACKNOWLEDGEMENTS AND DISCLOSURES}

The authors state that there are no declared conflicts of interest regarding this paper.

\section{REFERENCES}

1. https://www.who.int/news-room/fact-sheets/detail/suicide

2. D'Souza R, George K. Spirituality, religion and psychiatry:its application to clinical practice. Australas Psychiatry. 2006;14(4):408-412.

3. Shin JH, Yoon DJ, Rasinski KA, Koenig HG, Meador KG, Curlin FA. A spiritual problem? Primary care physicians' and psychiatrists' interpretations of medically unexplained symptoms. J Gen Intern Med 2013;28(3):392-8.

4. Lee E, Zahn A, Baumann K. How do psychiatric staffs approach religiosity/spirituality in clinical practice? Differing perceptions among psychiatric staff members and clinical chaplains. Religions 2015;6(3):930-47.

5. Judge D, Holistic Care: Are You Recognizing a Need for Spiritual Care? JNP - Journal for Nurse Practitioners, 2016;12(10): e439-e440, DOI: https://doi.org/10.1016/j.nurpra.2016.06.018.

6. Norko MA, Freeman D, Phillips J, Hunter W, Lewis R, Viswanathan R. Can Religion Protect Against Suicide? J Nerv Ment Dis 2017;205(1):9-14.

7. Curlin FA, Lawrence RE, Odell S. Chin MH, Lantos JD, Koenig HG, Meador KG. Religion, spirituality, and medicine:psychiatrists' and other physicians' differing observations, interpretations, and clinical approaches. Am J Psychiatry 2007b;164:1825-31.

8. World Psychiatric Association. WPA position statement on spirituality and religion in psychiatry. World Psychiatry. 2016;15:87-8. doi:10.1002/wps.20304. 
(n)

9. Koenig HG. Religion and mental health:what should psychiatrists do? Psychiatr Bull 2008;32:201-203.

10. Li S, Okereke OI, Chang S-C, Kawachi I, VanderWeele TJ. Religious Service Attendance and Lower Depression among Women - a Prospective Cohort Study. Ann Behav Med 2016;50(6):876-84.

11. Holt CL, Roth DL, Huang J, Clark EM. Role of religious social support in longitudinal relationships between religiosity and health-related outcomes in African Americans. J Behav Med 2018;41(1):62-73. doi:10.1007/s10865-0179877-4.

12. Fiala WE, Bjorck JP, Gorsuch R, The Religious Support Scale:Construction, Validation, and Cross-Validation, Am. J. Community Psychol, 2002;30(6):761-786.

13. Robinson JA., Bolton JM., Rasic D, et al. (2021) Exploring the relationship between religious service attendance, mental disorders, and suicidality among different ethnic groups:results from a nationally representative survey, Depression and Anxiety 2021;29(11):983-990.

14. Koenig HG, Pearce MJ, Nelson B, Daher N, Effects of religious versus standard cognitive-behavioral therapy on optimism in persons with major depression and chronic medical illness, 2015, 32(11), 835-842.

15. Burshtein S, Dohrenwend BP, Levav I, Werbeloff N, Davidson M, Weiser M. Religiosity as a protective factor against suicidal behavior. Acta Psychiatr Scand 2016;133:481-8.

16. Vijaykumar L, Suicide and its prevention: The urgent need in India, Indian J Psychiatry. 2007 Apr-Jun; 49(2): 8184. doi: 10.4103/0019-5545.33252

17. Kleiman EM, Liu RT. Prospective prediction of suicide in a nationally representative sample:religious service attendance as a protective factor. Br J Psychiatry 2014;204:262-6.

18. Nkansah-Amankra S, Diedhiou A, Agbanu SK, Agbanu HL, Opoku-Adomako NS, Twumasi-Ankrah P. A longitudinal evaluation of religiosity and psychosocial determinants of suicidal behaviors among a population-based sample in the United States. J Affect Disord 2012;139:40-51.

19. VanderWeele TJ, Li S, Tsai AC, Kawachi I. Association Between Religious Service Attendance and Lower Suicide Rates Among US Women. JAMA Psychiatry 2016;73 (8):845-51. doi:10.1001/jamapsychiatry.2016.1243.

20. Lawrence RE, Oquendo MA , Stanley B. Religion and Suicide Risk:A Systematic Review. Arch Suicide Res 2016;20(1):1-21. doi:10.1080/13811118.2015.1004494

21. Nisbet PA, Duberstein PR, Conwell Y, Seidlitz L. The effect of participation in religious activities on suicide versus natural death in adults 50 and older. J Nerv Ment Dis 2000;188:543-6.

22. Webb M, Charbonneau AM, McCann RA, Gayle KR. Struggling and enduring with God, religious support, and recovery from severe mental illness. J Clin Psychol 2011;67(12):1161-76. doi:10.1002/jclp.20838.

23. Rasic D, Robinson JA, Bolton J, Bienvenu OJ, Sareen J. Longitudinal relationships of religious worship attendance, and spirituality with major depression, anxiety disorders, and suicidal ideation and attempts:findings from the Baltimore epidemiologic catchment area study. J Psychiatr Res 2011;45:848-854.

24. Cole-Lewis YC, Gipson PY, Opperman KJ, Arango A, King CA. Protective Role of Religious Involvement Against Depression and Suicidal Ideation Among Youth with Interpersonal Problems. J Relig Health 2016;55(4):117288. doi:10.1007/s10943-016-0194-y.

25. Recommendations for psychiatrists on spirituality and religion. Position Statement PS03/2013, November 2013. This position statement was written by Professor Christopher C. H. Cook on behalf of the Spirituality and Psychiatry Special Interest Group.

26. Curlin FA, Odell SV, Lawrence RE et al., The Relationship Between Psychiatry and Religion Among U.S. Physicians, Psychiatric Services 2007;58(9):1193-8.

27. Mowla A, Dastgheib SA, Jahromi LR. Comparing the Effects of Sertraline with Duloxetine for Depression Severity and Symptoms:A Double-Blind, Randomized Controlled Trial. Clin Drug Investig. 2016;36(7):539-43.

28. Pargament KI, Lomax JW. Understanding and addressing religion among people with mental illness. World Psychiatry 2013;12:26-32.

\section{Correspondence:}

Speranța-Giulia Herea,

PhD stud, "Grigore T. Popa" University of Medicine and Pharmacy, "Socola" Institute of Psychiatry, Iasi, Romania 


\title{
Dyslexia intervention to combat specific language disorder, a consequence of the economic migration
}

Katalin Tiron

Tiron Katalin - PhD Student, Psychology and Education Sciences Faculty, "Alexandru Ioan Cuza" University of Iaşi

\begin{abstract}
In the conditions of a strong economic migration, quite a few children are exposed to radical changes, which affect their development, especially in terms of communication. In the present study, we presented the case of a 7-year-old child who had a language disorder, stuttering and dyslexia. Following the intervention, based on syllabic training, stuttering, dyslexia and language were greatly reduced.
\end{abstract}

\section{KEYWORDS}

Specific language impairment, stuttering, dyslexia, intervention.

\section{INTRODUCTION}

After 1989, major economic changes took place in Romania. Many people have become unemployed and the lack of social support has forced them to look for strategies to adapt to the transition period (1). With the opening of the borders, thousands of people left Romania in search of a better life. One person left one family, others both parents. Many children were left in the care of grandparents, friends. And there is another category of children, those displaced once or even several times.
They moved with their parents, attended an educational institution there, and then they all returned. Often children are put in a position to cope in a new world, without even knowing the language well. Those who knew the Romanian language on departure, adapt more easily on return. Children born abroad, or who were very young on departure, often learn the adopted state language as a foreign language. When they return, they have great difficulties in adapting, behavioral problems, language disorders, which lead to school failure. In the present study we present the results of an 


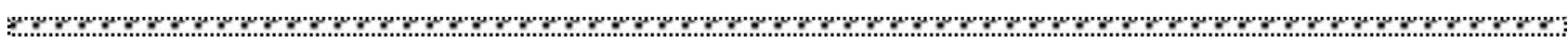

experiment performed on a 7-year-old student, who has a language disorder, stuttering and dyslexia. P. F. was born in Italy. He lived there for 4 years, then his parents moved back to Romania. When he returned to the country, he had a rather good receptive dictionary for the Italian language, for the Romanian language he is quite poor. He was enrolled in the kindergarten with extended program. Due to the fact that he did not know the Romanian language when entering kindergarten, it made it difficult for him to communicate. Not only the ignorance of the language was a difficulty, but also the multiple sounds affected in pronunciation. Interestingly, the tetism presented did not prove to be a consequence of the wrong setting, but of a very serious impairment of phonemic hearing. At the time of presentation in speech therapy, the child could not repeat two-syllable words after the speech therapist. The first word learned was "geam", which he said from the first meeting. In addition, he had developed stuttering.

Specific language disorder: is defined as persistent difficulty and language acquisition, due to hearing impairments and not due to hearing impairment or sensory abnormalities, motor dysfunction or other medical or neurological disorders and cannot be explained by intellectual disability or global retardation of development (2). It is an output disorder, which affects auditory perception, and prevents the development of appropriate learning strategies (3). The disorder is accompanied by poorly developed short-term verbal memory, poor vocabulary, and poor comprehension, especially if the interlocutor speaks quickly (4). Language is a tough process in the face of obstacles, and if one route is blocked, we usually find another. But if two or more development pathways are blocked, language will be compromised (4). In this case, there was a strong genetic component, highlighted by the fact that his brother also has a language disorder. Not having access to a developed internal dictionary, every time he tried to speak, he would get stuck and stutter. Stuttering usually sets in at an early age, just before 18 months (5). It is manifested by repetitions of sounds and syllables or monosyllabic words and induces anxiety in communication situations (2). These combined deficiencies led to a marked language disorder, which proved very difficult to compensate. The severity of the problems, accompanied by inconsistent and inconsistent parental support, led to the fact that at the beginning of first grade, P.F. still had an accentuated dyslalia, mainly due to the confusion of $\mathrm{S}-\mathrm{S}$-T, Th. The speech was intelligible, and the degree of stuttering decreased. For this reason, we expected it to develop dyslexia as well (6). Dyslexia is a disorder that leads to reading difficulties, characterized by reduced fluency (7). Fluency has three key elements: accuracy (degree of correctness), speed (the number of words reads correctly in a unit of time), and intonation (7). In order to be able to read at the appropriate speed, the child must first learn the letters and then read them in turn (decoding). Decoding ability is measured by reading non-words. After a word has been encountered several times, we recognize it and the reading becomes fluent. From this moment we can focus our attention on understanding the text (8). The process of literacy, although it seems relatively simple, is a complex process, which also involves the development of related skills, such as: knowledge of letters, phonological awareness and quick naming. These are the most important predictors for reading in a language with regular spelling (9). Phonological awareness is the ability to manipulate phonological units (10). In languages with regular spelling, the difference of dyslexic children compared to those with normal 
development is only a lower speed (11), but Romanian students are also affected by accuracy (12). Intervention: is based on PGST theory (13), according to which reading learning is influenced by the following factors: availability, consistency and granularity of language. By availability we mean that some phonological structures are not aware before learning to read (eg phoneme awareness), by consistency we mean that different sounds or spelling units can be written in several ways. This is especially reflected in the regularity of spelling. Granulation expresses the size of the spelling unit needed to learn to read. In languages with irregular spelling, such as English, it is not enough to learn the letters to be able to read. The PGST theory was developed through the Theory of syllabic connection (14). The latter highlights how the phoneme-syllable association is created. Romanian is a language with a fairly high orthographic regularity, but some sounds have several letters associated with it: cum e and â / î. Letter groups, CCV structures (consonant / consonant / vowel), CCVV, diphthongs, etc. raises special issues for children with dyslexia. In fact, they cannot make the transition from letter-to-letter decoding to word-reading. For this reason, we performed the intervention based on syllabic training. The child was exposed to each new sound to syllabic structures below the image of the corresponding word. I tried to include especially the frequent syllables and as much as possible in the initial position. Children with dyslexia have great difficulty identifying rhyme or a phonological unit in the middle of a word (15). This type of intervention has been shown to be used successfully by other researchers $(16,17,18)$.

\section{OBJECTIVES}

We wanted to see to what extent dyslexic intervention, performed by syllabic training, can reduce dyslexia in case of a language disorder.

\section{HYPOTHESIS}

H1: We assumed that with the syllabic drive a secure fixation of the letters (LK) will be achieved.

$\mathrm{H} 2$ : The syllabic training intervention will develop decoding skills (NWRA accuracy and NWRF decoding fluency).

H3: Following the intervention to combat dyslexia, the student will develop reading skills, characterized by accuracy (WRA) and fluency (WRF).

H4: At the end of the intervention, the student will present a developed phonological awareness. H5 : Following the intervention, the student will have fewer words affected by pronunciation disorder.

\section{METHOD}

Procedure: The entire WISC IV test was administered before the intervention. The score obtained IQ $=102$. He easily solved the nonverbal tests, and even in the verbal ones he had high scores. We also administered the general visual ability assessment test: developed by (19). VA $=12$, presenting spatio-visual abilities superior to his age. The language was evaluated with "Independent speech testing" developed by Vrăjmaș \& Stănică (1994). At the beginning of the intervention to combat dyslexia there were still confusions of sounds: Ş-S; J-Z; T-T. For long words with 4 or more syllables omit parts of the word. The grammatical structure of the sentences is correct, sometimes it depends on the adjective-noun agreement or on the plural of some nouns. The intervention took place during the school year 2020 2021, with tests in the second half of January, respectively in mid-July. The series of tests 
were presented in the following order: knowledge of letters, reading of words, reading of non-words, PA). We measured the time of the tasks. In the evaluation, we used, at both moments of the intervention (initial and final) DDE-2 (The Battery for Assessment of Dyslexia and Evolutive Dysorthography, Sartori et al., 1995; adapted for the Romanian population, 20). When assessing the knowledge of the letters we used Test 1 , when reading the words Test 2 , and when reading the non-words (for decoding) Test 3. The knowledge test of the letters contains 26 capital letters. Test 2 includes high frequency and uncommon words.
Phonological awareness was assessed by the deletion of syllables or sounds. For example: bamu becomes mu by removing the first syllable. For the assessment of phonological awareness (AP) we administered the Deletion subtests from "Onset Deletion Test from Battery d'evaluation du language ecrit et de ses disorders" (BELEC), by Mousty, et al. 1994, adapted for the Romanian population, 12).

\section{RESULTS}

The results obtained from the measurements are presented in Table 1 .

Table 1. The results obtained the main variables: LK- knowledge of letters; WRA-reading accuracy, WRF-reading fluency, NWRA - decoding accuracy; NWRF-decoding fluency, PA phonological awareness with the three subtests: B1, B2 and C1, WPA-words pronunciation affected

\begin{tabular}{|c|c|c|c|c|c|c|c|c|c|}
\hline & \multirow[t]{2}{*}{$L K$} & \multirow[t]{2}{*}{$W R A$} & \multirow[t]{2}{*}{$W R F$} & \multirow[t]{2}{*}{ NWRA } & \multirow[t]{2}{*}{$N W R F$} & \multicolumn{3}{|c|}{$P A$} & \multirow[t]{2}{*}{$W P A$} \\
\hline & & & & & & $B I$ & $B 2$ & $C 1$ & \\
\hline Pretesting & 4 & 0 & 0 & 0 & 0 & 0 & 0 & 0 & $60 \%$ \\
\hline Testing & 26 & $80 \%$ & 8 & $85 \%$ & 6 & 16 & 16 & 10 & $80 \%$ \\
\hline
\end{tabular}

The results obtained fully support our hypotheses. The fact that the scores from the decoding samples are very close to those from the reading, shows us that PF still uses the sublexical route in reading (decoding, 12). Although at the beginning of the intervention the phonological awareness was not developed, until the end of the intervention, it reached the ceiling level. The letter learning stage is also over. In terms of language: we have an improvement in the correctness of speech, but in some words, there are still pronunciation errors. Grammatical errors are fewer, some sounds have been fixed correctly (eg J and T,).

Table 2. The results for the main variables for normal developed first-grader children

\begin{tabular}{cccccc}
\hline & $\mathrm{N}$ & Minimum & Maximum & Mean & Std. Deviation \\
\hline LK & 206 & 23 & 26 & 25.90 & .388 \\
RAN & 206 & 8.75 & 46.00 & 18.0143 & 4.63380 \\
B1 & 206 & 4 & 16 & 15.44 & 1.231 \\
B2 & 206 & 1 & 16 & 15.37 & 1.543 \\
C1 & 206 & 0 & 16 & 9.72 & 1.185 \\
WRA & 206 & 30.36 & 100.00 & 93.6720 & 9.45660 \\
WRF & 206 & .01 & .40 & .0391 & .04135 \\
NWRA & 206 & .00 & 100.00 & 84.2536 & 18.26310 \\
NWRF & 206 & .01 & 1.21 & .0626 & .09586 \\
\hline
\end{tabular}


We compared his scores with the average obtained by testing 206 students from schools in Suceava County. Although PF has improved results compared to the beginning of the intervention, we notice that they are still lower than those of normal development colleagues. The results are in agreement with other research $(21,22)$, which shows that students with dyslexia, even after an intensive intervention, have delays compared to children with normal development.

\section{DISCUSSIONS}

Dyslexia is an unexpected reading disorder considering the child's IQ. Language disorder is strongly correlated with reading difficulties (23). In the conditions of a strong economic migration, I think that we will have, unfortunately, several cases like the one presented. Even this child's brother has a language disorder, this time accompanied by behavioral problems. Intense speech therapy reduces the extent of the language disorder, but if it is severe, it probably will not resolve until school age. The aim of this study was to reveal the educational aspects specific to such cases. Dyslexia itself is a disorder, which is quite difficult to compensate, things becoming much more serious if the child is also struggling with a language disorder. Although PF has superior intelligence, pronunciation problems prevent him from achieving good school results. The intervention aimed to develop reading skills. In the conditions of an affected phonemic hearing, we considered it useful to rely on syllabic structures and especially on their visual representations (24). In addition to developing reading skills, we wanted to develop language and correct certain affected phonological representations. The results show that the student managed to develop reading skills. The scores obtained are below the average of students with normal first grade development. This is not surprising, as children with dyslexia have lower fluency and reading accuracy than their peers, even under intense intervention (25).

For the future, the intervention will have to be continued, which from now on will include more varied activities, to motivate the student. I think that motivating parents, advising, and training them so that they can help their children is very important.

\section{ACKNOWLEDGEMENTS AND DISCLOSURES}

The authors declare that they have no potential conflicts of interest to disclose

\section{REFERENCES}

1. Sârca, V. (2018) O Românie migratoare, Plecarea în străinătate a românilor între sacrificii și bunăstare, Școala Ardeleană, pp.12

2. Edition, F. (2013). Diagnostic and statistical manual of mental disorders. Am Psychiatric Assoc, 21.

3. Bishop, D. V. (1992). The underlying nature of specific language impairment. Journal of child psychology and psychiatry, 33(1), 3-66.

4. Bishop, D. V. (2006). What causes specific language impairment in children?. Current directions in psychological science, 15(5), 217-221.

5. Yairi, E., Ambrose, N. (2013). Epidemiology of stuttering: 21st century advances. Journal of fluency disorders, 38(2), 66-87.

6. Snowling, M. J. (2014). Dyslexia: A language learning impairment. Journal of the British Academy, 2(1), 43-58.

7. Hudson, R. F., Lane, H. B., Pullen, P. C. (2005). Reading fluency assessment and instruction: What, why, and how?. The Reading Teacher, 58(8), 702-714. https://doi.org/10.1598/RT.58.8.1

8. Snowling, M. J., Hulme, C. (2021). Annual Research Review: Reading disorders revisited-the critical importance of oral language. Journal of Child Psychology and Psychiatry, 62(5), 635-653. https://doi.org/10.1111/jcpp.13324 


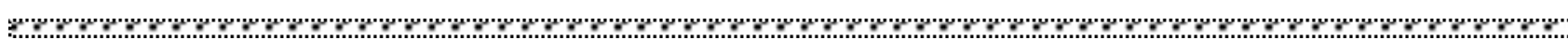

9. Tiron, K., Gherguţ, A. (2019). The predictors of dyslexia in a regular orthography. Annals of AII Cuza University. Psychology Series, 28, 67-90.

10. Anthony, J. L., Francis, D. J. (2005). Development of phonological awareness. Current directions in psychological Science, 14(5), 255-259.

11. Wimmer, H., Schurz, M. (2010). Dyslexia in regular orthographies: manifestation and causation. Dyslexia, 16(4), 283-299.

12. David, C., Roşan, A., Gavril, L. (2018). Strategie czytania rumuńskich czytelników z dysleksją w klasach podstawowych. Prima Educatione, 2, 89-98.

13. Ziegler, J. C., Goswami, U. (2005). Reading acquisition, developmental dyslexia, and skilled reading across languages: a psycholinguistic grain size theory. Psychological bulletin, 131(1), 3

14. Doignon-Camus, N., Zagar, D. (2014). The syllabic bridge: the first step in learning spelling-to-sound correspondences. Journal of Child Language, 41(5), 1147-1165.

15. Das-Smaal, E. A., Klapwijk, M. J., van der Leij, A. (1996). Training of perceptual unit processing in children with a reading disability. Cognition and Instruction, 14(2), 221-250.

16. Ecalle, J., Kleinsz, N., Magnan, A. (2013). Computer-assisted learning in young poor readers: The effect of graphosyllabic training on the development of word reading and reading comprehension. Computers in Human Behavior, 29(4), 1368-1376.

17. Müller, B., Richter, T., Karageorgos, P. (2020). Syllable-based reading improvement: Effects on word reading and reading comprehension in Grade 2. Learning and Instruction, 66, 101304.

18. Tressoldi, P. E., Vio, C., Iozzino, R. (2007). Efficacy of an intervention to improve fluency in children with developmental dyslexia in a regular orthography. Journal of learning disabilities, 40(3), 203-209.

19. Rosner, J. (1994). Helping Children Overcome Learning Difficulties. Optometry and Vision Science, 71(7), 474475 .

20. David, C., Roșan, A. (2017) Repere diagnostice bazate pe dovezi științifice în tulburările specifice de învățare

21. Zoccolotti, P., De Luca, M., Di Pace, E., Gasperini, F., Judica, A., Spinelli, D. (2005). Word length effect in early reading and in developmental dyslexia. Brain and language, 93(3), 369-373.

22. Van Bergen, E., De Jong, P. F., Plakas, A., Maassen, B., van der Leij, A. (2012). Child and parental literacy levels within families with a history of dyslexia. Journal of Child Psychology and Psychiatry, 53(1), 28-36.

23. Catts, H. W., Adlof, S. M., Hogan, T. P., Weismer, S. E. (2005). Are specific language impairment and dyslexia distinct disorders?

24. Barber, H., Vergara, M., Carreiras, M. (2004). Syllable-frequency effects in visual word recognition: evidence from ERPs. Neuroreport, 15(3), 545-548.

25. De Groot, B. J., Van den Bos, K. P., Van der Meulen, B. F., Minnaert, A. E. (2017). Rapid naming and phonemic awareness in children with or without reading disabilities and/or ADHD. Journal of Learning Disabilities, 50(2), 168179.

\section{Correspondence:}

KatalinTiron,

PhD Student, Psychology and Education Sciences Faculty, "Alexandru Ioan Cuza" University of Iaşi, katalintiron@yahoo.com

Submission: 20 aug 2021

Acceptance: 12 sep 2021 


\title{
Meditation and melotherapy as adjuvant treatments of chronic dermatoses
}

\author{
Bogdan M Tarcău, Ioana A Halip, Adriana I Pătrașcu, Laura Stătescu, \\ Dan Vâță, Adrian Cantemir, Laura Gheucă Solovăstru
}

\begin{abstract}
Bogdan Marian Tarcău - MD, Dermatology Clinic, "Saint Spiridon" County Hospital, Iasi, Romania

Ioana Alina Halip - MD, PhD, assistant professor, Department of Dermatology, "Grigore T. Popa" University of Medicine and Pharmacy, Faculty of Medicine, Iasi, Romania.

Adriana Ionela Pătrașcu - MD, Dermatology Clinic, "Saint Spiridon" County Hospital, Iasi, Romania

Laura Stătescu - MD, PhD, associate professor, Department of Dermatology, "Grigore T. Popa" University of Medicine and Pharmacy, Faculty of Medicine, Iasi, Romania. Dermatology Clinic, "Saint Spiridon" County Hospital

Dan Vâță - MD, PhD, associate professor, Department of Dermatology, "Grigore T. Popa" University of Medicine and Pharmacy, Faculty of Medicine, Iasi, Romania. Dermatology Clinic, "Saint Spiridon" County Hospital

Adrian Cantemir - MD, PhD, assistant professor, Department of Psychiatry, "Grigore T. Popa" University of Medicine and Pharmacy, Faculty of Medicine, Iasi, Romania

Laura Gheucă Solovăstru - MD, PhD, professor, Department of Dermatology, "Grigore T. Popa" University of Medicine and Pharmacy, Faculty of Medicine, Iasi, Romania. Dermatology Clinic, "Saint Spiridon" County Hospital
\end{abstract}

\section{ABSTRACT}

Stress levels have increased overall, moreover since the beginning of the coronavirus disease 2019 pandemic. Several chronic dermatoses, such as psoriasis and atopic dermatitis, are well known to be caused or aggravated by stress. It is common sense that, especially now, the patients affected by stress need to be offered more alternatives in order to control their skin conditions. Psychodermatology is a subspecialty of dermatology which through the joint efforts of dermatologists, psychiatrists and psychologists targets the complex mind-skin pathways. Meditation is a common arousal reduction intervention in the field of psychodermatology and it works by redirecting one's thoughts to calm one's mind. Melotherapy (music therapy) is another widely accesible stress reduction intervention, which despite its simplicity could prove efficient and address the general low compliance to psychological procedures.

\section{KEY WORDS:}

Psychodermatology, meditation, melotherapy, chronic dermatoses, psoriasis. 


\section{INTRODUCTION}

COVID-19 (coronavirus disease 2019) is the disease associated with the novel coronavirus 2 of the Severe Acute Respiratory Syndrome (SARS-CoV-2) $(1,2)$. The pandemic caused by this virus led to several safety measures such as home isolation, transport restrictions, social distancing and the use of protection equipment (3). All these measures, added to the fear factor of COVID-19, contribute to the psychological discomfort, stress and anxiety among the general population. This context represents the premise to an increased burden of the chronic dermatoses caused or aggravated by stress. Now, more than ever, psychodermatology must step forward through a mutidisciplinary team of dermatologists, psychiatrists and psychologists and help patients suffering from stress.

Psychodermatology is a relatively new subspecialty of dermatology which is gaining momentum. It aims at aiding in the treatment of cutaneous diseases by psychological and psychiatriac means which reduce the stress levels and control the harmful thoughts and behaviours. The effects of such interventions rely on the complex interactions between the nervous, immune, endocrine and cutaneous systems (4). Several psychological techniques can be used in the management of chronic dermatoses, such as: cognitive behavioural therapy, hypnosis, auto-hypnosis, meditation, guided imagery and melotherapy (music therapy) (5).

\section{METHODES}

This review of the literature will present the results of meditation and melotherapy recorded in the field of dermatology up until july 2021. The information presented includes evidences from peer-reviewed journals and controlled trials. Only articles written in English were reviewed.

\section{PSORIASIS AND STRESS}

Psoriasis is a chronic inflammatory skin condition, with a prevalence varying from $0.91 \%$ to $8.5 \%$ of the population worldwide (6). Genetic, epigenetic, environmental and lifestyle factors are associated with the onset and recurrence of psoriasis (7). The course of the disease is defined by periods of remissions and exacerbations (8).

Psychological stress does not only trigger exacerbations, but also contributes to the initial development of the disease in predisposed individuals (9-12). Fortune et al. studied the clearence of psoriasis during phototherapy, which was impaired in the patients who manifested excessive stress (13). The link between stress and psoriasis was also observed in the general population, as in two retrospective studies on 491 patients, stress was believed to be responsible for the appearance or exacerbation of the psoriasis in $37-88 \%$ of the patients $(14,15)$. Daily stressors cause increased itch and psoriasis severity, especially in the excessively worried individuals $(16,17)$.

Manolache et al. investigated the degree of stress in a targeted population and reported more stressful events in 169 patients with psoriasis than in the control group. In over half of these patients $(54 \%)$, at least one stressful event in the previous year was linked to the onset or recurrence of the disease (18).

A stress responder is defined as a psoriasis patient who deals with increased amounts of stress and holds the stress responsible for the worsening of his skin disease (19). It has been reported that high stress responders have a 
lower cortisol response to acute stress compared with low stress responders (20).

Psoriasis is still an incurable condition in which the physical burden is doubled by the psychological one. Stigma, social anxiety, negative self-image and higher levels of depressive symptoms are observed in the patients with psoriasis, especially when the lesions are distributed on more visible areas such as the arms, hands, head and neck (21). $62 \%$ of the psoriasis patients suffer from depression (22) and 43\% from anxiety (23).

The lack of adequate depression management is reflected in the fact that suicidal ideation is not uncommon, with reports of 1 out of 5 psoriasis patients with suicidal thoughts (24). The patients suffering from psoriasis are even more prone to commit suicide or to develop psychiatric disorders than the patients diagnosed with melanoma, one of the most aggressive cutaneous conditions (25). Psoriasis may also be wrongly considered contagious, contributing to the stigmatization (26).

\section{PSORIASIS AND MEDITATION}

Given the tremendous psychological impact psoriasis can have and the obvious link between stress and the disease, researchers have tested different approaches to reduce the arousal levels in the psoriasis patients.

Meditation has long been used for reducing stress and it originates from the eastern culture. Meditation can be practiced as mindfulness meditation, mantra meditation, yoga, tai chi and chi gong (27). Mindfulness meditation is the most researched method and it has been succesfully used in various mental and physical health conditions. It is typically described as non-judgemental attention to experiences in the present moment and it implies regulating one's attention and approaching one's experiences with openness and acceptance (28).

Several mindfulness-based stress reduction (MBSR) studies have shown a non-specific effect on stress reduction, similar to that observed with standard relaxation practices. Meditation could reduce the stress levels by improving self-regulation, promoting neuroplasticity and by increasing the parasympathetic activity which in turn interferes with the sympathetic-adrenalmedullary and hypothalamic-pituitary-adrenal axes (29-31).

Jon Kabatt-Zinn (the author of the mindfulness-based stress reduction programme), in a blinded randomized controlled trial from 1998, investigated the effect of meditation on psoriasis patients undergoing phototherapy. 37 patients with moderate to severe psoriasis were divided in 2 major groups - ultraviolet B (UVB) and psoralen plus ultraviolet A (PUVA), and subsequently each group was divided into control and meditation. The meditation groups had to listen to a recorded mindfulness meditation audiotape during 40 phototherapy sessions, while the control groups were instructed to relax by any means. The meditation group was instructed through the tape how to increase their moment-to-moment nonjudgmenetal awareness of breathing, body sensations, sounds, thoughts, feelings and they were asked to visualize how the ultraviolet light alone (UVB group) or in combination with psoralen (PUVA group) slowed down the growth and division of the skin cells. The group receiving the intervention through meditation reached skin clearing significantly faster (halfway point $\mathrm{p}=0.013$; clearing point $\mathrm{p}=0.033$ ). Neither group recorded any significant changes in the psychometric assessment (Symptom Checklist 90 Revised, SCL-90-R) or in the anxiety level 
\%

(State-Trait Anxiety Inventory, STAI) between pre-intervention and postintervention. Although the results are impressive, the patients have not been observed over a longer period of time (followup period of 1 week) and so the duration of remission was not assesed. Moreover, an attrition rate of $37.8 \%(n=14)$ was recorded (32).

Gaston et al. randomly assigned 18 psoriasis patients to 4 groups: meditation $(n=5)$, meditation and imagery $(\mathrm{n}=4)$, waiting list $(n=5)$ and treatment-free control group $(n=5)$. The meditation and imagery groups received the same meditation training during the first 6 weeks, while afterwards the patients in the imagery group were taught how to imagine their lesions transforming and healing. After a 12-week intervention (4 weeks pre- and postbaseline periods), the meditation group recorded a significantly better improvement in psoriasis severity, with no substantial benefits from the addition of imagery techniques. The authors reported a positive correlation between the psoriasis symptom severity and both psychological distress $(\mathrm{p}<0.01)$ and adverse life event impact $(\mathrm{p}<0.05)$. The limitations of this study consist in the reduced number of subjects, the lack of mean baseline disease severity quantification and the lack of psychological assessment. The attrition rate was $25.0 \%(\mathrm{n}=6)(33)$.

In a pilot study from 2015, Fordham et al. examined 29 psoriasis patients who were randomly distributed in either the mindfulness-based cognitive therapy (MBCT) group or the control group. The patients involved in the study were considered stress responders according to their evaluation through the Illness Perception Questionnaire (believed stress caused or exacerbated their psoriasis). The MBCT group received a 8week mindfulness group therapy intervention in addition to the usual psoriasis therapy, while the control group received only the psoriasis therapy. The MBCT group recorded statistically lower Self-administered Psoriasis Area Severity Index $(p=0.05)$ and Dermatology Life Quality Index $(\mathrm{p}=0.2)$ impairment scores than the control group. However, the reduction in stress and distress levels, evaluated through the Perceived Stress Scale $(\mathrm{p}=0.94)$ and Hospital Anxiety and Depression Scale $(p=0.11)$, was nonsignificant. The follow-up time was not described and the attrition rate was $45 \%$ $(n=10)$, patients dropping out of the study due to impracticality (34).

\section{PSORIASIS AND MUSIC THERAPY}

Lazaroff and Shimshoni investigated the effects of Medical Resonance Therapy Music on 28 neurodermatitis and 20 psoriasis patients, while the control groups consisted of 10 neurodermatitis and 10 psoriasis patients. Medical Resonance Therapy Music was developed by the classical composer and musicologist Peter Huebner in 1987. It is based on the ancient music medicine of Pythagorus, according to which the harmony laws of the world of music are identical to the harmony laws of the biological life. All the psoriasis patients received their psoriasis treatment over the course of 14 days. The patients in the experimental group were additionaly offered 3 x 30-minute sessions of listening to Medical Resonance Therapy Music everyday, while the patients in the control group were instructed to relax by any means. The degree of sickness was evaluated by the doctors according to a five-unit scale. After the intervention, at the end of the 14 days, the degree of sickness in the psoriasis experimental group was reduced by $65 \%$. The control group recorded a reduction in the degree of sickness of just $20 \%$. The stimulus to scratch had reduced in the experimental group by $86 \%$, while in the control group by 
29\%. The heart rate and the blood pressure had also lower values after the music therapy intervention (35).

\section{NEURODERMATITIS AND MUSIC THERAPY}

In the same study conducted by Lazaroff and Shimshoni on psoriasis patients, the effect of Medical Resonance Therapy Music was also tested on 28 neurodermatitis patients. After 14 days of 3 therapy music sessions a day, the degree of sickness was reduced by $41 \%$, versus $12 \%$ in the control group. The stimulus to scratch in the experimental group reduced by $59 \%$ versus $14 \%$ in the control group. Blood pressure and heart rate were also influenced, as lower values were recorded in the experimental group (35).

\section{ATOPIC DERMATITIS AND MEDITATION CONCLUSIONS}

Given the actual COVID-19 pandemic situation, arousal reduction techniques could play an even greater role in reducing the burden of stress-associated diseases. Mindfulness meditation has been investigated in several studies with promising results in psoriasis patients $(32,33,34)$, in contrast to atopic dermatitis patients (36). Melotherapy, however, was investigated in only one psoriasis and neurodermatitis study and even though it proved to be an efficient adjunctive therapy (more in psoriasis than in neurodermatitis), no statistical data was reported (35).

The studies investigating mindfulness meditation and music therapy share the same limitations as any other psychological intervention, such as the lack of a standardized protocol, high attrition rates and small sample sizes. This points to the need of more quality studies, comparing different psychological interventions and investigating which intervention best suits specific subsets of patients, in the effort to minimize the high dropout rates.

\section{ACKNOWLEDGEMENTS AND DISCLOSURES}

The authors declare that they have no conflicts of interest to disclose.

\section{REFERENCES}

1. WHO. Naming the coronavirus disease (COVID-19) and the virus that causes it. World Health Organization (WHO); https:// www. who.int/emergencies/ diseases/novel-coronavirus-2019/technical-guidance/naming-thecoronavirus-disease-(covid-2019)-and-the-virusthat-causes-it.

2. Coronaviridae Study Group of the International Committee on Taxonomy of Viruses. The species Severe acute respiratory syndrome-related coronavirus: classifying 2019-nCoV and naming it SARS-CoV-2. Nat Microbiol. 2020 Apr;5(4):536-544. doi: 10.1038/s41564-020-0695-z. 


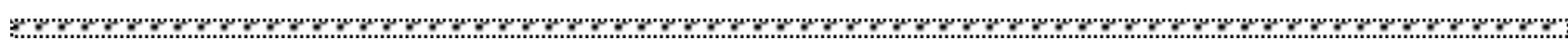
3. Cucinotta D, Vanelli M. WHO Declares COVID-19 a Pandemic. Acta Biomed. 2020 Mar 19;91(1):157-160. doi: 10.23750/abm.v91i1.9397

4. Jafferany M, Franca K. Psychodermatology: Basics Concepts. Acta Derm Venereol. 2016 Aug 23;96(217):35-7. doi: 10.2340/00015555-2378.

5. Shenefelt PD. Psychological interventions in the management of common skin conditions. Psychol Res Behav Manag. 2010;3:51-63. doi: 10.2147/prbm.s7072.

6. Ryan C, Korman NJ, Gelfand JM et al. Research gaps in psoriasis: opportunities for future studies. J Am Acad Dermatol 2014; 70:146-167.

7. Albanesi C, Madonna S, Gisondi P, Girolomoni G. The interplay between keratinocytes and immune cells in the pathogenesis of psoriasis. Front Immunol. 2018;9:1549.

8. Gaikwad R, Deshpande S, Raje S. et al. Evaluation of functional impairment in psoriasis. Indian J DermatolVenereol Leprol. 2006;72:37-40.

9. Heller MM, Lee ES, Koo JY. Stress as an influencing factor in psoriasis. Skin Therapy Lett. 2011;16:1-4.

10. Rousset L, Halioua B. Stress and psoriasis. Int J Dermatol.2018;57:1165-72.

11. Hunter HJ, Griffi ths CE, Kleyn CE. Does psychosocial stress play a role in the exacerbation of psoriasis? Br J Dermatol. 2013;169:965-74.

12. Malhotra SK, Mehta V. Role of stressful life events in induction or exacerbation of psoriasis and chronic urticaria. Indian J Dermatol Venereol Leprol. 2008;74:594-9.

13. Fortune DG, Richards HL, Kirby B, et al. Psychological distress impairs clearance of psoriasis in patients treated with photochemotherapy. Arch Dermatol. 2003;139:752-6.

14. Al'Abadie MS, Kent GG, Gawkrodger DJ. The relationship between stress and the onset and exacerbation of psoriasis and other skin conditions. Br J Dermatol. 1994;130:199-203.

15. Fortune DG, Richards HL, Main CJ, Griffiths CEM. What patients with psoriasis believe about their condition. J Am Acad Dermatol. 1998;39:196-201.

16. Verhoeven EW, Kraaimaat FW, de Jong EM, et al. Effect of daily stressors on psoriasis: a prospective study. J Invest Dermatol. 2009;129:2075-7.

17. Verhoeven EW, Kraaimaat FW, de Jong EM, et al. Individual differences in the effect of daily stressors on psoriasis: a prospective study. Br J Dermatol. 2009;161:295-9.

18. Manolache L, Petrescu-Seceleanu D, Benea V. Life events involvement in psoriasis onset/recurrence. Int J Dermatol. 2010;49:636-41.

19. Gupta MA, Gupta AK, Kirkby S, Schork NJ, Gorr SK, Ellis CN, Voorhees JJ. A psychocutaneous profile of psoriasis patients who are stress reactors. A study of 127 patients. Gen Hosp Psychiatry. 1989 May;11(3):166-73.

20. Richards, H., Ray, D., Kirby, B., et al. (2005), Response of the hypothalamic-pituitary-adrenal axis to psychological stress in patients with psoriasis. British Journal of Dermatology, 153: 1114-1120.

21. Lakuta P, Marcinkiewicz K, Bergler-Czop B, et al. Associations between site of skin lesions and depression, social anxiety, body-related emotions and feelings of stigmatization in psoriasis patients. Adv Dermatol Allergol.2018;35:606.

22. Esposito M, Saraceno R, Giunta A et al. An Italian study on psoriasis and depression. Dermatology 2006; 212: $123-127$.

23. Richards HL, Fortune DG, Griffiths CE, Main CJ. The contribution of perceptions of stigmatisation to disability in patients with psoriasis. J Psychosom Res 2001; 50: 11-15.

24. Krueger G, Koo J, Lebwohl M et al. The impact of psoriasis on quality of life: results of a 1998 National Psoriasis Foundation patientmembership survey. Arch Dermatol 2001; 137: 280-284.

25. Pompili M, Snast I, Reiter O, et al. Psychological stress and psoriasis: a systematic review and meta-analysis. BJD. 2018;178:1044-55.

26. Bhosle MJ, Kulkarni A, Feldman SR, Balkrishnan R. Quality of life in patients with psoriasis. Health Qual Life Outcomes 2006; 4: 35 .

27. Ospina, M. B. et al. Meditation practices for health: state of the research. Evid. Rep. Technol. Assess. (Full Rep.) 155, 1-263 (2007).

28. Baer, R. A. Mindfulness training as a clinical intervention: a conceptual and empirical review. Clin. Psychol. Sci. Practice 10, 125-143 (2003).

29. Thayer, J. F. \& Lane, R. D. A model of neurovisceral integration in emotion regulation and dysregulation. J. Affective Disord. 61, 201-216 (2000). 

30. Creswell, J. D. in Handbook of Mindfulness: Theory, Research, and Practice Ch. 23 (eds Brown, K. W., Creswell, J. D. \& Ryan, R. M.) (Guildford Press, 2014).

31. Ditto, B., Eclache, M. \& Goldman, N. Short-term autonomic and cardiovascular effects of mindfulness body scan meditation. Ann. Behav. Med. 32, 227-234 (2006).

32. Kabat-Zinn J. Influence of a mindfulness meditation-based stress reduction intervention on rates of skin clearing in patients with moderate to severe psoriasis undergoing phototherapy (UVB) and photochemotherapy (PUVA). Psychosom Med. 1998;60:625-632.

33. Gaston L, Crombez J-C, Joly J, Hodgins S, Dumont M. Efficacy of Imagery and Meditation Techniques in Treating Psoriasis. Imagination, Cognition and Personality. 1989;8(1):25-38. doi:10.2190/PQKE-CMAM-T4MTQVBL

34. Fordham, B., Griffiths, C. E. M., \& Bundy, C. (2014). A pilot study examining mindfulness-based cognitive therapy in psoriasis. Psychology, Health \& Medicine, 20(1), 121-127. doi:10.1080/13548506.2014.902483

35. Lazaroff I, Shimshoni R. Effects of Medical Resonance Therapy Music on patients with unipsoriasis and neurodermatitis--a pilot study. Integr Physiol Behav Sci. 2000 Jul-Sep;35(3):189-98. doi: 10.1007/BF02688779.

36. Bostoen J, Bracke S, De Keyser S, Lambert J. An educational programme for patients with psoriasis and atopic dermatitis: a prospective randomized controlled trial. Br J Dermatol. 2012 Nov;167(5):1025-31. doi: 10.1111/j.13652133.2012.11113.x.

\section{Correspondence:}

Bogdan Marian Tarcău,

MD, Dermatology Clinic, “Saint Spiridon” County Hospital, Bd. Independentei, nr. 1, Iasi, Romania, bogdan.tarcau@yahoo.com

Submission: 14 jul 2021

Acceptance: 28 aug 2021 



\title{
Particularity of suicide in the countries of the European Union
}

\author{
Andrei Scripcaru, Costel Marius Frăsilă, Silvia Şpac, \\ Mădălina Maria Diac, Călin Scripcaru
}

\begin{abstract}
Andrei Scripcaru - MD, PhD student, Grigore T.Popa University of Medicine and Pharmacy Iasi Costel Marius Frăsilă -"Ştefan cel Mare" University Suceava

Silvia Şpac - MD, Institute of Legal Medicine Iași

Mădălina Maria Diac - MD, PhD student, Grigore T.Popa University of Medicine and Pharmacy Iasi

Călin Scripcaru - MD, PhD, professor, "Ştefan cel Mare" University Suceava
\end{abstract}

\begin{abstract}
Starting from the bio-psycho-social concept developed by Petre Brânzei it is obvious that suicide has a complex motivation that combines genetic, psychological and social elements. The paper aims to analyze the social motivation in various countries of the European Union as the underlying mechanism triggering the suicidal gesture and especially the "trigger" factor that determines the transition to the act, are still unclear. It is most likely that important endocrine factors, possibly explaining the decrease in suicide rates in Europe from north to south, are involved. The decrease from east to west seems to be the consequence of higher living standards in the west, but also of more effective prophylactic measures in these countries.
\end{abstract}

\section{KEYWORDS:}

Suicide attempt, prophylaxis, triggers.

\section{SUICIDAL BEHAVIOUR AS A RESULT OF SOCIAL TRENDS AND PRESSURES} In its essence and by the multiple consequences it entails, suicide is an extremely important social problem, which is of a justified interest to sociologists, psychologists, criminologists, lawyers, doctors, to different categories of specialists, practitioners, representatives of the authority and, last but not least, to the public. A social problem - sociologists point out - is an undesirable and harmful condition for society, which affects its order requirements, prevents social change and has a negative impact on the existence, security and well-being of society members (1). 
rog

The statistics or estimates compiled by the World Health Organization are relevant in this respect, highlighting that suicide is a global problem of humanity, which manifests itself in all countries of the world with great intensity, being amplified by the conditions of the current crisis.(1)

Consistent with this interpretation of suicide as a social problem, sociologists believe that suicide rates can only be explained by social factors, independent of the biological traits, characteristics and mental tendencies of the individual $^{1}$. If the act of suicide as such may involve such individual characteristics and motivations, suicide rates are necessarily subjected to social trends and pressures, being - as the well-known sociologist É Durkheim pointed out. - a consequence of the "social acts" that manifest themselves and act in a particular society. And such social acts are, in fact, a product of social relations and types of human association, consisting of "ways of working, of thinking and feeling, external to the individual and which are endowed with a power of compulsion by virtue of which they are imposed on him" (Durkheim, 2).

\section{SUICIDE, CRISIS AND ECONOMIC PROSPERITY}

Émile Durkheim is probably the first sociologist to point out that "every people has a collective tendency towards suicide that is their own", as demonstrated (1999, pp. 247261) by the fact that as long as society does not change, the number of suicides remains constant" (Durkheim,2).

The increase in the extent of suicides Durkheim observes - occurs when society is changing, i.e. either in a state of economic crisis (in a negative sense) or in a state of economic prosperity (in a positive sense). "Any shaking of balance, even if it provokes abundance and increased social vitality, fosters suicide" (Durkheim,2).

Durkheim's theory seems, in one way or another, tested by the current economic crisis, although the data of various research carried out in this field are contradictory to each other. Thus, some studies have shown that periods of economic crisis lead to a significant increase in suicides, other studies have stressed that in such periods suicide is committed especially by vulnerable people (who are already affected by stress, mental disorders, unemployment, alcohol consumption, etc.), while other studies have pointed out, on the contrary, that in periods of economic recession the number of suicides decreases, due to the fact that individuals mobilize more strongly than in "normal" times to cope with life difficulties (Carey, 2011). Research undertaken in the United States has, on the other hand, highlighted the fact that, contrary to Durkheim's conception, suicide rates decrease during periods of economic expansion, with some exceptions, related to age groups. Thus, during the economic boom of the 1960 s, the suicide rates of the population in the 30 to 50 years interval increased in the United States, and during the recession in the middle of the 7th decade, suicide rates decreased among the elderly population, who were the beneficiary, among other things, of the Social Security program of the previous decade (Carey, 2011).

\section{SUICIDE IN EUROPE}

R.B. Ginsberg (1966) pointed out that suicide is "procyclical" in that suicide rates decrease during periods of economic depression and increase during periods of economic expansion. On the contrary, A.F. Short and J.F. Short (1954) have highlighted that suicide is "anti-cyclical": thus, during periods of economic prosperity, the suicide rate decreases and during periods of economic crisis it increases 
ry

A study by Bijou Yang (1992) on the evolution of the suicide rate in the United States between 1940 and 1984 disproved the assumptions circumscribed to Durkheim's conception. In this regard, the study found that: suicide rates did not increase during periods of economic boom or economic crisis in the United States, any change in these rates being dependent on the characteristics of the social groups involved. On the other hand, unemployment rates had a significant negative effect only on the suicide rate characteristic to white men, and the rate of participation of women in the workforce had a beneficial influence on suicide rates, both those characteristics to white women and those specific to black women.

\section{THE RELATION BETWEEN SUICIDE AND ECONOMIC CRISES}

A suggestive example that points out that suicide is determined by or is related to socioeconomic factors is the finding - resulting from social history studies - that, during periods of economic recession, the number of suicides of the population included in the age range of 25 to 64 years, increases.

The period of the Great Depression, for example, which began a decade earlier than the Second World War, is a suggestive example from this point of view. Thus, the sharp decline in economic indicators, in particular the decline in production, trade, unemployment and, by implication, income, has led to numerous suicides.

In the United States, for example, the average death rate by suicide per 100,000 inhabitants increased, compared to the previous period (1920-1928), by almost 50\% in 1929 and by $27 \%$ between 1930-1940. In the same country, during the most pronounced period of crisis, 1928-1933, when the unemployment rate reached $24 \%$, the highest suicide rates in
American history were reached. On the contrary, in 2000, when the US unemployment rate did not exceed $4 \%$, it was the lowest suicide rate in the country's history (Sternheimer, 2011).

Beyond such findings, it can be pointed out that suicidal rates recorded during the crisis that began in 2008 are much more pronounced, at least in Europe, than during the Great Depression (Stuckler, 2011).

As an example, the countries that faced the most difficulties during the economic crisis that began in 2008, such as Greece and Ireland, recorded the largest increase in the suicide rate (according to Mediafax, 2011).

In Greece, the number of suicides increased by $17 \%$ between 2007 and 2009, and some unofficial data even mention a $25 \%$ increase in 2010 (Kentikeles, Stucker et al., 2011). According to the Ministry of Health in Athens, in the first half of 2011, the number of suicides increased by $40 \%$ compared to the same period the year before (Stancu, 2011). Before the financial crisis, Greece had one of the lowest suicide rates in Europe: 2.8 per of one thousand inhabitants. In 2011, this figure doubled. Suicide attempts have also increased (Smith, 2011).

These trends, coupled with those aimed at doubling the number of murders and thefts between 2007 and 2010, complementary to the deterioration of the public health system due to lack of funds, have led US researchers at the University of Cambridge, Alex Kentikeleris and David Stuckler, to appreciate that a genuine "Greek tragedy" can be talked about (Kentikeles, Stucker et al., 2011).

In Ireland, during the same time period (20072009), when Ireland felt the strongest effects of the economic and financial crisis, the 


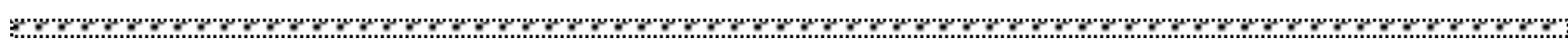

suicide rate increased by $15 \%$. In line with the data of the Report prepared by the Central Statistical Office of Ireland, from the end of 2006 to 2009, the suicide rate increased by $25 \%$, the highest annual rate ever recorded in this country (Queen, 2010).

The largest increases in the suicide rate occurred among the young population (15-24 years): $23 \%$ for men and $13 \%$ for women. The suicide of young people was, during that period, the 5th place in Europe, after the ones recorded in Estonia, Latvia, Lithuania and Finland (Queen, 2010). As a characteristic trend in Ireland, suicide acts were committed, in the years of crisis, mainly by the heads of young families, who faced numerous financial problems, which led them to consume alcohol excessively. On the other hand, there has been an increase in suicides in rural areas and in the construction industry, which have been most affected by the economic and financial crisis. Along with the effects of this crisis, alcohol and drug abuse were the factors that strongly enhanced suicidal behavior (Thomas, 2012).

With the exception of these two countries, almost all European countries have seen increases in suicide rates caused by the economic crisis.

A study carried out, for example, by David Stuckler and his collaborators on the evolution of the mortality rate recorded in 26 European countries during the economic crises of the last three decades, revealed that unemployment is one of the main factors associated with the increase in suicides among the population under the age of $65^{2}$. Thus an increase of more than $3 \%$ in the unemployment rate has strong effects on the suicide committed by this category of population. Based on the analyses carried out, these authors predicted that the period of economic crisis started in 2008 would have similar consequences (Stuckler et al., 2009).

The authors of the study processed data on mortality causes by age groups from the data compiled by the World Health Organization, and the information on unemployment trends characteristic to the adult population had taken them from statistics published by EUROSTAT.3 (Euro-indicators Calendar). As complete information on 17 of the 27 European countries was missing, the analysis focused mainly on 10 countries, six of which joined the European Union before 2004 (Austria, Finland, Greece, Ireland, the Netherlands and the United Kingdom), and four others joined the Union after 2004 (Czech Republic, Hungary, Lithuania and Romania). Data on the situation in the two groups of countries were evaluated in ration with the population size (Stuckler et al., 2011).

The findings of the study showed the following:

in both groups of countries, officially recorded unemployment rates did not increase until 2009, the year following the economic crisis. Since this year, the unemployment rate has risen rapidly in all 10 countries, by around $35 \%$ from the level reached in 2007 , with an increase between $2 \%$ and $6 \%$ across the European Union.

however, the steady decline in suicide rates, which was observed in both groups of countries before the start of the crisis, was simultaneously reversed in all the countries analysed. Thus, in 2008, the increase in suicide rates was less than $1 \%$ in countries that more recently joined the European Union and by around $7 \%$ in those countries that joined the Union a longer time before.

in 2009, the growth trend increased in all countries (at at least 5\% compared to 
2007), with the exception of Austria, which in 2009 recorded fewer suicides (with about 5\%) than in 2007.

surprisingly, Finland, which has one of the strongest social protection systems, has seen an increase of more than $5 \%$ in suicides compared to Austria, which also has a highly functioning social protection system;

Greece and Ireland, as we have already mentioned, have had the greatest increases in suicides. Latvia also had an increase of more than $17 \%$ between 2007 and 2008;

in the UK, the suicide rate increased from 6.14 per 100000 people in 2007, to 6.75 per 100000 in 2008, thus increasing by $10 \%$, remaining at the same level in 2009;

despite these fluctuations, that study could not identify a definite trend of deviation during the crisis period, compared to the past, in respect of all cases of mortality, except for suicides, which increased in magnitude and intensity, and car accidents, which decreased significantly, probably due to the decrease in the availability of machinery usage and of the use of more worn-out vehicles, which did not allow excessive speed in traffic.

Except for the difficulties faced by the authors of that study, due in particular to the difficulties in weighting the data, as well as the pronounced variations from one country to another, in terms of their availability (Romania is mentioned, in this respect), this study suggestively highlighted the association link (not necessarily causal) between periods of economic crisis and the increase in suicide rates.

\section{SUICIDE, WELL-BEING AND HEALTH CONDITIONS OF THE POPULATION}

Clearly, suicide is not an effect of factors or processes that act in isolation or autonomously. It should be noted, in this respect, that periods of crisis do not in themselves lead to an increase in suicide rates, but only through intermediate variables, such as: unemployment, declining of incomes, deterioration of quality of life, consumption of alcohol or drugs, disruption of physical health, but especially of mental health, etc. A period of crisis is complementary, in fact, to these changes in the lives of individuals, which affects - as the results of several studies and research highlights - the social well-being of the population. Suicide, as such, is a significant indicator of the decrease in social well-being and, first and foremost - as many experts in the field point out - of mental health.

As defined by the World Health Organisation, health, in its entirety, is an essential dimension of human life, which is an important indicator of social well-being and quality of life. It is a "condition of physical, mental and social well-being" that actually reflects the living standards of a particular community. ${ }^{3}$

However, as a whole, the findings of empirical research focusing on the link between periods of economic crisis and the deterioration of social well-being, including health status, are contradictory to each other. Thus, some analysts consider that, excluding suicides - which are an "exception" economic crises have no negative effects on health (Anderson, 2011, p. 2). Paradoxically, during the Great Depression, which preceded the Second World War, the overall mortality rate decreased for all age groups, but suicide rates increased.

With the exception of the influence of economic crises, there is an association link between the health of a population and its tendencies towards suicide, with variations from one country to another. Health status can 
best be highlighted through mortality rates.

But because mortality is different within different age groups and from one country to another, statistical institutes or offices have to sum them up and standardize them in different comparable ways.

In the period 2008-2009, for example, during which the economic crisis began and expanded, the lowest mortality rates for all cases of death in European countries were recorded in Switzerland, Italy, Iceland and Spain (between 490 and 520 deaths per hundred thousand inhabitants), and the highest rates were recorded in Lithuania and Latvia (over 1,000 deaths per hundred thousand inhabitants). Bulgaria, Romania and Hungary also had mortality rates of more than 900 deaths per hundred thousand inhabitants (OECD, 2010, p. 30-31) - see fig. 1

Fig. 1 Death rate for all deaths in 2008 for ten European countries

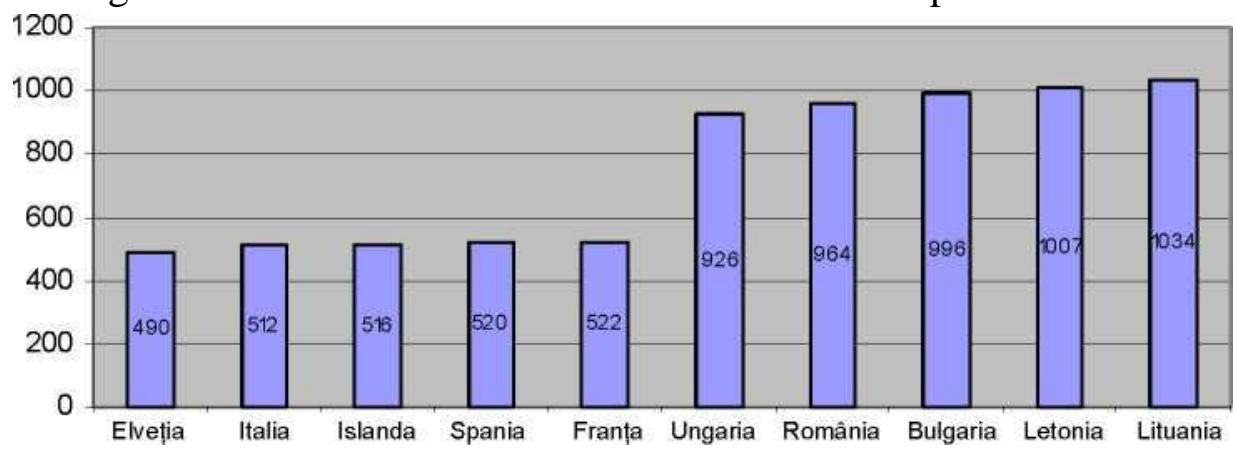

Source: OECD Health Data 2010

In terms of suicide rates, they were lower in Italy, Spain and Iceland (between 6.3 and about 12 per hundred thousand inhabitants) and higher in Lithuania (over 34 per hundred thousand inhabitants), Hungary and Latvia (approximately between 32-25 per hundred thousand inhabitants).

Bulgaria and Romania, respectively, recorded about 12 suicides per thousand inhabitants (fig 2).

Fig 2 Suicide mortality rate in 2008 (2009) in ten European countries

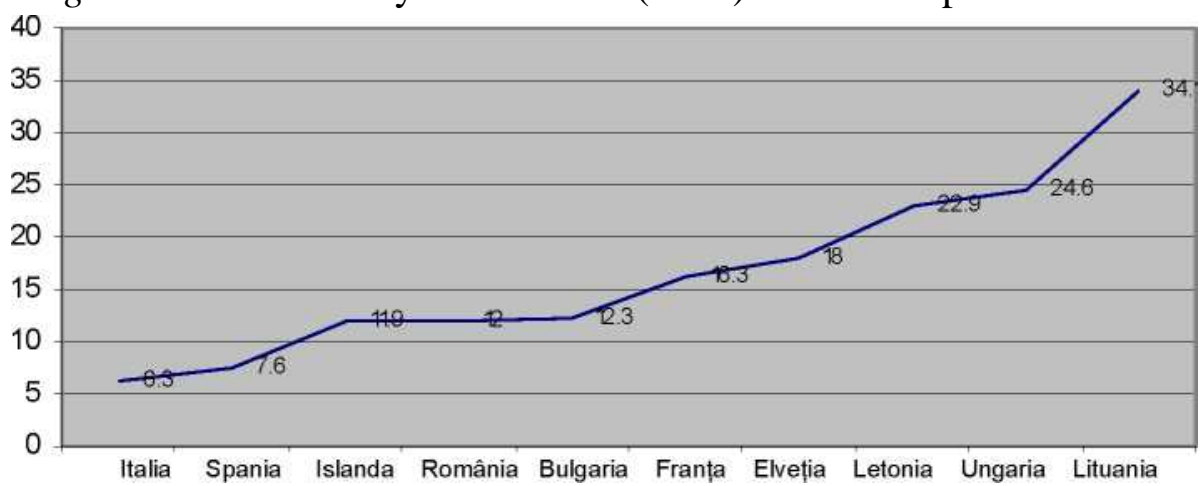

Source: Eurostat Statistics Data, 2010

Based on the data mentioned, a positive correlation between mortality rates - as indicators of population health - and suicide rates can be inferred. Thus, Italy, Spain and
Iceland, which had the lowest mortality rates among European countries, also had the lowest suicide rates. The exception is Switzerland, which had the lowest mortality 
rate in Europe, but recorded a medium-level suicide rate (18 per cent of thousands of inhabitants). By contrast, Lithuania and Latvia, which had the highest mortality rates of all European countries, also had the highest suicide rates. An exception is the case of Hungary, which had an average mortality rate, but instead recorded one of the highest suicide rates. A particular situation was recorded in Romania and Bulgaria, which, although had high mortality rates (immediately after those recorded by Lithuania and Latvia), had relatively low suicide rates, but about twice as high as those recorded, for example, by Switzerland.

These exceptions are explained, amongst others, by the variations between different countries in terms of unemployment, alcohol and drug use, the state of depression that characterizes individuals and, therefore, their mental health.

It should be noted, on the other hand, that both mortality rates and suicide rates are much higher among men than among women. Thus, the mortality rates of men exceeded with 50 to $100 \%$ that of women, while the suicide rates of the same men exceed those of women even 3-4 times (OECD, 2010). In the case of suicide attempts, the differences between the two sexes are smaller, among others, because women tend to use less lethal suicide methods than those used by men.

\section{SUICIDE, UNEMPLOYMENT AND MENTAL HEALTH}

In most countries with market economies there is a 'business cycle', characterized by an increase in unemployment during periods of economic recession and a reduction in it during periods of economic expansion (Kposowa, 2003). Such a cycle therefore has a special impact on suicides, especially those committed by the working population.
One of the main objectives of studies focused on the role of this cycle, in general, of socioeconomic factors in increasing or, on the contrary, lowering suicide rates is the relationship between suicide and unemployment. Socio-economic variables seem to have the greatest contribution to the impact of occupational status on suicide (Preti, 2003). Several studies have pointed out that a low level of occupational status of individuals correlates with a higher risk of suicide. In many European countries, changes in occupational rates have influenced suicide rates. Suicide risk is linked, among other things, to the fear of employees losing their jobs and the stress that characterizes the unemployed with regard to the drastic reduction of income and the deterioration of their living standards (Yur'iev et al., 2010).

Research carried out in the Member States of the European Union has shown, for example, that trends in the increase in national unemployment rates have been and are still associated with increased suicide rates and, among other factors, the increased incidence of mental illness or mental disorders ${ }^{4}$.

Except for these findings, several studies and research (Kposowa, 2001) have concluded that the effect of unemployment on suicide is more pronounced immediately after individuals become unemployed. As time goes on, the new unemployed adapt to their new status, which is why they are less inclined to commit suicide. In addition, with the passage of time, the unemployed can find work and leave the status of unemployed. These issues were ignored by studies dealing with the association link between unemployment and suicide and which did not take into account the duration of the period of unemployment. 
p.

Summarizing the main characteristics and effects of the relationship between suicide, unemployment and health, the Strategic Center for Suicide Prevention in the United States highlighted the following findings (Suicide Prevention Resource Center, 2008):

\section{UNEMPLOYMENT AFFECTS}

GENERAL HEALTH.

- Unemployment is associated with poor health and mortality through all cases of death (except cancer and strokes).

\section{UNEMPLOYMENT CONTRIBUTES TO THE RISK OF SUICIDE BUT DOES NOT "CAUSE" SUICIDE BY ITSELF.}

- Occupational status is just one of the factors that interacts with individuals, communities and societies, affecting suicide risk.

- Although unemployment is associated with increased suicide rates, many individuals may have lower employment rates due to poor mental health and drug use, which are also associated with increased suicide rates.

Unemployment causes financial difficulties and can lead to depression or other problems that individuals perceive as a loss of personal control.

Economic conditions, as such, are not sufficient to cause a suicidal act; in fact, we do not know any singular factor, i.e. sufficient by itself, to "determine" a suicidal act. Stressors such as losing a job, housing or retirement can produce feelings of shame, humiliation and despair, and in this context can precipitate the suicide attempts of those people who are already vulnerable or do not have enough resources to get support. In most, but not in all cases, mental health problems are among the factors that increase this vulnerability.
We can expect an acute economic crisis to lead to a suicide risk among working adults and in older adults whose retirement security is threatened.

\section{SUICIDE IN ROMANIA, ABOVE THE EUROPEAN AVERAGE IN THE MOST LIKELY AGE GROUPS}

Eurostat results were presented on Tuesday at the launch of the study "Depressive Disorder" New research directions", by doctors Camelia Popa, clinical psychologist, researcher in the Department of Psychology of the Romanian Academy, and Adela Ciobanu, psychiatrist at the "Alexandru Obregia" Hospital and teacher at the University of Medicine Bucharest.

According to Eurostat, the age groups with the highest incidence of suicide are: 15 - 19 years, 50 - 54 years and over 85 years.

Lithuania, the European country with the most suicides, has a suicide rate ten times higher than Greece, the country with the fewest suicides.

Suicide rates are low in southern European countries - Greece, Cyprus, Italy, Malta, Spain and Portugal - but also in the UK, and high in the Baltic and Central and Eastern European States - Lithuania, Hungary and Latvia, as well as Finland.

Suicide death rates are three times higher for men than for women across the European Union, with wide variations between countries.

In Romania, suicide among young people aged 15 to 19 has a rate of 6.3 deaths per 100,000 inhabitants, compared to the European average of 4.6. The male suicide rate is 9.2, compared to 6.9, the EU average and the female suicide rate is at 3.2, compared to 2.2, the EU average. 
For the age group 50 to 54 years, Romania has a rate of 22 suicides per 100,000 inhabitants for both sexes, compared to 18.3 , the European average. If the suicide rate among Romanian women aged 50 to 54 was below the European average (5 deaths per hundred thousand inhabitants, compared to 8.1 deaths per thousand inhabitants - the EU average), the male suicide rate was extremely high - 40.6, compared to 28.7 per 100000 inhabitants - the EU average.

At the top of the EU as frequency of suicide among young people are the Baltic and northern European countries - Lithuania, Estonia, Finland and Ireland. European countries with the fewest young suicides include Greece, Spain, the UK, Germany and France.

A significant and steady decrease in suicide rates among young people can be observed in the case of Hungary, which in 2010 had a suicide rate for the group 15 to 19 years lower than that of Romania, after Romania for decades was at the top of the European ranking as a frequency of suicide.

On the other hand, in the group of suicidal risk 50 - 54 years in the first places are Lithuanians, Hungarians, Slovenians and Polish. The countries with the fewest cases of suicide in this age group are Spain, the United Kingdom and Greece.

\section{ACKNOWLEDGMENTS AND DISCLOSURE}

The authors state that they are no declared conflicts of interest regarding this paper.

\section{REFERENCES}

1. Rădulescu S, Suicide in Europe in the Context of the Global Economic Crisis. The Romanian Journal of Sociology. 2012; 23(5-6):385-403.

2. Durkheim E. Suicide, Sociological Study, European Institute Publishing House. 1993.

3. A.F. Short, G.F. Short. SUICIDE AND HOMICIDE-SOME ECONOMIC, SOCIOLOGICAL AND PSYCHOLOGICAL ASPECTS OF AGGRESSION.1954

4. Kentikelenis A., Stucker D. et al. Health effects of financial crisis: omens of a Greek tragedy. The Lancet.2011;378(9801):1457-1458

5. E. Rădulescu. Sociologia sanatatii si a bolii. 2002

6. Health at a Glance: Europe 2000, OECD Publishing.2010.

7. World Health Organization. Impact of economic crises on mental health. Geneva. 2011

8. http://www.mediafax.ro/externe/criza-economicadetermina-mai-multe-sinucideri-dar-maiputine-accidente-auto-in-europa-8463984

9. De Gioannis A., De Leo D. Managing suicidal patientes in clinical practice. Open Journal of Psychiatry. 2012; 2:49-60.

10. Diekstra R.F.W., Gulbinat W., Kienhorst I., De-Leo D. Preventive Strategies on Suicide. Vol. 2. Co-publication WHO, Geneva E.J. Brill,1995

\section{Correspondence:}

Călin Scripcaru,

$\mathrm{MD}, \mathrm{PhD}$, professor, "Ştefan cel Mare" University Suceava, calinscripcaru 



\title{
The therapeutical role of psychedelic drugs in treatment of mental disorders
}

\author{
Cătălin Oprea, Loretta Epure, \\ Vasile Chiriță, Adrian Cantemir
}

\begin{abstract}
Cătălin Oprea - Medical Resident in psychiatry, "Socola" Psychiatry Institute, Iasi
Loretta Epure - Medical Resident in psychiatry, "Socola" Psychiatry Institute, Iasi Vasile Chiriță - Honorary Member of Academy, Professor, PhD, psychiatrist,

Adrian Cantemir - MD, PhD, assistant of professor, Grigore T. Popa University of Medicine and Pharmacy Iasi
\end{abstract}

\begin{abstract}
Psychedelic drugs (also called hallucinogens, psychotogenics, psycholytics, entheogens) are substances that act mainly on the 5-HT2 serotonergic receptor. There are two main groups of psychedelics: indoleamines (lysergic acid diethylamide-LSD, N, N-dimethyltryptamine-DMT, and psilocybin) and phenethylamines (mescaline, dimethoxymethamphetamine-DOM, methylenedioxyamphetamine-MDA, and methylenedioxymethamphetamine-MDMA). These drugs have a long history, being used in the past in spiritual and religious ceremonies and also in the treatment of physical and mental illnesses. Studies have been conducted over the years on the therapeutic utility of these psychedelic drugs (especially psilocybin, LSD) in the psychiatric field and their beneficial effect has been highlighted in conditions such as anxiety, major depressive disorder, obsessive-compulsive disorder, alcohol addiction, smoking addiction.
\end{abstract}

\section{KEYWORDS:}

Psychedelic, psychiatry, therapeutic role.

\section{INTRODUCTION}

Despite a century of experimental data, there is not even one psychedelic drug licensed for medical application. The term used for psychedelics has evolved over the ages. Different terms, including "hallucinogens" (to induce hallucinations), "psychotomimetics" (to mimic psychosis), "psychotogenics" (to induce a psychosis), "psycholytics" (to "loosen the mind"), "psychedelics" (to "manifest mind") and "entheogens" (to generate the divine within) reflect the varying medical and social attitudes to drugs. (1)

The history of psychedelics in medicine begins in the middle-ages when the 
physician's ancestors used psychotropic plants (henbane, belladonna) to heal physical and mental diseases. (2)

The earliest classification of psychoactive drugs was provided by Louis Lewin in the late nineteenth century, using the terms "euphoriants" (for opiates), "inebriants," (for alcohol), and "phantastica," which later become the psychedelics. (3)

In 1912 the pharmaceutical company Merck synthesized 3,4 methylenedioxymethamphetamine for the first time. (4)

In 1919 the mescaline was synthesized by Ernst Spath, an austrian chemist. In 1927 a german chemist, Kurt Beringer, proposes one of the earliest models for psychosis based on the mescaline induced psychedelic experience. (5) Also, Walter Frederking explored in 1930 the mescaline as a tool in psychotherapy.

In 1938 Albert Hofmann discovered LSD-25 while investigating the vasoconstrictor properties of ergot at Sandoz Laboratories. After 5 years, in 1943, Hofmann, accidentally, had the world's first LSD induced experience, which led to a phase one study on the Sandoz staff; dozens of members were included, trying to demonstrate its safety for human consumption. (6)

The development of the phenothiazines, chlorpromazine being first synthesized in 1950, have been significantly helped by the LSD and mescaline research. (7)

In the 1960s LSD was embraced by psychiatry being used for a wide range of conditions including social anxiety, depression, anxiety disorder, autism, pain relief, as well as sensible topics as homosexuality and female frigidity. (1)
In the 1970s and 80s Nixon's 'war on drugs led to the dark ages for psychedelics medicine, limiting the research. (8)

The first report on MDMA psychoactivity was published by David E. Nichols in 1978 (9), which described the experience gentler and more euphoric that with LSD. (1)

In the early 1980 psychotherapists using MDMA were keen to keep it for clinical use, but the substance's growing popularity for recreational use led to its ban by the DEA in 1985.

In december 1990 Strassman revived psychedelic medical research starting a DMT pilot study with a strict methodology, demonstrating that the authorities can be convinced to consider psychedelic studies again (10)

In 2000s researches related to psychedelic drugs were conducted in centers including Johns Hopkins University, the University of New Mexico, McLean Hospital in Harvard, Imperial College London, and Bristol University in the UK (11)

After 2010 the golden age for publication on the field had emerged, in 2011 Grob et al. opened the road with the study 'Determining the therapeutic value of psilocybin in advanced stages of cancer anxiety' the result being significant reduction at one and three months after treatment and improvement of the mood after 6 months. (12) Many studies have been made with optimistic results in the field of addictions, depression, and anxiety $(13,14,15,16,17)$.

\section{What are psychedelic drugs?}

Psychedelics drugs are a grouped class of molecules that can produce a non- 
physiological state of consciousness, acting on serotonergic receptor type 2 .

They are divided into two main classes, indoleamines which include: lysergic acid diethylamide (LSD), N,N-dimethyltryptamine (DMT), and psilocybin; and phenethylamines that include: mescaline, dimethoxymethamphetamine (DOM), methylenedioxyamphetamine (MDA), methylenedioxymethamphetamine (MDMA). (18)

\section{How do psychedelics work?}

Nichols et al. in the study 'Psychedelics as Medicines: An emerging new paradigm' propose that psychedelics destabilize the local brain network hubs and global network connectivity by promoting neuronal avalanches which provide the opportunity for the brain network to 'reboot', thus permitting a rewiring of the neuronal paths. (19)

Another mechanism is proposed by David E. Olson on 'The Subjective Effects of Psychedelics May Not Be Necessary for Their Enduring Therapeutic Effects', where the ability of psychedelics to engage neuroplasticity mechanisms promote rewiring of neuronal circuits. (20)

Also, they promote the growth of cortical pyramidal neurons by increasing dendritic arborization and stimulate synapse formation, which makes them well suited for a disease characterized by prefrontal cortex neuronal atrophy such as stress-related neuropsychiatric disease. (21)

\section{PSILOCYBIN}

Mushrooms are the main natural source of psychedelic drugs. Groups of psychoactive fungi include species of the genera Conocycle, Gymnopilus, Panaeolus, Pluteus, Psylocibe, and Stropharia. Psilocybin is a psychedelic substance that was isolated by
Albert Hoffman in 1957 from the fungus Psilocybe mexicana, the first synthetic psilocybin product being produced in 1958. It was used traditionally in religious and spiritual ceremonies (along with mescaline and dimethyltryptamine), but also in the treatment of neuropsychiatric disorders. Dried mushrooms contain about $0,5 \%$ psilocybin $(22,23,24)$. The most used mushroom is Psilocybe cubensis which contains $10-12 \mathrm{mg}$ of psilocybin per gram of dried mushrooms (25).

Psilocybin is metabolized by the liver to the active ingredient psilocin, which crosses the blood-brain barrier and stimulates 5-HT2A, 5HT2C, 5-HT1A， 5-HT1D serotonergic receptors $(26,27,28)$. Psilocin is also active on histaminergic receptors $\mathrm{H} 1$, alpha $2 \mathrm{~A}$, and alpha 2B adrenergic receptors and dopaminergic receptors D3 (29). It is considered that the psychoactive effect of psilocybin is due to its role as a partial agonist on the 5-HT2A receptor which is associated with increasing neuronal excitation, improving memory and learning, bronchial and gastric smooth muscle contractions, cardiovascular and gastrointestinal antiinflammatory effect. 5-HT2C receptors modulate propiomelanocortin activation and the release of $\mathrm{CRH}$ (cortisol releasing hormone), which are involved in modulating appetite, insulin sensitivity, glucose homeostasis, and response to anxiogenic and stressful stimuli $(30,31)$. The dopaminergic effects of psilocybin are minimal, mainly to D3 receptors with unknown effects $(30,32)$. The most common side effects are nausea, vomiting, diarrhea, anxiety, tachycardia, delusions and confusion (31). More serious side effects include perceptual disturbances, seizures, and a hypothetical risk of heart valve disease (32). 
r.m\%\%

Preliminary studies have shown a positive role of psilocybin in psychiatric disorders such as obsessive-compulsive disorder, anxiety, major depressive disorder, alcohol dependence, tobacco dependence $(33,34)$.

\section{Depressed Mood}

Hendricks et al. evaluated the relationship between psilocybin and stress reduction. It was found that people who were using only psilocybin had a better mood and a lower risk of autolytic ideas or attempts compared to those who used other drugs.(22) In 2006 and 2008, Griffiths et al. studied the psychological effects of psilocybin in healthy volunteers who did 2-3 sessions of psilocybin. Two months after administration, there was an improvement in mood, a more positive attitude, and a better social life, without any significant side effects 14 months after ingestion $(35,36)$.

\section{Cancer and Anxiety}

Among the first clinical studies published about the therapeutic role of psilocybin, was the one conducted by Grob et al. who used this psychedelic to treat anxiety in patients with cancer. They received a dose with 200 $\mathrm{mcg} / \mathrm{kg}$ active psilocybin and several weeks apart, it was administrated $250 \mathrm{mg}$ niacin, used as a control and to prevent heat flashes given frequently by psilocybin. Before treatment, during treatment, and after treatment, the State-Trait Anxiety Inventory Scale (STAIS) was measured, at 2 weeks, one month, and 6 months post-therapy. According to STAIS, anxiety decreased significantly after psilocybin treatment, with an improvement in mood for 2 weeks. (12)

\section{Obsessive-Compulsive Disorder (OCD)}

To evaluate the therapeutic role of psilocybin in patients with obsessive-compulsive disorder (OCD), Moreno et al. conducted a study of 9 OCD patients with at least one therapeutic failure. Each patient received 4 different doses of psilocybin $(25 \mathrm{mcg} / \mathrm{kg}, 100$ $\mathrm{mcg} / \mathrm{kg}, 200 \mathrm{mcg} / \mathrm{kg}, 300 \mathrm{mcg} / \mathrm{kg}$ ) at least one week apart. According to the Yale-Brown Obsessive-Compulsive Scale (YBOCS), $88.9 \%$ of patients experienced a reduction of at least $25 \%$ in symptoms 24 hours after administration, and $66.7 \%$ of patients had a decrease of at least $50 \%$ of symptoms 24 hours after ingestion, without significant adverse effects (37).

\section{Alcohol and Tobacco Dependence}

To evaluate the therapeutic role of psilocybin in ethanol dependence, Bogenschutz et al. conducted a study on 10 patients, after 4 weeks of psychotherapy, they received a dose of psilocybin and after another 4 weeks, they received a second dose of the drug. A significant reduction in alcohol consumption was observed in all patients after ingestion of psilocybin, and the only adverse effect was a mild headache on half of the patients, that resolved within less than 24 hours (33).

Due to the positive evidence for the efficacy of 5-HT2A receptor agonists, Johnson et al. conducted a study with 15 smoking participants from at least 10 cigarettes per day and with failed attempts to quit (without substitution treatments or other drugs). The length of the study was 15 weeks, psilocybin was administrated at weeks 5, 7, and 13, combined with 4 weeks of cognitivebehavioral therapy. The result of the study is promising, as $80 \%$ of participants remained abstinent 6 months after the end of the study. Notable side effects were a slight increase in heart rate and blood pressure, headache, and dysphoric manifestations (13).

Psilocybin may have some utility in treating psychiatric disorders, but its use is limited by the low applicability of studies, the addictive potential of the drug (lower than other drugs) that requires rigorous monitoring of patients. 
However, extensive and rigorous studies are needed for demonstrating the utility of psilocybin in psychiatry, opening new doors for the future.

\section{LYSERGIC ACID DIETHYLAMIDE LSD}

From the discovery of LSD in 1938 by Swiss chemist Albert Hofmann who was searching for a substance derived from ergot with the goal to reduce postpartum hemorrhage, lysergide has maintained an unstable relationship with psychiatry $(38,39)$. The potential psychiatric use of LSD began at the end of the 1940s, being used in Europe and the USA under the brand name 'delisin' marketed by Sandoz. (40). Even the US army and secret services have been using it as a truth serum and as an incapacitant agent without success (41).

LSD chemical structure is similar to psilocybin and dimethyltryptamine (42), being a part of classical hallucinogens (40). It is one of the most potent hallucinogens with a half-life of approximately $3 \mathrm{~h}$ and an active dose between 0.5 and $2 \mathrm{mcg} / \mathrm{kg}(43,44)$. The mental effects are a distortion of the sense of time and identity, alteration in depth and time perception, visual hallucinations, euphoria, distorted perception of size and shape of objects, movements, colors, sounds, touch and body image and delusions. (45)

One of the risk of administration is so called ' the bad trip', described as strong anxiety, confusion, dysphoria (46), and an exacerbation or the prolonging of psychotic disorder, depending on the previous state of the subject. (47) LSD does not create physical dependence as the most recreational drugs do (opioids, cocaine, and methamphetamine). (49) It has very low toxicity, without any evidence of organic damages and neuropsychological deficits. $(50,51)$
LSD was used in the treatment of anxiety, depression, psychosomatic diseases and addiction (52). In patients with advanced cancer, it has also been observed that LSD could reduce pain, anxiety, and depression. $(53,54,55)$

\section{Addiction}

Fuentes et al., in his systematic review, analyzed 11 eligible papers from an initial total of 3,668 and concluded that LSD may be helpful in alcohol use disorder, having superiority over placebo with an odds ratio of 1.96 (95\% confidence interval 1.36-2.84 OR, $\mathrm{p}=0.0003$ ), being compared in terms of efficacy with the daily intake of naltrexone, acamprosate, or disulfiram $(52,56)$

Anxiety, Depression, and Psychosomatic Diseases

Denson et al. found significant difference improvement in the symptomatology of patients at 6 and 12 months $(\mathrm{p}<0.05)$. (57) Savage et al. found also a significant improvement in symptomatology after 6-8 weeks, being greater in the LSD treatment group compare to the classical treatment on the control group as well compared to the placebo group $(\mathrm{p}<0.05)$. (58)

In the study by Gasser et al., anxiety associated with chronic inflammatory disease, chronic motor disease, and cancer, has been reduced, the reduction being observed 2 months post ingestion and maintained after 12 months. (59)

In the future LSD is seen as a potential therapeutic agent in the fields of addictions despite its controversy and difficulty of designing clinical trials. New and modern studies are needed to increase the knowledge in the field. 
METHYLENEDIOXYMETHAMPHETA

MINE (MDMA)

MDMA interacts with several receptors in the brain but it has the strongest affinity for serotonergic receptors followed by norepinephrine and dopamine receptors (60). The main effect is on extracellular and cellular concentration of serotonin $(61,62)$ and also on the concentration of extracellular dopamine and norepinephrine.

MDMA is rapidly absorbed in the gastrointestinal tract, reaching its peak within 60 to 180 minutes; it has a half-life of approximately $8 \mathrm{~h}$ (63)and it is metabolized mainly by hepatic enzyme P450 2D6 to methylenedioxyamphetamine (MDA).
MDMA is used for a number of mental disorders like anxiety and PTSD, increasing social interactions. (64)

In PTSD it was recently proved that MNDA is an effective adjuvant because it decreases extremely negative experience relieving thus being easier to revisit and integrate the traumatic memories. $(65,66,67)$

There have been a small number of studies to assess the effectiveness of MDMA in PTSD who meet DSM IV criteria, with preliminary finding being encouraging; however, is important to consider that the effects that MDMA can limit its use in psychiatry. (68, 69)

\section{CONCLUSIONS}

In conclusion, psychedelics, despite the controversy around them and the difficulty in designing clinical trials, have a potential therapeutic use in psychiatry. New and modern standardized studies are needed in order to enlighten the knowledge path.

A question that needs to be put on the table is related to the potential risk associated with the use of psychedelics (the risk of neurotoxicity, persistent cognitive deficits, potential misuse).

By studying and understanding the mechanism underlying the positive effect of psychedelics in psychiatry, new and more effective pharmacotherapies can be developed without the potential of harm.

\section{ACKNOWLEDGE AND DISCLOSURE}

The authors declare no conflicts of interest regarding this paper.

\section{REFERENCES}

1. Sessa B. The history of psychedelics in medicine. Handbuch Psychoaktive Substanzen. Springer Reference Psychologie. Berlin: Springer, 2016.

2. Schultes R. E, Hofmann A., Rätsch C. (1979). Plants of the gods. Inner Traditions.Rochester, Vermont.

3. Lewin L. (1894). Über Anhalonium Lewinii Und Andere Cacteen - On Anhalonium Lewinii And Other Cacti. In Archives of Experimental Pathology and Pharmacology, 34(5-6), 14, 374391.

4. Iversen, L. (2006). Speed, ecstasy, ritalin: The science of amphetamines. Oxford: OUP.

5. Beringer, K. (1927). Der Meskalinrausch: Seine Geschichte Und Erscheinungsweise. Berlin: Julius Springer.

6. Hagenbach, D., Werthmuller, L. (2013). Mystic chemist: The life of Albert Hofmann and his discovery of LSD. Santa Fe: Synergetic Press. 
\%

7. Freedman, D. X. (1961). Effects of LSD-25 on brain serotonin. The Journal of Pharmacology and Experimental Therapeutics, 134(2), 160-166.

8. Dahlberg C. C., Mechaneck R., Feldstein S. (1968). LSD research: The impact of lay publicity.The American Journal of Psychiatry, 125(5), 685-689.

9. Shulgin A. T., Nichols D. E. (1978). Characterization of three new psychotomimetcs. In R. C.Stillman, R. E. Willette (Eds.), The psychopharmacology of hallucinogens. New York:Pergamon Press.

10. Strassman, R. (2001). DMT: Spirit molecule. Rochester: Park Street Press.

11. Gouzoulis-Mayfrank, E., Daumann, J. et al. (2000). Impaired cognitive performance in drug free users of recreational ecstasy (MDMA). Journal of Neurology, Neurosurgery, and Psychiatry, $68,719-725$.

12. Grob CS, Danforth AL, Chopra GS et al. Pilot study of psilocybin treatment for anxiety in patients with advanced-stage cancer. Arch Gen Psychiatry 2011; 68: 71-78

13. Johnson MW, Garcia-Romeu A, Cosimano MP et al. Pilot study of the 5-HT2AR agonist psilocybin in the treatment of tobacco addiction. J Psychopharmacol 2014; 28: 983-992

14. Bogenschutz MP, Forcehimes AA, Pommy JA et al. Psilocybinassisted treatment for alcohol dependence: a proof-of-concept study. J Psychopharmacol 2015; 29: 289-299

15. Carhart-Harris RL, Bolstridge M, Rucker J et al. Psilocybin with psychological support for treatment-resistant depression: an open-label feasibility study. Lancet Psychiatry 2016; 3: 619-627

16. Griffiths RR, Johnson MW, Carducci MA et al. Psilocybin produces substantial and sustained decreases in depression and anxiety in patients with life-threatening cancer: a randomized doubleblind trial. J Psychopharmacol 2016; 30: 1181-1197

17. Ross S, Bossis A, Guss J et al. Rapid and sustained symptom reduction following psilocybin treatment for anxiety and depression in patients with life-threatening cancer: a randomized controlled trial. J Psychopharmacol 2016; 30: 1165-1180

18. Goodman, Gilman's: The Pharmacological Basis of Therapeutics, Thirteenth Edition. s.l. : McGraw-Hill Education, 2017.

19. Nichols, David E.; Johnson, Matthew W.; Nichols, Charles D. Psychedelics as medicines: an emerging new paradigm. Clinical Pharmacology Therapeutics, 2017, 101.2: 209-219.

20. Olson, David E. The subjective effects of psychedelics may not be necessary for their enduring therapeutic effects. ACS Pharmacology Translational Science, 2020, 4.2: 563-567.

21. LY, Calvin, et al. Psychedelics promote structural and functional neural plasticity. Cell reports, 2018, 23.11: 3170-3182.

22. Hendricks P.S., Johnson M.W., Griffiths R.R. Psilocybin, psychological distress, and suicidality. J.Psychopharmacol. 2015;29:1041-1043.doi:10.1177/0269881115598338.

23. Max M. Houck PhD, FRSC, Jay A. Siegel PhD, in Fundamentals of Forensic Science (Third Edition), 2015.

24. Inaba DS. All arounders. In: Cholewa E, von Radics E, editors. Uppers, downers, all arounders - physical and mental effects of psychoactive drugs. 8th ed. Medford (OR): CNS Products, Inc; 2014. p. 6.5-6.11.

25. Elflein J. Psychedelic therapy-Statistics and Facts. 2018

26. Jeffrey K. Aronson, in Manson's Tropical Infectious Diseases (Twenty-third Edition), 2014

27. L.F. Tófoli, D.B. de Araujo, in International Review of Neurobiology, 2016.

28. Chen, J., Li, M., Yan, X., Wu, E., Zhu, H., Lee, K., Chu, V., Zhan, L., Lee, W., and Kang, J. (2011) Determining the pharmacokinetics of psilocin in rat plasma using ultra-performance liquid 
r.\% chromatography coupled with a photodiode array detector after orally administering an extract of Gymnopilus spectabilis, Journal of Chromotography. B, Analytical Technologies in the Biomedical and Life Sciences 879, 2669-2672.

29. Halberstadt, A., and Geyer, M. (2011) Multiple receptors contribute to the behavioral effects of indoleamine hallucinogens, Neuropharmacology 61, 364-381

30. Buhot, M. C., Martin, S., and Segu, L. (2000) Role of serotonin in memory impairment, Ann Med 32, 210-221.

31. Hasler, F., Grimberg, U., Benz, M. A., Huber, T., and Vollenweider, F. X. (2004) Acute psychological and physiological effects of psilocybin in healthy humans: a double-blind, placebocontrolled dose-effect study, Psychopharmacology (Berl) 172, 145-156.

32. Orsolini, L., Papanti, G., De Berardis, D., Guirguis, A., Corkery, J., and Schifano, F. (2017) The "Endless Trip" among the NPS Users: Psychopathology and Psychopharmacology in the Hallucinogen-Persisting Perception Disorder. A Systematic Review., Frontiers in Psychiatry 8, 240 33. Bogenschutz, M. P., Forcehimes, A. A., Pommy, J. A., Wilcox, C. E., Barbosa, P., and Strassman, R. J. (2015) Psilocybin-assisted treatment for alcohol dependence: a proof-ofconcept study, Journal of Psychopharmacology 29, 289-299.

34. Carhart-Harris, R., Bolstridge, M., Day, C., Rucker, J., Watts, R., Erritzoe, D., Kaelen, M., Giribaldi, B., Bloomfield, M., and Pilling, S. (2018) Psilocybin with psychological support for treatment-resistant depression: six-month follow-up, Psychopharmacology 235, 399-408.

35. Griffiths RR, Richards WA, McCann U, Jesse R. Psilocybin can occasion mystical-type experiences having substantial and sustained personal meaning and spiritual significance. Psychopharmacology (Berl). 2006;187(3):268-83.

36. Griffiths R, Richards W, Johnson M, McCann U, Jesse R. Mysticaltype experiences occasioned by psilocybin mediate the attribution of personal meaning and spiritual significance 14 months later. J Psychopharmacol. 2008;22(6):621-32

37. Moreno FA, Wiegand CB, Taitano EK, Delgado PL. Safety, tolerability, and efficacy of psilocybin in 9 patients with obsessive-compulsive disorder. J Clin Psychiatry. 2006;67(11): 173540.

38. González-Maeso J, Yuen T, Ebersole BJ, Wurmbach E, Lira A, Zhou M, et al.Transcriptome fingerprints distinguish hallucinogenic and nonhallucinogenic 5-hydroxytryptamine $2 \mathrm{~A}$ receptor agonist effects in mouse somatosensory cortex. J Neurosci (2003) 23:8836-3.

39. Busch AK, Johnson WC. L.S.D. 25 as an aid in psychotherapy; preliminary report of a new drug. Dis Nerv Syst (1950) 11:241-3.

40. Osmond H. A review of the clinical effects of psychotomimetic agents. Ann NY Acad Sci (1957) 66:418-4.

41. Lee MA, Shlain B. Acid dreams : the complete social history of LSD : the CIA, the sixties, and beyond. New York City, USA: Grove Weidenfeld (1992).

42. Hill SL, Thomas SHL. Clinical toxicology of newer recreational drugs. Clin Toxicol (2011) 49:705-9.

43. Abanades S, Peiró AM, Farré M. Club drugs: old medicines as new party drugs. Med Clin (2004) 123:305-1.

44. Passie T, Halpern JH, Stichtenoth DO, Emrich HM, Hintzen A. The pharmacology of lysergic acid diethylamide: a review. CNS Neurosci Ther (2008) 14:295-4.

45. Liester MB. A review of lysergic acid diethylamide (LSD) in the treatment of addictions: historical perspectives and future prospects. Curr Drug Abuse Rev (2014) 7:146-6. 
46. Carbonaro TM, Bradstreet MP, Barrett FS, MacLean KA, Jesse R, Johnson MW, et al. Survey study of challenging experiences after ingesting psilocybin mushrooms: Acute and enduring positive and negative consequences. J Psychopharmacoly. (2016) 30:1268-8.

47. Grinspoon L, Bakalar JB. Psychedelic drugs reconsidered. New York, NY:Lindesmith Ctr 1997.

48. Barnes DT. The uses and abuses of L.S.D. and other hallucinogenic drugs. Aust N Z J Psychiatry.1970;4:170-3.

49. Fantegrossi WE, Murnane KS, Reissig CJ. The behavioral pharmacology of hallucinogens. Biochem Pharmacol (2008) 75:17-3.

50. Gable RS. Toward a comparative overview of dependence potential and acute toxicity of psychoactive substances used nonmedically. Am J Drug Alcohol Abuse (1993) 19:263-1.

51. Strassman RJ. Adverse reactions to psychedelic drugs. A review of the literature. J Nerv Ment Dis (1984) 172:577-5.

52. Abramson H. LSD in psychotherapy and alcoholism. Am J Psychother (1966) 20:415-38.

53. Grof S, Halifax J, Kübler-Ross E. The Human Encounter With Death. EP Dutton: New York, NY (1978).

54. Grof S, Goodman LE, Richards WA, Kurland AA. LSD-assisted psychotherapy in patients with terminal cancer. Int Pharmacopsychiatry.(1973) 8:129-4.

55. Kast EC, Collins VJ. Study of lysergic acid diethylamide as an analgesicagent. Anesth Analg. (1964) 43:285-1.

56. Krampe H, Ehrenreich H. Supervised disulfiram as adjunct to psychotherapy in alcoholism treatment. Curr Pharm Des (2010) 16:2076-0.

57. Denson R, Sydiaha D. A controlled study of LSD treatment in alcoholism and neurosis. Br J Psychiatry (1970) 116:443-5.

58. Savage C, McCabe OL, Kurland A, Hanlon T. LSD-assisted psychotherapy in the treatment of severe chronic neurosis. Farmingdale, New York: Baywood Pub. Co.

59. Gasser P, Holstein D, Michel Y, Doblin R, Yazar-Klosinski B, Passie T, et al. Safety and efficacy of lysergic acid diethylamide-assisted psychotherapy for anxiety associated with lifethreatening diseases. J Nerv Mental Dis (2014) 202(7):513-20.

60. Battaglia G, Brooks BP, Kulsakdinun C, et al. Pharmacologic profile of MDMA (3,4methylenedioxymethamphetamine) at various brain recognition sites. Eur $\mathrm{J}$ Pharmacol. 1988;149:159-163.

61. Green AR, Cross AJ, Goodwin GM. Review of the pharmacology and clinical pharmacology of 3,4-methylenedioxymethamphetamine (MDMA or "Ecstasy"). Psychopharmacology (Berl). 1995; 119:247-260.

62. White SR, Obradovic T, Imel KM, et al. The effects of methylenedioxymethamphetamine (MDMA, "Ecstasy") on monoaminergic neurotransmission in the central nervous system. Prog Neurobiol. 1996;49:455-479.

63. Mas M, Farre M, de la Torre R, et al. Cardiovascular and neuroendocrine effects and pharmacokinetics of 3, 4-methylenedioxymethamphetamine in humans. J Pharmacol Exp Ther. 1999;290:136-145.

64. Kamilar-Britt P, Bedi G. The prosocial effects of 3,4-methylenedioxymethamphetamine (MDMA): controlled studies inhumans and laboratory animals. Neurosci Biobehav Rev. 2015;57:433-446. 

65. Oehen P, Traber R, Widmer V, et al. A randomized, controlled pilot study of MDMA (+/-3,4methylenedioxymethamphetamine)-assisted psychotherapy for treatment of resistant, chronic posttraumatic stress disorder (PTSD). J Psychopharmacol. 2013;27:40-52.

66. Bouso JC, Doblin R, Farre M, et al.MDMA-assisted psychotherapy using low doses in a small sample of women with chronic posttraumatic stress disorder. J PsychoactiveDrugs. 2008;40:225236.

67. Mithoefer MC, Wagner MT, Mithoefer AT, et al. The safety and efficacy of $\{+/-\} 3,4-$ methylenedioxymethamphetamine-assisted psychotherapy in subjects with chronic, treatmentresistant posttraumatic stress disorder: the first randomized controlled pilot study. J Psychopharmacol. 2011;25: 439-452.

68. Mithoefer MC, Wagner MT, Mithoefer AT, et al. Durability of improvement in post-traumatic stress disorder symptoms and absence of harmful effects or drug dependency after 3,4methylenedioxymethamphetamine-assisted psychotherapy: a prospective long-term follow-up study. J Psychopharmacol. 2013;27:28-39.

69. Amoroso T, Workman M. Treating posttraumatic stress disorder with MDMA-assisted psychotherapy: a preliminary meta-analysis and comparison to prolonged exposure therapy. J Psychopharmacol. 2016;30:595-600.

\section{Correspondence:}

Cătălin Oprea,

Medical Resident in psychiatry, "Socola" Psychiatry Institute, Iasi, 36 Bucium road, opreacatalinu@gmail.com 


\title{
The psychological impact of aesthetic procedures on the young patient
}

\author{
Ioana A Halip, Laura Gheucă Solovăstru, Laura Stătescu, Ioana A Popescu, \\ Adriana I Pătrașcu, Andra G Salahoru, Bogdan-Marian Tarcău, \\ Alina Stîncanu, Doinița Olinici Temelie, Dan Vâță
}

\begin{abstract}
Ioana-Alina Halip - M.D., Ph. D., Assistant Professor, Department of Dermatology, Faculty of Medicine, "Grigore T. Popa" University of Medicine and Pharmacy Iasi, Romania

Laura Gheucă Solovăstru - M.D., Ph. D., Professor, Department of Dermatology, Faculty of Medicine, "Grigore T. Popa" University of Medicine and Pharmacy Iasi, Romania. Senior Dermatovenerolog in Dermatology Clinic County Emergency Hospital "St. Spiridon" Iasi, Romania Laura Stătescu - M.D., Ph. D., Lecturer, Department of Dermatology, Faculty of Medicine, "Grigore T. Popa" University of Medicine and Pharmacy Iasi, Romania. Senior Dermatovenerolog in Dermatology Clinic County Emergency Hospital “St. Spiridon” Iasi, Romania

Ioana-Adriana Popescu - M.D., Ph. D. student, Department of Dermatology, of Medicine, "Grigore T. Popa" University of Medicine and Pharmacy Iasi, Romania.

Adriana I Pătrașcu - M.D., Ph. D. student, Department of Dermatology, Faculty of Medicine, "Grigore T. Popa" University of Medicine and Pharmacy Iasi, Romania. Senior Dermatovenerolog in Dermatology Clinic County Emergency Hospital "St. Spiridon” Iasi, Romania

Andra Georgiana Salahoru - Ph. D. student, Department of Psychology, "Alexandru Ioan Cuza" University, Iasi, Romania

Bogdan-Marian Tarcău - M. D., Dermatovenerology Clinic, "Sf. Spiridon" County Emergency Hospital Iasi, Romania

Alina Stîncanu - Senior Dermatovenerolog in Dermatology Clinic County Emergency Hospital "St. Spiridon" Iasi, Romania

Doinița Olinici Temelie - M.D., Ph. D., Lecturer, Department of Cell Biology, Faculty of Medicine, "Grigore T. Popa" University of Medicine and Pharmacy Iasi, Romania. Senior Dermatovenerolog in Dermatology Clinic County Emergency Hospital "St. Spiridon" Iasi, Romania Dan Vâță - M.D., Ph. D., Lecturer, Department of Dermatology, Faculty of Medicine, "Grigore T. Popa" University of Medicine and Pharmacy Iasi, Romania. Senior Dermatovenerolog in Dermatology Clinic County Emergency Hospital “St. Spiridon” Iasi, Romania
\end{abstract}

\section{ABSTRACT}

The field of aesthetic medicine is a trend in modern medicine and nowadays patients not only want to be healthy, they also want to enjoy life, be fit and minimize the effects of physiological 
s aging. Societal acceptance of aesthetic procedures is increasing and desire to improve the external appearance may be related to the extensive media coverage which basically increases the considered benefits. Young patients should understand that results of surgical aesthetical procedures may lead to permanent change. A complete assessment of reason why the young patient wishes to have the procedure, and what difference the patient thinks it will make to his/her life, should be undertaken. Poor psychological outcomes are possible and unrealistic expectations may should warn the doctor against procedure until the patient is emotionally mature and may need a psychological referral in order to maintain the psychosocial health and improve the quality of life.

\section{KEYWORDS:}

Aesthetic procedures, body dissatisfaction, psychological outcomes, quality of life, psychosocial health.

\section{INTRODUCTION}

What is beauty? The concept of beauty and attractiveness seems to be similar across cultures and religions and the characterization of a person as beautiful, is often based on some combination of inner beauty and outer beauty. Whereas inner beauty includes psychological factors such as personality, grace, intelligence and elegance, physical attractiveness refers to physical attributes which are valued on an aesthetic basis. Research shows that subjective attractiveness is largely biological and can be influenced by social trends and advertising especially in younger people. Moreover, studies which evaluated the consistency of physical attractiveness ratings across cultural groups showed that body attractiveness, and especially facial beauty is species-specific, not race-specific $(1,2)$.

Physical aspect and particularly the face is the public relations organ by excellence and may be considered the clock of age and the barometer of feelings. Health is the first thing that is considered indispensable in life and the second one is a pleasant appearance. Nowadays societal acceptance of aesthetic procedures is increasing and desire to improve the external appearance may be related to the extensive media coverage which

basically increases the considered benefits (3). A survey of American Society for Aesthetic Plastic Surgery shows that $53 \%$ of women and $49 \%$ of men approved of aesthetic surgery, while $27 \%$ of married Americans and $33 \%$ of young and unmarried Americans would consider it for themselves in the future (4).

The field of aesthetic medicine is a new trend in modern medicine and patients not only want to be healthy, they also want to enjoy life, be fit and minimize the effects of physiological aging. Indeed, patients are requesting non-invasive procedures with very little risk. Many of very valuable improvements of the face can be achieved by simple techniques and today many patients who want to improve their physical appearance are young or mature. Similarly, men and women are aware of such advances due to the media and their desire to improve physical appearance may become strong. Moreover, having a good look is considered a culture and it is even a need in many fields of activity.

Everybody at any age would like to have a pleasant aspect, without any blemish due to aging and aesthetic procedures are more 
accessible. Young people want to remain young and they want to correct the first signs of facial aging, to treat a minor defect or to enhance the beauty of a normal feature. In contrast with younger persons, senior patients do not want to change and very often want to have several simple procedures together instead of a major one (5).

\section{AESTHETIC PROCEDURES AND PSYCHIATRIC APPROACH}

Aesthetic procedures are an optional or medically unnecessary procedure requested by a patient to correct imperfections and improve appearance $(6,7)$. They are elective and they comprise all medical procedures that are aimed at improving the physical appearance and satisfaction of the patient, using non-invasive to minimally invasive procedures. Some aesthetic procedures are performed under local anaesthesia while some of them do not require it. Mainly, aesthetic procedures consist of:

- injections of neurotoxins (botox) and dermal fillers,

- chemical peels, microdermabrasion,

- body contouring and treatment of cellulite,

- skin nutrition,

- hair transplant or hair reduction,

- lifting, fat grafting,

- Platelet Rich Plasma (PRP),

- lasers and IPL (Intense Pulsed Light) treatments,

- scars management,

- venous treatment.

The real benefit of practicing aesthetic medicine is the type of care that practitioners are offering to their patients. Simple techniques for rejuvenation or associated with other minor surgical techniques give a natural look and not a postsurgical look, which is sometimes the result of a major procedure. The satisfaction of the patient may be the same as surgical treatment of skin neoplasia or tumors' pathology of severe photo damage in senior persons $(8,9,10)$.

The largest age group of patients who demand aesthetic procedures (surgical and nonsurgical) is between 35 and 50 years (11). However, in 2016 statistical data from American Society for Aesthetic Plastic Surgery show that $25.3 \%$ belongs to group 19-34 years and $25.6 \%$ belongs to older age, respectively $35-50$ years (11). These results may be related to the increasing societal acceptance of aesthetic surgery. Furthermore, may be the result to the obsession of popular media with body image which increases the focus on such procedures, particularly in the younger age group with internet navigation. But how young is too young for aesthetic procedures? The number of teenage patients who are requiring such dermatologic treatment is small and is reported that only $1.8 \%$ of all patients undergoing surgical procedures in 2016. American Society for Aesthetic Plastic Surgery indicated in data from the last 16 years similar rates every year over the time period, ranging between 1 and $3 \%$ (11).

Food and Drug Administration (FDA) reported that the greatest concern is that the teen will have unrealistic expectations. Clearly, the doctor should assess the emotional and physical maturity of younger patients before any invasive procedures. It is mandatory that the young patient should understand that results of surgical aesthetical procedures may lead to permanent change. A complete assessment of reason why the young patient wishes to have the procedure, and what difference the patient thinks it will make to his/her life, should be undertaken. Unrealistic expectations may should warn the 


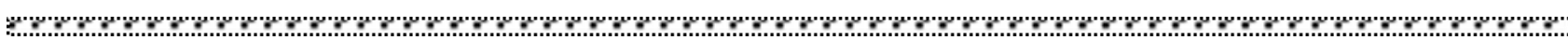

doctor against procedure until the patient is emotionally mature and may need a psychological referral (11).

Unfortunately, the ideal patient (young or senior) who is referring to dermatologist for aesthetic procedure does not exist. The ideal patient should be able to develop discussions and show understanding, having effective communication skills. Moreover, he should be pleasant to the medical staff, well educated, and especially well informed regarding the aesthetical treatment. The ideal patient has realistic expectations of the outcome and a full understanding of potential complications, being compliant with pre and post procedure instructions.

On the one hand, aesthetic procedures improve the quality of the patients' lives after they accepted the good results of procedures. On the other hand, it was also reported that some patients were considered to have psychological problems, and the morbidity rate was reported to be higher (12). Young patients may have social functional disturbance, and a considerable number of these patients may seek aesthetic procedures rather than ask psychiatrists for help. Anxiety, depression, obsessive-compulsive disorder, body dysmorphic disorder, dependent personality disorder may be identified according to psychological examination. These psychological disorders might lead to a poor surgical outcome and high risk of dissatisfaction, and even recurrent surgical interventions (12). This is the reason why is necessary to understand the psychological status of every person seeking aesthetic surgical or nonsurgical procedures, and patients' selection is considered to be the first factor that determines the success or failure of it (13).
In a cross-sectional study (14) which included 315 patients with an average age of $30 \pm 8.4$ years admitted to the Department of Plastic Surgery in a General Hospital in China from July 2016 to July 2017, investigated the prevalence and risk factors in preoperative patients who visited a aesthetic plastic surgery clinic. The results indicated that the preoperative anxiety was more obvious than depression. Also, education level was associated with the diagnosis of anxiety ( $\mathrm{p}=$ $0.034)$ while education level $(\mathrm{p}=0.001)$ and occupation $(\mathrm{p}=0.015)$ were associated with the diagnosis of depression (14).

Gillen (15) investigated that subjects with greater positive body image had less depression, higher self-esteem, a smaller percent of unhealthy dieting behaviours and greater intentions to protect their skin from sun exposure and photo damage and these associations were not correlated with gender (15). Therefore, Gillen concluded that healthcare providers should promote positive body image because of its potential health benefits (15). Similarly, other investigators $(16,17)$ provided a great impact of aesthetic surgery (breast augmentation or reduction, abdominoplasty and facial procedureblepharoplasty, rhinoplasty, lipoplasty or scar correction) on body image with a connection between aesthetic procedures and physical and mental health.

Physical appearance is an integrative part of personal identity and its relation to individuals' self-perception begins early in life (18). The socio-cultural environment may influence perceptions of attractiveness (19). Tripartite Influence Model (20) sustain that attractiveness ideals are transmitted by three primary sociocultural influences: parents, colleagues and the media. A research about influence of traditional media such as television programs, adverts or newer types of 
media (social networking sites) on women's consideration of aesthetic surgery enrolled 118 women aged 18-29 years (20). The participants were divided in two arms. One arm received images from social networks with young adult women who had rhinoplasty, soft tissue fillers, Botox, laser skin resurfacing and microdermabrasion using an Analogue Visual Scale in order to evaluate satisfaction (20). The second arm received for evaluation 30 travel images. Results showed that participants who had seen images of enhanced females revealed a tendency for an increased desire for aesthetic surgery compared to participants who saw images of travel. Moreover, the relationship between social media use and desire for aesthetic surgery was not mediated by body dissatisfaction. The appearance pressures from social media may lead people who are more involved in their appearance to desire changing strategies such as aesthetic procedures and therefore may have greater expectations from therapies (20). In this way, screening measures should be used before aesthetic treatments in order to assess better patients' motivations and their psychological functioning. It is likely that aesthetic treatments will have negative outcomes if their motivations were based on resembling someone they have seen on social media (21).

Other studies $(22,23)$ have shown a connection between body dissatisfaction and acceptance of aesthetic surgery among women, suggesting that people may consider aesthetic treatment as a method to obtain psychological benefits such as higher selfesteem and social benefits becoming more attractive. Self-compassion has positive (mindfulness, common humanity, selfkindness) and negative (over-identification, isolation, self-judgment) components. 220 young Italian women with age between 19 and 31 years, completed a questionnaire with reference to the fields of interest (24). It was examined the association between selfcompassion components and body dissatisfaction and acceptance of aesthetic surgery among women and physical appearance comparison. Analysis revealed that higher mindfulness was directly associated to lower acceptance of aesthetic surgery. Common humanity and self-kindness were connected to acceptance of aesthetic surgery for social reasons (24). However, other experimental studies claimed that even if their body dissatisfaction had decreased, body image quality of life and self-esteem have not increased in women who had received aesthetical procedures (25).

Overall, systematic reviews after 1950 which have analysed the impact of aesthetic procedures showed mixed results probably due to variation in the procedures or to the methodological quality of life used in studies. Some of them revealed satisfaction, selfesteem and improved psychological distress following aesthetical procedures (7, 26), others showed few positive long-term psychological effects $(27,28)$. Predictors of poor outcomes included clinically diagnosed disorders with a psychological component like depression or body dysmorphic disorder, but they may also include non-clinically diagnosed disorders such as anxiety, low selfesteem and social parameters like age and relationship status (29).

In a review of 37 studies (29), factors as being young, being male, having unrealistic expectations of the procedure or previous unsatisfactory aesthetic surgery, minimal deformity or motivation based on relationship issues were associated with poor psychosocial outcome. Aesthetical surgical procedures were associated with both intimate partner violence and verbally abused women, smoker 


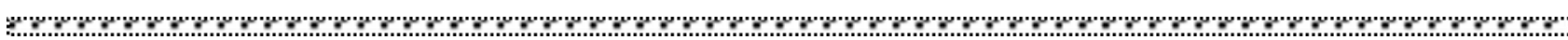

or people taking medication for anxiety, nervous conditions or sleep disorders (30).

A review of nine studies studied the effect of aesthetic interventions on post procedure psychological outcomes (31). Various types of aesthetic procedures such as botulinum toxin type A injection and facelift were included. Facelift was associated with improvement of self-esteem and quality of life/social functioning, but had no positive effects of anxiety or depression $(26,29)$. The impact on psychosocial health of aesthetic procedure such as hyaluronic acid fillers and botulinum toxin type $\mathrm{A}$ remains however poorly defined.

Body dysmorphic disorder represents the disorder which is characterized as a preoccupation with a slight or no observable defect in appearance and is associated with obsessive thinking and compulsive behaviours and which leads to a disruption in activities of daily life. This psychiatric condition is likely of greatest relevance to the aesthetic doctor (32). It occurs in approximately $1 \%$ to $2 \%$ of the general population and is estimated equally across women and men (33). Patients with this disorder may present concern with any feature of the body such as facial skin, nose, and hair. They are often convinced that they will feel better if they change their physical appearance and therefore they are seen frequently in aesthetic medical practices. The majority of studies of persons with body dysmorphic disorder unfortunately suggested that greater than $90 \%$ of patients reported no change or a worsening of their symptoms following an aesthetic treatment. Some of them reported that the level of preoccupation with the given feature was not improved and others indicated that they became concerned about another aspect of their physical appearance (33).
Data (33) suggests that many providers have identified patients with this condition during the preoperative consultation and refused with the required treatment. Specific questions should be prepared to assess for the presence of body dysmorphic disorder. Examples of relevant questions may include the following:

1. Is the patient preoccupied with the perceived physical defect?

2. Does this preoccupation cause clinically significant distress like anxiety, depression or hopelessness?

3. Does the preoccupation with physical defect cause clinically significant impairment in functioning like difficulty with or avoidance of family, school, social or work activities?

Analysing patients answers, those individuals with no or minimal physical defect who experience resulting clinically significant distress or impairment in functioning and who perform at least one associated repetitive behaviour are likely to have body dysmorphic disorder. Due to the safety risks for both patients and aesthetic surgeons or dermatologists and the evidence that aesthetic treatment outcomes among people are poor, body dysmorphic disorder is considered a contraindication for aesthetic treatments.

Saying "no" to a patient can be difficult but is sometimes necessary. You should listen to your intuition and be cautious. If you have concerns, do not offer the patient aesthetic procedure. So when to say "no"? The aesthetic doctor may consider the patient unsuitable for several reasons. According to Gorney and Martello, the patient may be either anatomically or psychologically unsuitable for the procedure (34). From an anatomic viewpoint, the feature that the patient wishes to have corrected must be visible to the surgeon and able to be corrected. The ideal patient fits around the 
diagonal of Gorney's patient selection graph (35).

Lately, young women are being encouraged to embrace and accept the way that they look, and this may help to avoid aesthetic procedures. For example, the number of aesthetic procedures conducted in 2016 fell $40 \%$ from a record-breaking high in 2015 (36). In this manner, the decreased societal pressure for an idealized beauty standard may be encouraging women away from having aesthetic procedures (37). Psychological assessment of young women who are interested in aesthetic surgical or nonsurgical procedures is highly recommended $(38,39)$.

Aesthetic surgery does not necessarily help young people to improve their body image
$(25,33)$. When women seek aesthetic surgery without changing their attitude toward the self, is a great chance that they will have low self-esteem also after undergoing surgery. This fact could lead them to look for further procedures, without ever feeling comfortable with their body. Surgeons and dermatologists might recommend alternative strategies, such as self-compassion trainings, that could help women to change the way they relate to their body image. Optimal levels of common humanity and mindfulness could decrease women's acceptance of aesthetical procedures as well, at least for psychosocial health. The existence of self-kindness and acceptance of aesthetic procedures should be further explored before considering the advantages and disadvantages of trainings that specifically focus on this dimension.

\section{CONCLUSIONS}

It is well known that minor imperfections of the skin or aesthetic anomalies can cause much distress. Prevention is better than cure and mini invasive aesthetic techniques are frequently indicated. In young patients simple procedures are very often enough. Aesthetic procedures today is not only rejuvenation but it is also maintenance of youth and improvement of the mind. It is not rare the situation when the social media and he publicity creates in the public's mind an image that is unreal and deceptive and may affect peoples psychosocial health.

In aesthetic medicine, it is necessary to know how and also why a procedure has to be selected. All the problems of patient selection should be discussed as well as minor surgical details about all the procedures used for physical appearance improvement of region of the face, neck, and scalp, including also peelings, biological fillers, short access facial elevation or lifting, mesotherapy techniques or removal of the fat.

Understanding the patients' motivations for aesthetic interventions and their expectations of the outcomes are the keys to achieving satisfied patients. Vulnerable patients should be identified and given appropriate care. Doctors should explore with patients the reasons for their request for aesthetical procedures using validated screening tools that look at psychosocial issues in addition to body image disorders. Practitioners should be aware of reasons underlying requests and of those who are at risk of poor outcomes. Moreover, the dermatologist should require a full patient education including discussions about the benefits and the possible risks. Favourable and unfavourable results to aesthetic procedures should be considered and fully discussed. Similarly, a second consultation after an aesthetic procedure is almost always necessary, with post procedure follow-up including detailed written instructions for the recovery. Those patients with 

unsatisfactory outcomes should be seen more often to improve communication in order to evaluate the psychological outcomes.

\section{ACKNOWLEDGEMENTS AND DISCLOSURES}

The authors state that they are no declared conflicts of interest regarding this paper.

\section{REFERENCES}

1. Bashour M. History and current concepts in the analysis of facial attractiveness. Plast Reconstr Surg 2006; 118:741-756.

2. Cunningham MR, Roberts AR, Barbee AP, et. al. "Their ideas of beauty are, on the whole, the same as ours": consistency and variability in the cross-cultural perception of female physical attractiveness. J Pers Soc Psychol 1995; 68:261-279.

3. Lee S-Y. The effect of aesthetic surgery realty shows on women's beliefs of beauty privileges, perceptions of aesthetic surgery, and desires for aesthetic enhancements. Am Commun J 2014; 16:1-14.

4. http://www.surgery.org/sites/default/files/Stats2010_1.pdf.

5. Shiffman MA, Mirrafati SJ, Lam SM (2007). Simplified Facial Rejuvenation, 2008th ed.; Springer: Berlin Heidelberg, Germany; pp:46-69.

6. Rohrich RJ. The American Society of Plastic Surgeons' procedural statistics: what they really mean. Plast Reconstr Surg 2003;112:1389-1392.

7. von Soest T, Kvalem IL, Wichstrom L. Predictors of aesthetic surgery and its effects on psychological factors and mental health: a population-based follow-up study among Norwegian females. Psychol Med 2012;42:617-626.

8. Gheucă Solovăstru L, Vâță D, Stîncanu A, Ciubara AM, Andrese E. The pshychosocial impact on patients with skin neoplasia. Bulletin of Integrative Pshychiatry 2013;3(58):33-38.

9. Grajdeanu IA, Gheuca Solovastru L, Vata D et al. Improving the quality of life of patients by using imaging techniques. Bulletin of Integrative Psychiatry 2019; (80)1:43-48.

10. Gheucă Solovăstru L, Vâță D, Stătescu L, Constantin MM, Andrese E. Skin cancer between myth and reality, yet ethically constrained. Rev Rom Bioet 2014; 2(12): 47-52.

11. http://www.surgery.org/sites/default/files/ASAPS-Stats2016.pdf

12. Herruer JM, Prins JB, van Heerbeek N, Verhage-Damen GW, Ingels KJ. Negative predictors for satisfaction in patients seeking facial aesthetic surgery: a systematic review. Plast Reconstr Surg 2015;135:1596-1605.

13. Andretto Amodeo C. The central role of the nose in the face and the psyche: review of the nose and the psyche. Aesthet Plast Surg 2007;31:406-410.

14. Wei L, Ge C, Xiao W, Zhang X, Xu J. Cross-sectional investigation and analysis of anxiety and depression in preoperative patients in the outpatient department of aesthetic plastic surgery in a general hospital in China. J Plast Reconstr Aesthet Surg 2018;71(11):1539-1546.

15. Gillen MM. Associations between positive body image and indicators of men's and women's mental and physical health. Body Image 2015;13:67-74.

16. Cingi C, Songu M, Bal C. Outcomes research in rhinoplasty: body image and quality of life. Am J Rhinol Allergy 2011; 25(4):263-267.

17. Litner JA, Rotenberg BW, Dennis M, Adamson PA. Impact of aesthetic facial surgery on satisfaction with appearance and quality of life. Arch Facial Plast Surg 2008;10(2):79-83.

18. Davison KK, Birch, LL. Weight status, parent reaction, and self-concept in five-year-old girls. Pediatrics 2001;107(1):46-53.

19. Cafri G, Yamamiya Y, Brannick M, Thompson, JK. The influence of sociocultural factors on body image: A meta-analysis. Clinical Psychology:Science and Practice 2005;12, 421-433.

20. Shome D, Vadera S, Male SR, Kapoor R. Does taking selfies lead to increased desire to undergo aesthetic surgery. J Cosmet Dermatol 2020;19(8):2025-2032.

21. Lee HH, Damhorst ML, Paff OJ. Body satisfaction and attitude theory: Linkages with normative compliance and behaviors undertaken to change the body. Fam Consum Sci Res J 2009; 37(4):466-488. 
22. Lunde C. Acceptance of aesthetic surgery, body appreciation, body ideal internalization, and fashion blog reading among late adolescents in Sweden. Body Image 2013; 10: 632-635.

23. Markey CN, Markey PM. Correlates of young women's interest in obtaining aesthetic surgery. Sex Roles 2009;61:158-166.

24. Nerini A, Matera C, Di Gesto C, Policardo GR, Stefanile C. Exploring the Links Between Self-Compassion, Body Dissatisfaction, and Acceptance of Aesthetic Surgery in Young Italian Women. Front Psychol 2019; 10:2698.

25. Sobanko JF, Dai J, Gelfand JM, Sarwer DB, Percec I. Prospective cohort study investigating changes in body image, quality of life, and self-esteem following minimally invasive aesthetic procedures. Dermatol Surg 2018; 44:1121-1128.

26. Shridharani SM, Magarakis M, Manson PN, Rodriguez ED. Psychology of plastic and reconstructive surgery: a systematic clinical review. Plast Reconstr Surg 2010;126:2243-2251.

27. Cook SA, Rosser R, Salmon P. Is aesthetic surgery an effective psychotherapeutic intervention? A systematic review of the evidence. J Plast Reconstr Aesthet Surg 2006; 59:1133-1151.

28. Sarwer D. The psychological aspects of aesthetic breast augmentation. Plast Reconstr Surg 2007;120 (1):110117.

29. Honigman RJ, Phillips KA, Castle DJ. A review of psychosocial outcomes for patients seeking aesthetic surgery. Plast Reconstr Surg 2004; 113:1229-1237.

30. Schofield M, Hussain R, Loxton D, Miller Z. Psychosocial and health behavioural covariates of aesthetic surgery: Women's Health Australia study. J Health Psychol 2002;7:445-447.

31. Brunton G, Paraskeva N, Caird J, Bird KS, Kavanagh J, Kwan I et al. Psychosocial predictors, assessment, and outcomes of aesthetic procedures: a systematic rapid evidence assessment. Aesthetic Plast Surg 2014;38(5):1030-1040.

32. Crerand CE, Franklin ME, Sarwer DB. Patient safety and body dysmorphic disorder in aesthetic surgery patients. Plast Reconstr Surg 2008;122:1-15.

33. Sarwer DB, Pruzinsky T, Cash TF, Goldwyn RM, Persing JA, Whitaker LA (2006). Psychological aspects of reconstructive and aesthetic plastic surgery. Lippincott Williams \& Wilkins: Philadelphia; pp:267-283.

34. Gorney M, Martello J. Patient selection criteria. Clin Plast Surg 1999; 26:37-40.

35. Gorney M. Mirror, mirror on the wall: the interface between illusion and reality in aesthetic surgery. Facial Plast Surg Clin North Am 2008;16: 203-205.

36. https://baaps.org.uk/media/press_releases/29/the bust_boom_busts

37. Henderson-King D, Henderson-King E. Acceptance of aesthetic surgery: scale development and validation. Body Image 2005; 2: 137-149.

38. Mulkens S, Bos AE, Uleman R, Muris P, Mayer B, Velthuis P. Psychopathology symptoms in a sample of female aesthetic surgery patients. J Plast Reconstr Aesthet Surg 2012; 65: 321-327.

39. Naami A, Salehi HM. Prediction of aesthetic surgery tendency based on mindfulness, personality dimensions, perfectionism and mental health components. Int J Sch Health 2016;3:e32746.

\section{Correspondence}

Laura Gheucă Solovăstru,

M.D., Ph. D., Professor, Department of Dermatology, Faculty of Medicine, "Grigore T. Popa"

University of Medicine and Pharmacy Iasi, Romania

Adress: Dermatology Clinic County Emergency Hospital “St. Spiridon”, Bd. Independenței no. 1, Iasi, Romania, lsolovastru13@yahoo.com

Submission: 10may2021

Acceptance: 27 jul2021 



\section{BPI ${ }^{\text {Bulletetin of Integrative }}$ \\ Psychiatry \\ Buletin de Rihistrie Integratiod}

Humanistic

Contributions 



\title{
Artificial intelligence, transhumanism and translation as a universal property of thinking
}

\author{
Miroslava Metleaeva (Luchianchicova)
}

Miroslava Metleaeva (Luchianchicova) - Doctor of Philology, Researcher Institute of Romanian Philology "Bogdan Petriceicu-Hasdeu", Republic of Moldova

\begin{abstract}
Transhumanism assumes human improvement as an unfinished link in evolution based on its fusion with technological elements. The new human-machine organism, from the author's point of view, is a dubious boon for human civilization and the planetary ecological system. This idea is, first of all, anachronistic and pursues the main goal - the singularity, i.e. control over human intellectual energy by technology. Cognitive activity and one of its most difficult aspects - translation of thought into linguistic form - represent an obstacle to the creation of perfect Artificial Intelligence, since translation is not limited to formulas. The accuracy of terminology and the absence of ambiguity of the word are the basis of Artificial Intelligence and, at the same time, the limitation of the development of linguistic thinking. The article outlines the sequence of the translation process, the difference between the mental operations of Artificial Intelligence and humans. The author assumes that translation is a universal property of human thinking, and the process of translating thought into speech form is due to bio-genetic, emotional, socio-historical memory and experience, since a person translates his thought from a fuzzy, vague thought-text into a linguistic form.
\end{abstract}

\section{KEYWORDS:}

Transhumanism, man-machine, singularity, Artificial Intelligence, translation process, memory, experience.

\section{INTRODUCTION}

Transhumanism is an evolving trend in philosophy that has become increasingly important in understanding the phenomena of the main aspects of social life taking into consideration the future. It would seem that the main goals of transhumanism - the constant improvement of man as an unfinished link of evolution on the basis of scientific and technical discoveries and new technologies that can bring a person to a new, previously unattainable level, have good 
ryor

intentions. However, while at the end of the 20th century this direction was perceived by futurologists positively as a whole, over time the assessment of the ideas of transhumanism began to become clearly ambiguous. Opponents of this line of philosophical thought have come to the conclusion that the realization of ideas of transhumanism will undermine the traditional values of humanism in all spheres of human existence, developed by millennia of human history.

Mark O'Connell, author of the book "To be a machine: Adventures among cyborgs, utopians, hackers, and the futurists solving the modest problem of death" demonstrates that in spite of all its aspiration for the future, transhumanism has the paradoxical power of its anachronism. In the future, where transhumanism is eagerly striving, it will always still look back into the past" (1).

Without delving into the origins of the emergence of transhumanist ideas in their modern understanding, one should nevertheless turn to the teachings of Ludwig Feuerbach with his thesis that man created God in his own image and likeness.

Feuerbach clearly traces the ideas of collective consciousness and the conclusion that the human community can never achieve perfection and happiness, provided there are individuals in it (2, p. 82).

Kai-Fu Lee, a renowned Chinese scientist in the field of modern technology, emphasizes that one can be optimistic in the development of Artificial Intelligence only by remembering the responsibility in this area. As an example of the technocratic direction of transhumanism, he cites the ideas of Ray Kurzweil, the inventor and the largest ideologue of GOOGLE, who believes that in the future, people and machines will merge together. "According to him, people will... constantly renew body tissues with the help of nanorobots injected into the bloodstream. Kurzweil predicts that by 2029 we will get computers with intelligence comparable to human, and the singularity point will be reached by $2045 "$ (3, p. 144).

Singularity as a term means the superiority of machine intelligence over the human person who created it. However, with all the cybernetic improvements of the intellectual creature with the inclusion of a truncated biostructure (mainly brain structures), its modifiers - the technocratic elite - pursue the main goal - managing intellectual energy within the strict framework of the technology.

That is, the question of power is again raised: there is a return to the old ideas of the creation of human, starting with the creation of Adam, continuing with the Golem, and then with Frankenstein (we will not mention all the automata imitating a person, which the great Leonardo da Vinci did) right down to the ideas the theoretical founder of transhumanism Ludwig Feuerbach and the earlier Thomas Hobbes. Hobbes argued that order in society can be achieved only through the conclusion of an agreement between citizens and the state, to which each citizen cedes his power, receiving in return the protection of life and property (1, p. 132).

The question is what is the relation of translation, as one of the types of human activity, to pressing philosophical problems, including transhumanism?

European organization COST - European Cooperation in Science \& Technologies has developed a project with three strategic priorities: the promotion and dissemination of best practices, the development of interdisciplinary research for breakthroughs in 
science and the empowerment of attracting young researchers and innovators. COST fulfills its mission by funding upstream, excellence-oriented, open and inclusive networks for peaceful purposes in all areas of science and technology.

In a document which was sent to the Institute of Romanian Philology "Bogdan PetriceicuHasdeu" by the Ministry of Education, Culture and Research of the Republic of Moldova in order to attract employees who want to join the participants of the COST project in the direction chosen by the applicant, I was interested in the direction CA19102 Language in the Human-Machine Era (pag.4): "Within the next 10 years, many millions of people will be ... wearing relatively unobtrusive ... devices that offer an immersive and high-resolution view of a visually augmented world". This is the 'human-machine era', a time when our senses are not just supplemented by handheld mobile devices, but thoroughly augmented. The language we see, hear and produce will be mediated in real time by technology. This has major implications for language use, and ultimately language itself. Are linguists ready for this? Can our theory, methods, and epistemology handle it?" (4).

To some extent, the project developers identified the ethical consequences of the emergence of the language of technology: inequality of access to technology, confidentiality and security problems, new vectors for deception and crime, etc.

We list the areas of expertise in the scientific field related to the topic of our article languages and literature: translation and interpretation; tongue; Artificial Intelligence; human machine; interfaces, etc. COST project prioritizes languages and literature, translation and interpretation.
Translation, with all its antiquity and with all its significance in most spheres of human activity, continues to remain terra incognita in many of its aspects. The post-war information boom which led to significant changes in translation activities, as well as an interdisciplinary approach to the problems of linguistics, raised the issues of extralinguistic aspects of verbal communication, made possible the further development of the science of translation. Humboldt's theory of the impossibility of an adequate translation reflected the philosophical idea of the unattainability of perfection. It received a tangible blow, since linguistic factors give rise not only to difficulties for translation, but also conditions for overcoming them: "Regardless of the validity of one or another hypothesis, the presence of essential universal features in all languages is beyond doubt. This universality, of course, is an important prerequisite for a successful transition from one language to another in the process of translation " $(5$, p.17).

\section{OBJECTIVES}

Translation, like an X-ray, reveals the words hidden behind the clothes. From our point of view, what is being translated, namely, the author's literary text, is a separate stable mega-unit, i.e. a huge unchangeable combination of words united by the author's idea. The author's literary text, is a stable semantic mega-combination of words. With all the achievements of modern translation in the field of professional and technical translation, there are still gaps in the theory of literary translation. The fact that only "input" and "output" data are available to real observation and scientific analysis, and the intellectual process of translation transformation itself occurs secretly, in the most complex psycholinguistic energy nodes of the translator's brain activity, turns the theory of translation into a comparative 
r.m\%\%

discipline. All conclusions about the translation mechanism are made on the basis of a comparison of the initial and effective data. The data for comparison are works - the original (author's) and final (translation result).

Schematically, the explicit sequence of the translation process is a double logical semantic chain, where the external level is an emotional manifestation $\rightarrow$ determining the originality of the source text $\rightarrow$ establishing a key lexical sign; and the internal (psychophysical) level is pondering / spiritual attitude $\rightarrow$ the cognitive system $\rightarrow$ conflict at the intercultural level $\rightarrow$ establishing the interaction of the author/ translator. These two sides of the process are combined in the inter - and extra steps of compiling a comment, the result of which is the selection and reproduction of an adequate idiolectic key sign.

We have before us two sources of knowledge: objects of the external world and the activity of our own mind. External feelings are sent to the first, as a result of which impressions (ideas) about external things are obtained. As for the second source of knowledge, and it includes thinking, doubt, faith, reasoning, cognition and desires, it is known by a special inner feeling - reflection. Thus, a mental reaction can occur on two levels: a) perception, thought, desire; b) observation, contemplation of these ideas, thoughts and desires (6, p.257).

\section{MATERIAL AND METHODS}

In my research on the interpretation of translations of the world literature masterpiece of the poem "Luceafer" by the Romanian poet Mihai Eminescu into Russian, I place an emphasis on the introspective study of my own thought processes that occurred during the translation activity. For all its subjectivity, the "introspection method" is considered one of the basic methods of language research. Linguistic intuition is characteristic to one degree or another of all users of the language. These abilities are examples of the manifestation of selfobservation, which allows a person to be directly aware of certain aspects of the language. However, we do not absolutize this method, but use it in combination with others, using different approaches to the problems of translating poetry in our work. Reflections of writers and translators about the process of converting thought into linguistic form coincide with our observations.

\section{DISCUSSIONS}

When translating, our main goal was to semantically convey the author's idea with maximum fidelity to the artistic features of the original. The whole difficulty was that we had a linear text in front of us, and we had to convey the bulk of the idea to the target language without departing from the text. There was a risk awaiting each translator to become a "slave" to the visible, linear part of the content.

When translating, our main goal was to semantically convey the author's idea with maximum fidelity to the artistic features of the original. The whole difficulty was that we had a linear text in front of us, and we had to convey the bulk of the idea to the target language without departing from the text. There was a risk awaiting each translator to become a slave the visible, linear part of the content.

The transfer of the volume of an idea depends on the volumetric understanding by the translator of its meaning and its ability to identify nicks that are the key to opening doors to non-textual (subtext, intertext, intratext, etc.) associative space. 
All these elements of creative manifestations are an integral part of the mental activity of the translator of fiction (I emphasize, fiction), inextricably linked with the imagination. This mental activity is a field of collision of critical thinking, directed both at other people's judgments and at the translator's own judgments. This field of creative thinking is associated with generating your own ideas and evaluating the ideas of the author of the original text.

In psycholinguistics, there is the concept of a precedent text, that is, a text that is known to culture and to which there are references in speech. A reference may not be transformed and transformed, up to a single component - a word, increasing the semantic load of the text, and activates the reader (in our case, the translator).

There is not a single writer in any of the epochs who began to engage in creativity from scratch: consciously or subconsciously, he has concentrated sufficient national and world literary experience, which M. M. Bakhtin called the "memory of literature". In a broader sense, this memory can be identified with the previous experience.

Bogdan Giu, commenting translation activities, concludes: "We do not do it in different ways and, to a different degree, do nothing but translate, we initially translate. We do what changes everything. Or, more precisely: it can change everything ..." ( 7 , p.2).

He brings us to a very important conclusion: the authors are the first translators and that translation begins much earlier than interlinguistic translation itself, when an attempt is made to recreate the text of one language within the framework of another, that is, an attempt to transfer it from one linguistic space into the bizarre structures of another language.

If we approach the problem of translation more broadly, then we come to the conclusion that translation is a universal property of human thinking. Before we put thought into speech form, a process takes place in the mind, the sequence of which, in our opinion, is as follows: amorphous thought-form> thought-idea> thought-text> translation (transmission) into the source language for communicative exchange.

At this stage, we can talk about decodification, interpretation, translation of the "language" of the author's thinking by the author himself to reproduce what he wants to convey to the receptor (reader). Reflections on the creative act of transforming the way of thinking into verbal reflection, i.e., on translating inspiration into linguistic parameters, is an object of interest not only to psychology and philosophy, but also to the creators of literary texts themselves. This was very clearly expressed in his poem "Silentium" by the Russian poet F. Tyutchev "The thought uttered is a lie".

V.D. Psurtsev dwells on the aspect of sense formation (both in generation and in perception), noting that "the specificity of a literary text (...) lies in the fundamental absence of its creator and its interpreter of the installation of" simple evidence ", the onedimensionality of meaning. (Therefore, the antipode of the literary text will be a text that does not have such an attitude)" (8, p. 251252).

In this regard, the role of figurativeassociative components becomes an additional criterion. It is figuratively associative components that stylistically mark the literary text. It should also be noted a very 


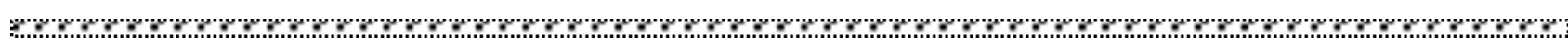

significant remark by V.D. Psurtsev, which is directly related to the translation: “(...) the text of the original and the text of the translation (...) are linear in their presence, while the concept and meaning are voluminous" $(8, \mathrm{p}$. 255)

Artificial Intelligence is not able to cope with the tasks that the author faces when transforming his own thought-text from an amorphous thought-form into his native language. Likewise, no machine can cope with the tasks of translating a literary source text into a target language. The transmission of the author's volumetric thought is associated with the codes of both the source and target languages. This decoding depends on the thinking of the translator and all psychosocial and other components of the environment of both participants in the translation process.

"Social influence is ubiquitous. It is carried out everywhere and always. This is a part of the structure of the world "( 9, p.15). One of the founders of social psychology, Kurt Lewin, gave us a long time ago a simple equation: "behavior is a function of two variables - the unique personality of the individual and the situation in which he or she acts." (9, p.51).

It is impossible for both the writer and the translator to distance themselves from this, despite the recognition of their individuality in the sphere of influence, are still under the influence of a second, no less significant component of influence - the power of the situation, the power of the temporal environment.

In the philosophy of postmodernism, the phenomenon of the power of language is widely analyzed. According to the concept of R. Bart, theoretically only two alternative variants of the correlation of power and language are possible: the cooperation of language with the government and its opposition to it - linguistic neutrality with respect to power, according to $\mathrm{R}$. Bart, is in principle impossible, "some languages speak out, develop, get their characteristic features in the light (or under the shelter) of the Authority ... Other languages are developed, acquired, armed outside the Authority and / or against it "(10). In the terminology of R. Barth, the languages of the first type are designated as "enkratic languages" (which correspond to "enkratic types of discourse"), the languages of the second type are referred to as "acratic" (and, respectively, "acratic types of discourse") (11).

Translation and interpretation are inseparable, and the influence of external factors on translation activity is widespread, as evidenced by numerous examples of inadequate translations created under the pressure of socio-historical factors of a particular era.

In this regard, Skopos theory, put forward in 1984 by German scientists Katharina Rice (K. Reiss) and Hans Vermeer (H. Vermeer) in the work "Grundlegungeiner allgemeinen Translationstheorie" (12), gained quite wide popularity. The authors proceed from the fact that the parameters of the translation are determined by the needs and requests of the reader-customer, that is, the purpose of the translation is the intended recipient, and the translator is free to either reproduce the original, or deviate from it, or completely neglect it, not particularly paying attention to linguistic subtleties. In fact, this theory claims to be the scientific justification for targeted translation.

From our point of view, this is one of the steps to mastering the thought process if it is 
impossible to reproduce it in full in an artificial version of the brain-machine. That is, if it is impossible to control thought processes from the inside, then it is much easier to influence them from the outside.

R. Bart noted: "Incidentally, the encratic language (that which arises and spreads under the protection of power) is by its very nature a language of repetition; all official linguistic institutions are machines that constantly chew the same gum: school, sports, advertising, mass culture, song production, media nonstop reproduce the same structure, the same meaning, and sometimes the same the same words: a stereotype is a political phenomenon, it is the very embodiment of ideology " (Quoted from the Russian translation by G.K. Kosikov, 13, p.494).

Thinking stereotypes narrow the horizons of consciousness, imposing automatic algorithms, and suppress individual thinking. When translating a text into a target language for Skopos theory, the degree of its correspondence to the original is insignificant if it meets a specific goal. Before us is not a theory of translation, but a theory of text alteration, a theory of its commercialization on the world market.

These ideas have long been reflected in the works of world literature. A harsh formulation of this phenomenon, inherent in the coming "society of technological ideas", which destroyed the absurdity of the "consumer society" and leads to a complete absence of freedom, was formulated in 1948 by George Orwell in his prophetic anti-utopia "1984":

"The purpose of Newspeak was not only to provide a medium of expression for the world-view and mental habits proper to the devotees of Ingsoc, but to make all other modes of thought impossible... Newspeak was designed not to extend but to DIMINISH the range of thought, and this purpose was indirectly assisted by cutting the choice of words down to a minimum" (14, p.376-377). And then follows: "Pre-revolutionary literature could only be subjected to ideological translation - that is, alteration in sense as well as language (14, p.391)

In the coming Oceania, the emotional and cognitive side of life is reduced to a minimum: books are written on machines, knowledge of foreign languages is prohibited for the majority. Here the doctrine of the "moving past" operates, according to which memory is criminal when it is true to the truth, and the past does not exist, minus the way it is constructed at the moment. Reality quite often coincided with the predictions of seer authors. So "Translation activities in the Republic of Moldova, like all activities, were limited until 1991. ... The study of foreign languages and the functioning of the relevant areas (teaching, translation, etc.) were under constant control (...), because related to activities that could have a great ideological impact on individual groups or society as a whole (...). Due to censorship, Moldavian journalists had to write their articles in Russian at first, and only then the text was translated into "Moldavian". (16 15, p.24).

The fate of Alexander Robot (Alter Rotman, 1916 - 1941), a Romanian writer and avantgarde poet, journalist and literary critic, whose work was especially influenced by the encratic language, is also very indicative. In the work of A. Robot, whose poetry in the 30s was perceived by his contemporaries as extremely experimental and to which such outstanding figures of literature and culture as G. Calinescu, E. Lovinescu, Perpessicius and others, there is a creative degradation associated with severe historical conditions of 
r.\%\%

the Soviet regime, where he finds himself, seeing no other salvation from fascism. His brilliant work of the early 30s. The twentieth century, under the conditions of the literary dominant - socialist realism, underwent cardinal changes that marked the victory of ideological pressure over the fate of the artist. Enormous talent has been brought to a common and anonymous denominator. For comparison, here are two lines from famous poems: a). A flower is like a butterfly. / And I found myself, like in a seine, in the net of the day (Landscape, 1932); b). Here is the first Soviet collective farm spring. / And, crossing the steppe, the Dniester blooms (Blossoming Moldova, 1940) (16).

To translate, as noted by M. Leclerc-Olive, means an attempt to "avoid the imposed normativity" of concepts, i.e. create, feel, feel the need for a certain local re"conceptualization" All transhumanist trends pursue a single goal - the creation of a person devoid of physical disabilities. But practically none of the founders of these philosophical concepts raises the question of the place of emotions, morality, culture in the consciousness of the future person.

The fact is that they are simply not there: the posthuman is represented by the highest biotechnological species. Artificial intelligence will become the basis of his consciousness. Thus, general human concepts about good and evil, about human history, about relationships with his own kind will not have any meaning for the man-machine. He will lose a huge part of the all-round previous experience unnecessary for him.

It should be noted that "creative imagination often acts as temporarily fulfilling the duties of logical thinking. ... In the strict sense, logical thinking is possible when there is enough information or it can be obtained in a logical way. And if they are few and impossible to obtain, creative intuition and imagination help by creating missing links and linking facts into the system " $(6$, p. 106) until real facts and connections between them are found, confirming or refuting the work of the imagination. "This role of creative imagination is not the same in various fields of activity: for example, its role in scientific research is somewhat less than in literary creativity" $(6$, p. 106).

The process of literary translation, based on the recreational imagination of the translator, is a vivid embodiment of creativity. "A person has never come down to a character that could be covered with an acceptable simplification as a whole. This is the vain dream of many. As soon as he was understood in its simplest aspect, how a person is affirmed again in his usual complexity "(17, p. 596).

It is strange to expect from a machine artificial intelligence that it will think like a person or will be guided by the same morality as homo sapiens.

If we return to the thesis of $\mathrm{B}$. Ghiu and assume that all of us (including ordinary citizens) are constantly engaged in nothing more than translation, i.e. this property is inherent in all people, it is natural that in the process of communication (we are social creatures) in the minds of everyone, to one degree or another, the same processes occur as the author of an idea or a professional translator who transforms their thoughts into linguistic semantic forms. That is, when we say that the translation process at its internal stage is a very complex psychophysical system, completely different for each homo sapiens, with many parameters common, we also mean that this is one of the most powerful properties of its survival. In 
connection with the division of labor, the emergence of professional languages and the complexity of the social hierarchy, an encratic language, which has much in common with the practical manifestations of transhumanism in its aspirations for Artificial Intelligence, has acquired special significance in enhancing the impact on mass consciousness.

The bulk of the idea is not for transhumanism, because with all the desire it is impossible to create such an Artificial Intelligence that would include all the natural and unpredictable intellectual identity of mankind. Therefore, Perfect Artificial Intelligence can unify only certain stages of the transfer of the thought process into a visible and auditory form for the technical improvement of a cybernetic device with the human organic system (or what remains of it).

Technical thinking as an applied part of unpredictable volumetric thinking inherent in a certain high-tech caste of professionals has a tendency to streamline, systematize and regulate. The same applies to the scientific and technical spheres of the language that do not tolerate synonymization, i.e. variety. The incapacity for multidimensional perception of reality inevitably turns into the indifference of technocrats, and such indifference is a demonstration of the absence of humanitarian tools of difference.

The bearers of a technocratic language - an applied language that does not contain emotional, psychological, ethnic, ethical, etc. content, most often are the support of power, interested in the mechanistic curb of consciousness and the approach of an ordinary person to the machine by accustoming the latter to the idea of the benefits of its improvement with the help of technologies that allow to overtake natural thinking and other abilities. Most often, examples are given of the ability of modern computers to beat a person in chess or in the Chinese game GO with countless combinations. Hence the attempts to reduce everything (from socioeconomic interests) to a universal language of numbers, which does not contain emotional, moral and cultural and historical components. But human existence is not limited to games, no matter how complex they may be. They are, first of all, regulated games. One way or another, the solution to game problems can be calculated with the help of AlphaGo, programmed by a human.

Mark O'Connell emphasizes that transhumanists, no matter how rational they think they are, cannot inspire confidence or sympathy with their humanitarian limitations, and living in their future is very problematic, since they do not have a concept of life in its usual sense.

However, O'Connell feels this future in modern reality, because not always sure if he lives in the present.

Working with a computer, we noted the manifestation of a certain dependence on it in everyday intellectual work. And this concerns translation, above all. Modern machine translation is unsuitable for transporting figurative text to another language environment. However, there is an easy opportunity to transform figurative text into its opposite. You can verify this by resorting to the GOOGLE translator. There are real prerequisites for a satisfactory translation of technical, scientific, professional texts, that is, those for which polysemy is contraindicated. The higher the terminological and structural accuracy (with the absence of figurative and emotional features), which also has an international character, the higher the quality of the machine translation, because it does not 


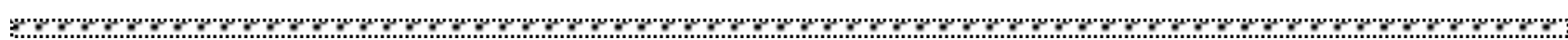

require from the machine what it cannot do to be human in every sense of the word.

So, when urgently translating our own text into another language, resorting to the help of a computer, quite deliberately (in which we gave a report in the subsequent introspective observation of our own translation process), we tried to formulate our thought lexically, grammatically and stylistically as neutral as possible adjusting to the algorithm of the machine. That is, we deliberately went "towards the machine", depriving ourselves of the possibility of figurative transmission of a message in order to facilitate our work.

When it comes to translating an unambiguous thought-text, such an approach to translating its meaning both in the source and in the target language is necessary, but if we are talking about a message that has precedent and other figurative aspects, then following the efficacy of the work, we lose in artistic expressiveness, and if we go further, then in the possibilities of creative self-expression and the development of the language as a whole.

Realizing that the whole complex of recognition and decoding of human communicative ability is inaccessible to the machine, now, without thinking about the consequences, being guided by pragmatics and going towards artificial intelligence, the computer user automatically goes to personal rapprochement with the machine and the irreplaceable loss of the natural course of translation of the thought-text, to its simplification of their own intellectual capabilities.

The process will go further due to the initially inherent tendency of a person to make his life easier, guided by socio-economic goals and pushing aside the emotional and ethical nuances. By reducing the amount of creative thought, the user follows the lead of its linear reproduction according to the imposed patterns of machine thinking. This is how the user's "education" is gradually imposed and carried out. So, it's not the victory of Artificial Intelligence, but the defeat of the human in pursuit of the illusion of its own improvement. For, by reducing our more time-consuming, but immeasurably wider creative opportunities for the sake of actualizing immediate tasks, we contribute to the loss of many skills and abilities.

Perversions in consciousness arise from satiety. One of the most ancient and most dangerous is the desire to create technologies for controlling human consciousness in the name of a very banal desire - unlimited power over their own kind, in the name of a pyramidal hierarchy with the so-called "superintelligence" at its top. While extolling science, current transhumanists primarily extol its applied results, ignoring fundamental sciences.

All that the encratic social system expects from us is the reduction of linguistic communication to the language of formulas and numbers. Freeing ourselves from the associative series, the precedence of thinking, etc., we lose huge layers of human experience, the empirical part of ourselves, and as a result, there remains the encratic language and the rudiments of a truncated biological nature that responds to electronic signals. It is becoming more and more obvious that it is easier to track individual mental activity using a machine than to create a Perfect Artificial Intelligence.

The history of transhumanism testifies to its mechanistic view of human life, namely that a person is a device, his duty is to become the best versions of himself, that is, transhumanism is a liberation movement that 
matter: an equivalent opposite interpretation, according to which such an apparent liberation is nothing more than a final and

\section{CONCLUSIONS}

A technical or specialized text differs from an artistic one by its one-dimensionality of meaning. Translation of such a text is available to Artificial Intelligence.

When translating artistic text, there is a significant difference between the mental operations of the translator and Artificial Intelligence. The process of translating creative thought into a speech form is due to numerous factors, namely: figurative and associative elements, psychosocial components, biological, genetic, emotional and historical memory, as well as culture and experience. The whole complex of recognition and decoding of human communication skills is inaccessible to a machine, that is, to Artificial Intelligence.

From our point of view, literary translation is an interdisciplinary activity. The science of it, as a study on the transformation of the figurative-emotional reflection of the world into a linguistic form, should become an independent part of the general theory of translation.

\section{ACKNOWLEDGEMENTS AND DISCLOSURES}

The author state that there is no declared conflicts of interest regarding this paper.

\section{REFERENCES}

1. Mark O'Connell. Artificial intelligence and the future of humanity. Moscow: Eksmo, 2019.

2. A.I. Korsakov. Religion and Science in the Works of the Founder of the First Positivism. In: Bulletin of PSTGU.

Series I: Theology. Philosophy. Issue 2 (40).Moscow, 2012.

3. Kai-Fu Lee. AI Superpowers. China, Silicon valley, and the new worlds order. Houghton Mifflin Harcourt.- Boston, New York, 2018.

4. www.cost.eu/cost-action/language-in-the-human-machine-era/

5. V.N. Komissarov Translation as an object of linguistic research. In: Problems of translation interpretation of the text in the works of Russian linguists of the late 20th, early 21st centuries. Yerevan: Lingua, 2009.

6. Yu. Golovin. Practical Psychologist Dictionary.2nd ed., Rev. and add. Minsk: Harvest, Moscow: AST, 2001.

7. Bogdan Ghiu. Europa este traducere. Interviu consemnat de Matei Martin. Dilema veche. 2015, nr. 586, p. 7-13.

8. V.D. Psurtsev. On the problem of translation and interpretation of a literary text: on one criterion of adequacy. In:

Problems of translation interpretation of the text in the works of Russian linguists of the late 20th, early $21 \mathrm{st}$

centuries.Yerevan: Lingua.

9. Philip Zimbardo, Michael Leippe. Social impact. - SPb. Ed. "Peter", 2000.

10. Le Conferenze dell'Associazione Culturale Italiana, 1973 B: Roland Barthes. Le bruissement de la langue P Seuil, 1984.

11. http://yanko.lib.ru/books/cultur/bart-all.htm

12. Katharina Reiss. Classification of texts and methods of translation. In: Questions of the theory of translation in foreign linguistics. Moscow, 1978.

13. Roland Barthes. Selected works. Semiotics. Poetics. Moscow: Progress, 1989.

14. George Orwell "1984”, pdf, 393 p. Free eBooks at Planet eBook.com 
120/Bulletin of Integrative Psychiatry ONew Series OSeptember 2021 O Year XXVII ONo. 3(90)

(1)

15. Irina Condrea. Traducerea din perspectivă semiotică. Chişinău: Cartdidact, 2006.

16. Alexandru Robot. Scrieri. Poezie. Proză. Publicistică. Eseu. Chișinău: Știința, 2018.

17. Fernand Braudel. Structures of everyday life: the possible and the impossible. T.I, Moscow Progress, 1986.

\section{Correspondence \\ Miroslava Metleaeva (Luchianchicova),}

PhD Philology, Researcher Institute of Romanian Philology "Bogdan PetriceicuHasdeu", Chișinău, Republic of Moldova, metleaevaslava@mail.ru

Submission: 14 may 2021

Acceptance: 22 aug 2021 


\title{
The hypocrisy - changing the vices into virtues
}

\author{
Iosif Tamaș
}

Iosif Tamaş - PhD, researcher, Institute of Interdisciplinary Research, Departament of Social Sciences and Humanities, Alexandru Ioan Cuza University of Iași

\begin{abstract}
This article focuses on identifying and presenting the roots and consequences of hypocrisy within the hidden pathological features of the human being. Hypocrisy belongs to the hypocrite, that is, to the individual in his ontic integrity as an immortal body, spirit, and soul. In this respect this scientific discourse has its place within the religious space as well, at the spiritual level of the perfect process of creation, where the new spiritual individual is always active; At the empirical, scientific and material level of the human activity there is only the ideological individual, proficient or not, just like in the unfortunate case of the priest sacerdos in aeternum who became professor after he jumped the fence of the house and he got into the yard of the University, with the passport in his pocket of course. We will approach the subject strictly through the paradigm of the theological-philosophical discourse, framed by the constitutive horizon of moral philosophy (philosophical ethics), which is defined as the second strand of bioethics as a modern science, according to the traditional medical ethics (1). Within this paper we will look at the following points: the formalism of religious hypocrisy; the blindness of the hypocrite as a pathological manifestation and finally about the availability as a permanent risk of hypocrisy.
\end{abstract}

\section{KEYWORDS:}

Vice, virtue, disease, [our] faith, pride.

\section{INTRODUCTION}

Being a mistake against reason, truth, a violation of a commandment, sin was called by St. Augustine "a word, deed, or desire contrary to eternal law," to the point of selflove and contempt for God (2). This is how the wise prophets once said: „Domnul zice:
„Pentru că poporul acesta se apropie de mine cu gura şi mă preamăreşte cu buzele, dar inima lui este departe de mine, iar teama de mine este o poruncă învăţată de la oameni, de aceea, voi face din nou fapte minunate pentru acest popor, va pieri înţelepciunea celor inţelepţi şi priceperea celor pricepuţi va 
122/Bulletin of Integrative Psychiatry ONew Series O September 2021 O Year XXVII ONo. 3(90)

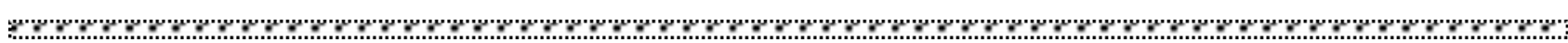

dispărea. Vai de cei care-şi ascund planul departe de Domnul, iar faptele lor sunt în intuneric şi zic: "Cine ne vede şi cine ne cunoaşte?»!" (Is 29, 13-15), [“The Lord says: "For this people draweth nigh unto me with their mouth, and honoureth me with their lips; but their heart is far from me, and their fear is a commandment learned from men, therefore I will do wonders for this people again, and the wisdom of the wise shall perish, and the understanding of the prudent shall depart. Woe unto them that seek deep to hide their counsel from the Lord, and their works are in the dark, and I say, 'Who seeth us, and who knoweth us?"'(Is 29, 13-15)], (3). Thus, it is Jesus of Nazareth who will identify and reveal the roots and pathological consequences of hypocrisy. According to his principle that the healthy do not need a doctor, Jesus turned to those who represented the verticality of the spiritual life of his time, to those who at that time took the "intelligence" (4) of the time, in a word to the teachers of the law, the scholars and hypocrites. The central idea emphasized by Jesus was that the facts did not express the intention, the causality of the actions determining the results: the blind man unable to see the light rises as a guide. Being aware that they were blind, they deceived themselves out of a perverse desire to deceive others. Here is the edifying passage: „Vai vouă, cărturarilor şi fariseilor ipocriţi! Voi daţi zeciuială din mentă, din mărar şi din chimion, dar lăsaţi la o parte ce este mai greu din Lege: judecata, indurarea, credinţa.
Acestea trebuia să le faceţi, iar pe acelea să nu le neglijaţi! Călăuze oarbe! Voi strecuraţi ţânţarul, dar înghiţiţi cămila. Vai vouă, cărturarilor şi fariseilor ipocriţi! Voi curăţaţi exteriorul paharului şi al farfuriei, dar în interior sunt pline de jaf şi necumpătare. Fariseu orb! Curăţă mai întâi interiorul paharului ca să devină curat şi exteriorul lui." ["Woe unto you, scribes and Pharisees, hypocrites! You tithe mint, dill, and cumin, but set aside the heaviest part of the law: judgment, mercy, faith. You had to do these, and don't neglect those! Blind guides! You sneak in the mosquito, but swallow the camel. Woe unto you, scribes and Pharisees, hypocrites! You clean the outside of the glass and the plate, but inside they are full of robbery and intemperance. Blind Pharisee! First clean the inside of the glass to make it clean.”] (Mt. 23, 23-26). This is the starting point. Where did I end up today? According to our scientific opinion, it is more difficult today: our "intelligence" translates to us what Jesus meant!

\section{THE FORMALISM OF RELIGIOUS HYPOCRISY}

Religious hypocrisy is not just a lie; it is a case of psychiatric clinical study, because here we find ourselves in the field of the pyramid apex syndrome. The religious hypocrite deceives his neighbor to gain his esteem, with gestures, with folklore, with lyrical moments, with symposia, meetings, synods and councils, with congresses, be they 
Bulletin of Integrative Psychiatry $\bigcirc$ New Series OSeptember $2021 \bigcirc$ Year XXVII ONo. 3(90)/123

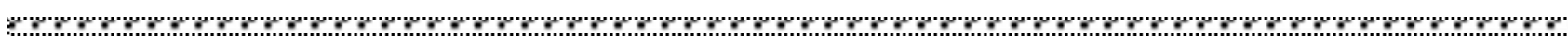

Eucharistic, whose intention is not at all simple, all bearing the confessional imprint. Only then will the non-Christian be able to say about Christians: this is how much they love each other! "Promoting the REBUILDING of UNITY among all Christians is one of the main goals of the holy Second Vatican Ecumenical Council" (5). The hypocrite, stirrer or propagandist, seems to act for God, when in fact, he acts only for himself or for the institution he represents. The formula of the cult of personality was abandoned and instead other formulas emerged, such as the citizen of honor, emeritus. The most recommended practices of Christian piety, prayer, fasting and almsgiving, are thus perverted by the concern "to be noticed", and the media abound with examples in this regard. ,Aşadar, când dai de pomană, nu trâmbiţa înaintea ta aşa cum fac ipocriţii în sinagogi şi în pieţe, ca să fie lăudaţi de oameni. Adevăr vă spun: şi-au primit răsplata. Iar când vă rugaţi, nu faceţi ca ipocriţii, pentru că lor le place să se roage stând în picioare în sinagogi şi la colţurile străzilor ca să se arate oamenilor! Adevăr vă spun: şi-au primit răsplata. Când postiţi, nu fiţi trişti ca ipocriţii, căci ei îşi schimonosesc fețele ca să arate oamenilor că postesc! Adevăr vă spun: şi-au primit răsplata. Toate faptele lor le fac pentru a fi văzuţi de oameni: îşi lărgesc filacterele şi îşi lungesc ciucurii." ["Therefore when thou doest thine alms, do not sound a trumpet before thee, as the hypocrites do in the synagogues and in the markets, that they may be praised of men. Truth be told: they have received their reward. And when thou prayest, thou shalt not be as the hypocrites are: for they love to pray standing in the synagogues and in the corners of the streets, that they may be seen of men. Truth be told: they have received their reward. When you fast, do not be as sad as hypocrites, for they twist their faces to show people that they are fasting! Truth be told: they have received their reward. They do all their deeds to be seen by men: they enlarge their phylacteries and lengthen their tassels."] (Mt $6,2.5 .16 ; 23.5)$. To put a barrier between the heart and the lips this education teaches man to hide evil intentions under a honeyed air, hence the nicknames Machiavellian, Jesuit. Such an episode occurred when a trap was laid under the cover of a legal question for Jesus: „Dar Isus, cunoscând răutatea lor, le-a zis: „Ipocriţilor, de ce mă ispitiţi? Arătaţi-mi moneda tributului!”. Iar ei i-au adus un dinár. El le-a zis: „Ale cui sunt imaginea aceasta şi inscriptia?”. I-au zis: „Ale Cezárului”. Atunci le-a zis: „Daţi-i, aşadar, Cezárului ceea ce este al Cezárului şi lui Dumnezeu ceea ce este al lui Dumnezeu!”. Când au auzit, au rămas uimiţi şi, lăsându-l, au plecat." ["But Jesus, knowing their wickedness, said to them," Why are you tempting the hypocrites? Show me the tribute coin! "And they brought him a penny. He said to them, "Whose is this image and inscription?" They said to him, "Caesar's." Then said he unto them, Render therefore 
unto Caesar the things which are Caesar's; and unto God the things that are God's. When they heard this, they were astonished, and went away from him.] (Mt 22, 18-23). Nothing new under the sun would say the Ecclesiastes [Book of Qohelét], we have heard the story: „Dar ei au zis: „Veniţi să facem planuri impotriva lui Ieremía! Căci legea nu va pieri din lipsă de preoţi, nici sfatul, din lipsă de inţelepţi şi nici cuvântul, din lipsă de profeţi. Haideţi să-l lovim cu limba şi să nu ţinem cont de niciunul dintre cuvintele sale!"." ["But they said, 'Come and make plans against Jeremiah! For the law shall not perish from the absence of priests, nor counsel from the wisdom of wise men, nor the word from the absence of prophets. Let us smite him with the tongue, and let him not regard any of his words."] (Ier 18, 18). Always determined to come out with a clean face and forehead up, he didn't eat garlic not even his mouth smells, the hypocrite knows how to position himself between precepts or to arrange them in an intelligent casuistry, shouting loudly: I have the answer, who has the question!? And so the sapiential dogmatists were the ones who explained to us how logical it is to believe. And so the mosquito could sneak in and swallow the camel, only then could the divine teachings return in the interest of greed and selfrestraint or group, since the lie has ISBN. We refer strictly to the rudeness of the Communist and religious confessional propagandistic ideology, which, wanting to mask the professional incompetence of each specific competence, of many newcomers, covered the personal "availability" with the institutional mask. How to consider the unqualified, proficient? Even then, the party security "invented the $I S B N$ " (6), and then the propaganda of insane hypocrites blessed and sanctified confessional television and radio stations. And the sad conclusion of the Savior who vibrates even today sends us back to the ancient wisdom: „Ipocriţilor! Bine a profeţit despre voi Isaía, când spune: «Acest popor mă cinsteşte cu buzele, însă inima lor este departe de mine. In zadar mă cinstesc propunând îvvăţături care sunt doar porunci ale oamenilor»" ["Hypocrites! Isaía prophesied well of you when she said, "This people honor me with their lips, but their heart is far from me. In vain do I honor myself by proposing teachings that are only the commandments of men.”] (Mt 15,7-9).

\section{THE BLINDNESS OF THE}

\section{HYPOCRITUS AS A PATHOLOGICAL MANIFESTATION}

Formalism can be treated and cured in the end, but hypocrisy with pathological manifestation certainly leads to stoning. Whitewashed graves end up swallowing everything that flies, everything that they crave, all the truth, all justice, to make others accept, to "believe". They consider themselves the pillars of justice: ,A spus această parabolă unora care se credeau în sine drepţi şi-i dispreţuiau pe alţii; Şi 
Bulletin of Integrative Psychiatry $\bigcirc$ New Series OSeptember 2021 Year XXVII ONo. 3(90)/125

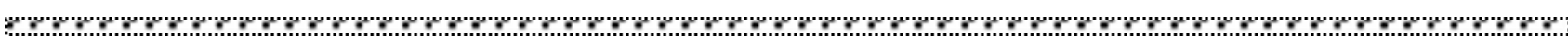

urmărindu-l cu atenţie, au trimis spioni care se prezentau ca fiind drepţi, ca să-l prindă cu vreun cuvânt şi să-l dea pe mâna autorităţii şi a puterii guvernatorului" ["He told this parable to some who believed themselves righteous and despised others; And they followed him closely, and sent spies, pretending to be righteous, to take him by the word, and deliver him into the hand of the governor and to the power of the governor"] (Lk 18:9; 20:20) and become opaque to any call to conversion. Theater actors, Oscar nominees (in Greek hypocrites), hypocritical Christians continue to play their part, especially as they occupy a higher rank and their word is heard. Here is the text: „Atunci Isus s-a adresat mulţimilor şi discipolilor săi, spunând: „Cărturarii şi fariseii s-au aşezat pe catedra lui Moise. Faceţi şi împliniţi tot ce vă spun ei, dar nu faceţi după faptele lor, pentru că ei spun, şi nu fac! " ["Then Jesus addressed his people and disciples, saying," The scribes and the Pharisees sat down on the throne of Moses. Do and do all that they tell you, but do not do according to their deeds, for they say, and do not!'] (Mt 23, 1-3s). Here we meet all those hypocritical propagandists, who from the height of the altars turn into electoral agents, throwing the seed of discord between the parishioners, increasing confusion and duplicity. What does it matter where the money comes from! But more serious is the fact that under the pressure of public opinion, those installed in the chair of Moses send reports about the institutional knowledge of the abominable deeds committed by those of their type. The pain and the will not to repeat the mistakes of the past that is not to put us in the situation of writing and presenting reports. We are the ones who demand guarantees! We are the ones who crush the broken reed, we extinguish the smoking wick! We were lied to! „Durerea este insoțită de o privire de speranță. Pentru ca aceste fenomene nu se mai repete, avem nevoie, pe lângă norme mai eficiente, de o convertire a inimilor. Este nevoie de păstori credibili, vestitori ai Evangheliei, și trebuie să fim cu toții conștienți că acest salt este posibil numai cu ajutorul harului Duhului Sfânt, încrezători fiind în cuvintele lui Isus: Fără mine, nimic nu puteți face" ["The pain is accompanied by a look of hope. Because these phenomena do not happen again, we need, in addition to more efficient rules, a conversion of hearts. We need credible pastors, heralds of the gospel, and we must all be aware that this leap is possible only with the grace of the Holy Spirit, trusting in the words of Jesus: Without me you can do nothing"] (7). Now we woke up from our dogmatic sleep, sorry! Exciting! It's the night of the mind! Brotherly correction is necessary, it is healthy. But here's the dilemma: how can the hypocrite take out the beam that prevents him from seeing, when it doesn't even cross his head, and he has no other concern than how to take out the straw that is in the neighbor's eye? „Sau cum vei spune fratelui tău: «Lasă-mă să 
scot paiul din ochiul tău» şi, iată, bârna este

în ochiul tău? pocritule, scoate mai intâi bârna din ochiul tău şi atunci vei vedea bine să scoţi paiul din ochiul fratelui tău” [“"Or how wilt thou say to thy brother, Let me pull out the mote out of thine eye; and, behold, a beam is in thine own eye? poor thing, take the beam out of your eye first, and then you will see to it that you take the straw out of your brother's eye."] (Mt 7: 4-5-5). Indeed, spiritual guides are necessary, but haven't they already taken God's place on earth when they replaced divine law with human traditions? Blind people who claim to lead others: Lăsați-i, ei sunt călăuze oarbe pentru orbi! Iar dacă un orb călăuzeşte un alt orb, amândoi cad în groapă" ["Leave them, they are blind guides for the blind! And if one blind man leads another blind man, they both fall into the pit"] (Mt 15:14) and their propaganda is nothing but a bad mound: ,IIn timp ce mulţimea se aduna cu miile, încât se călcau în picioare unii pe alţii, [Isus] a inceput să vorbească mai intâi discipolilor: „Feriţi-vă de aluatul fariseilor, care este ipocrizia, căci nu este nimic ascuns care nu va fi descoperit şi nici secret care nu va fi cunoscut! " ["While the multitude was in the thousands, so they trampled on one another, [Jesus] first began to speak to the disciples: "Beware of the leaven of the Pharisees, which is hypocrisy, for there is nothing hidden that will not be revealed and no secret that will not be known!'] ( $\mathrm{Lk} \mathrm{12,1-2).} \mathrm{This} \mathrm{is} \mathrm{the} \mathrm{state} \mathrm{of}$ the blind, the inability to recognize the signs of the times, that is, to reveal in Jesus of Nazareth the messenger of God. But the pride of the hypocrite has no limits and so he wants a sign from heaven: „Iar când bate vântul dinspre miazăzi, spuneţi că va fi cald şi aşa este. Ipocriţilor, aspectul pământului şi al cerului ştiţi să-l interpretaţi; dar de ce nu ştiţi să interpretaţi timpul de faţă?" ["And when the south wind blows, say that it will be warm and so it is. You hypocrites, you know how to interpret the appearance of the earth and the sky; but why do you not know how to interpret the present tense?"] (Lk 12: 55-56); blinded by his own wickedness, the hypocrite does not need the meekness and salvation brought by Jesus Christ and invokes the methodology, the law of the Sabbath, to keep him from doing good: „Atunci, Domnul $i$-a răspuns şi i-a zis: „Ipocriţilor! Nu-şi dezleagă fiecare dintre voi boul şi măgarul de la iesle şi-l duce la adăpat [chiar în zi de] sâmbătă? Şi această fiică a lui Abrahám, care era legată de Satana de optsprezece ani, nu trebuia să fie dezlegată în zi de sâmbătă?". ["Then the Lord answered and said to him," You hypocrites! Doesn't each of you untie his ox and the donkey from the manger and take it to the water [even on Saturday]? And this daughter of Abraham, who was bound to Satan for eighteen years, was not to be loosed on the Sabbath day?'] (Lk 13,15-16). The climax of the intrigue takes place the moment the hypocrite claims that Beelzebub is the instrument of Jesus' miracles, as if we were in the Harry Potter movie series: "But when the 
Bulletin of Integrative Psychiatry $\bigcirc$ New Series OSeptember 2021 Year XXVII ONo. 3(90)/127

\% \% \% \%

Pharisees heard it, they said, 'This fellow doth

not cast out devils, but by Beelzebub the chief of the devils'." (Mt 12,24). We are surprised, however, that they did not wonder if Jesus is a Freemason! But $\mathrm{He}$ is the prince of life, and in order to break down the gates of their hearts, Jesus will shame them before the community, exposing to them their hidden sin and decay: „Vai vouă, cărturarilor şi fariseilor ipocriţi! Voi zidiţi mormintele profeţilor şi impodobiţi monumentele drepților şi spuneţi: «Dacă eram în zilele părinţilor noştri, n-am fi fost complici cu ei la [vărsarea] sângelui profeţilor». Astfel, voi înşivă daţi mărturie împotriva voastră că sunteţi fiii celor ce au ucis profeții. Dar voi întreceţi măsura părinţilor voştri." ["Woe unto you, scribes and Pharisees, hypocrites! You build the tombs of the prophets and adorn the monuments of the righteous, and say, "If we were in the days of our fathers, we would not have been complicit with them in shedding the blood of the prophets." Thus testify against yourselves that you are the sons of those who killed the prophets. But you surpass your parents' measure."] (Mt 23,2932). And what is the end in the end? What we have to do? Here is the text: "But if that servant say in his heart, 'My lord delayeth his coming, he waits for the hour he does not know, he will punish him severely and make him one of the unbelievers." (Lk 12: 45-46). Let's wait full of zeal, wakefulness and confidence.

\section{THE AVAILABILITY AS A}

\section{PERMANENT RISK OF HYPOCRISY}

Let us not deceive ourselves and think that hypocrisy belonged only to the Pharisees of Jesus' day, and since then we have been immunized. No, the hypocrites have not disappeared. Of course, the synoptic tradition pushed the presumption of hypocrisy to all nations: „Apoi a spus mulţimilor:[...] Ipocriţilor [...]" ["Then he said to the multitudes, $[\ldots]$ to the hypocrites $[\ldots]$ ". $]$ ( $\mathrm{Lk}$ 12: 54-56). We understand the aspect, however maybe it was good for the Savior to make a statistic, a case study, a typology something; so St. John could no longer see through the Jews the unbelievers of all times. It is within everyone's reach to substantiate an ideology-philosophical-theological of opposites in society and to go with the sword through the world in the name of Jesus Christ. How? Has it already happened? Isn't the problem over? Who shouts, tolerance!? The Christian! It is said that either St. Peter did not escape this danger during the Antioch episode: „Dar, când a venit Chéfa la Antiohía, l-am înfruntat făţiş, căci era de condamnat. De fapt, inainte de a fi venit unii de la Iacób, stătea la masă cu păgânii, dar când au venit ei, s-a ferit şi a stat deoparte, temându-se de cei circumcişi. Împreună cu el au început să se poarte cu ipocrizie şi ceilalţi iudei, aşa încât şi Bárnaba a fost ademenit de ipocrizie. Dar când am văzut că ei nu merg drept, după adevărul evangheliei, i-am spus lui Chéfa în faţa tuturor: Dacă tu, care eşti 
128/Bulletin of Integrative Psychiatry ONew Series O September 2021 ○ Year XXVII ONo. 3(90)

r iudeu, te porţi ca un păgân şi nu trăieşti ca un addition we have extended ourselves with iudeu, cum îi poţi constrânge pe păgâni să trăiască asemenea iudeilor?" ["But when Chéfa came to Antioch, I openly confronted him, for he was to be condemned. In fact, before some came from Jacob, he sat at the table with the heathen, but when they came, he shunned and stood aside, fearing the circumcised. Along with him, the other Jews began to behave with hypocrisy, so that Barnabas was also seduced by hypocrisy. But when I saw that they did not walk uprightly, according to the truth of the gospel, I said to Chéfa in the presence of all: live like the Jews?"] (Gal 2: 11-15); but this is already another discussion and we prefer a little reserve. Let's go back to the clinical risks of our skidding. It didn't take long and the hypocritical scholars, from us and not only, needed a panacea, a word to avoid the Christian criteria of performance, namely the virtues. They found this miraculous word, availability, which emerged, to our knowledge, during the disaster of the French Revolution when, after shortening almost all the country's authority, they needed replacements. And it was difficult to tell your relative, your unqualified people, the proficient one, -so there the available relatives and totally unqualified for those positions gathered in all the key positions. And it was fine! We jump over times and history and see that nothing is new under the sun. We persevere and insist on mistakes and no one has the courage to cure themselves. In hypocrisy to the spiritual level of the perfect creation, let us turn dizzyingly to apostasy: „De altfel, Duhul spune clar că în timpurile de pe urmă unii îşi vor renega credinţa, luându-se după duhuri înşelătoare şi invăţături diabolice, [seduşi] de ipocrizia discursurilor false ale celor însemnaţi cu fierul roşu în cugetul lor" ["In fact, the Spirit clearly says that in later times some will renounce their faith, they are deceived by evil spirits and evil teachings, [seduced] by the hypocrisy of the false speeches of those marked with red iron in their minds"] (1 Tim 4: 1-2). Where is the meaning and why cannot we apply this quality, the availability of the human after all, to the religious, theological, spiritual discourse? Without determining pretentious linguistic analyzes, we find that specialists have emphasized in the semantics of the word in question, that trait specific to the individual as a state of mind in which feelings and reason are freely manifested and in their fullness. They, precisely the Christian teaching and the customs of the whole society in mind, have established that the religious and social individual needs the discernment of the facts and the moral-religious censorship. The word I referred to is successfully used for the human empirical, material, social plan. And the remedy comes, of course, also from Jesus Christ, through the rock of the foundation of his apostles, through St. Peter in addition to the problem, strengthened and persevering for good: "Therefore, removing 
Bulletin of Integrative Psychiatry $\bigcirc$ New Series OSeptember 2021 Year XXVII ONo. 3(90)/129

ry

all evil and all deception, hypocrisy, envy, and all evil speech, as newborn babies, desire spiritual milk, pure, that you may grow through it to salvation if you have indeed tasted how good the Lord is". (1 Pet. 1-4). So, no psychiatric control.

For more than a year we have been going through the sanitary pan-madness. We all remember that at the beginning of these problems, they had to align with the sanitary requirements and the church spaces. Indeed, the leaders of the religious edifices cheered in unison. The people will follow us through the internet, through television, the media is at the service of the individual. We witnessed uplifting, emotional, funny moments, some really comical, regardless of the confession we were referring to. Later, the same religious leaders began to moan, to tell us how sad it is to see shepherds without sheep. What to do? A restart of inter-social communication is required: "Humans are social beings and need to manifest themselves as such in the simplest ways that affirm their belonging to humanity: reason and communication. Even if most of the time the thought process is associated with the particular effort of silencing and distancing from the surrounding voices, in order to become reason, as Kant says, must be said and shared. Thinking becomes consistent only when it is brought into light and made known to others, discussed, challenged, questioned and understood, otherwise it is simply an empty exercise. The state of isolation and distancing between people has disrupted this normal movement of man throughout the world. The individual's need for humanity (to be a student, to be a child, a doctor, a researcher or anything else, to live in these times of crisis, to live, to care and educate those in need, to make discoveries, and to find the most appropriate solutions) can only be supported by effective communication, which goes beyond the barriers imposed by isolation and physical distancing. In a timely manner a responsible and informative communication is able to eliminate ambiguities while leading to understanding, knowledge and education" (8).

\section{CONCLUSIONS}

Hypocrisy belongs to the hypocrite, that is, to the individual in his ontic integrity as an immortal body, spirit, and soul. The individual lives in the community, so its first concern must be to rethink the work of sensitizing the people to the culture of life, not to the culture of waste and spoiled graves. We must also start from within the Christian communities, reversing the pyramidal structure, placing the people at the center of our concerns. With great clearness and courage to ask ourselves what type of culture we promote today in the family, in schools and universities, in research laboratories, in government forums. With clarity and determination let us discern the next steps in the service of life with all the fullness of its truth. One of these steps is, of course, to promote all environments of life in which justice and solidarity are expressed through every act and gesture of love and where the pathology has been cured. 
The authors declare that they have no potential conflicts of interest to disclose.

\section{REFERENCES}

1. Tamaș I, Tamaș C.Premisele bioeticii moderne în activitatea lui N. I. Camilli, primul episcop al Bisericii RomanoCatolice din Moldova (1884-1894; 1904-1915).Revista Română de Bioetică. 2011;9(1).

2. Tamaș I.. Mic dicționar teologic. Sapientia. 2008:263-265.

3. Toate citările biblice sunt făcute după: Biblia. Sapientia. 2013.

4. Vocabular de teologie biblică. Ed. Arhiepiscopiei Romano-Catolice de București. 2001:273-274.

5. Decret despre Ecumenism, „Unitatis Redintegratio”.Conciliul Ecumenic Vatican II.Traducerea Arhiepiscopiei Romano-Catolice de București. 1990:117.

6. Iosif Tamaș.Episcopul Marcu Glaser și dezlănţuirea urgiei comuniste. Vasiliana 98.2015:30.

7.Raportul Mccarrick, o pagină dureroasă din care Biserica are numai de învăţat.10.11.2020.Vatican. www.Catholica.ro.

8. Pricop L.. Reason and communication: digital form of communication in response to the COVID-19 pandemic. Bulletin of Integrative Psychiatry. 2020; 26: 3 (86).

\section{Correspondence}

\section{Iosif Tamas,}

$\mathrm{PhD}$, researcher, Institute of Interdisciplinary Research, Departament of Social Sciences and Humanities, Alexandru Ioan Cuza University of Iași, iosifta@yahoo.com

Submission: 10 jun 2021

Acceptance: 19 aug 2021 


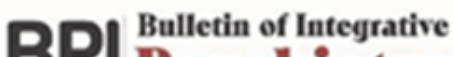

Psychiatry

Baletin de Roihlatrie Integrativa

\section{Case Reports}





\title{
Particularities and limitations of kinesiotherapy in genetic disorders and their medical recovery - Russell-Silver Syndrome: a case report
}

\author{
Adina Sorina Mitrică, Avram Carmen, Ada Bargau Petrache, \\ Adrian Cantemir, Vlad Teodor Iacob
}

\begin{abstract}
Adina Sorina Mitrică - Senior Kinesiotherapist, County Clinical Hospital "Saint Apostol Andrei”, Constanța

Avram Carmen - Senior M.D. in Physical Medicine and Balneology, Clinical Rehabilitation Hospital "Băile Felix", Children`s ward 1 Mai

Ada Bargau Petrache - Junior Pediatric Cardiologist, County Clinical Hospital "Gavril Curteanu", Oradea

Adrian Cantemir - M.D., PhD, Assistant Professor, "Grigore T. Popa" University of Medicine and Pharmacy Iaşi, Romania

Vlad Teodor Iacob - M.D., PhD student, “Socola” Institute of Psychiatry, Iași, Romania
\end{abstract}

\begin{abstract}
While some authors still separate the Russell-Silver syndrome as two independent disorders, it is presently considered as one whole entity. It is a rare syndrome, with over 400 reported cases (1). The first reported cases were in children with the syndrome's characteristic facial features, low birth weight, body asymmetry, and poor growth after birth (2), growth failure being the primary abnormality (3). Patients typically present with intrauterine growth retardation, difficulty feeding, failure to thrive, or postnatal growth failure $(4,5)$. The clinical features are more evident in infants or young children (6).
\end{abstract}

Methods. We present a 19-month-old girl, admitted to our hospital for functional rehabilitation due to mildly severe neuromotor retardation, associated with severe malnutrition, low body weight, congenital heart malformation and gastroesophageal reflux. We evaluated the child and her motion of joints and strength of muscles using, among other tests, the Gross Motor Function Measure (GMFM) scale. She underwent a kinesiotherapy program in order to enhance and rise her motor skills according to her chronological age. 
r.m\%\%\% Results. For one year, rehabilitation treatment improved muscle tone, motor skills, posture and spine alignment. Also, a specific kinesiotherapy program at home resulted in a systematic improvement in growth and development in this case.

Conclusions. Genetic anomalies are always a challenge for therapists. An early intervention program, in this particular case, is highly beneficial.

\section{KEY WORDS:}

\section{Kinesiotherapy, rehabilitation, Russell-Silver Syndrome.}

\section{INTRODUCTION}

Russell-Silver Syndrome (RSS) is a rare congenital imprinting disorder with a wide array of clinical presentations, but also with many characteristic features such as:

- Low birth weight and short stature, which frequently lead to difficulties regarding diagnosis and treatment

- Hypotonia, which is frequently related to neurological disorders, is more often present in newborns until they reach adolescence than in teenagers or adults. The increased frequency of hypotonia is correlated with the survival of children born prematurely with consecutive neurological impairments.

While RSS was first described separately by the two authors, due to similarities, it is now considered the same entity.

One of RSS's main features is growth retardation with a prenatal onset and a slow developmental regression, to which are added some anomalies that give it a characteristic facial appearance, easily recognizable.

\section{CASE REPORT}

\section{Reasons for admission}

The patient, aged 1 year and 7 months, was admitted for functional recovery treatment due to growth delay with short stature and poor weight gain, and moderate delay in psychomotor skills.

\section{Medical history}

Family history: healthy father, while the mother was diagnosed with multinodular goiter and hyperthyroidism.

The patient is the first-born, with a premature birth by cesarean section and dysgravidy, at 36 weeks, with a weight of 1900 grams, length of $45 \mathrm{~cm}$, Apgar score 7/8, resuscitated at birth using a bag valve mask and tactile stimulation.

Early postnatal, she has a functional respiratory disorder, neonatal hypoglycemia, E. coli infection in the amniotic fluid, and was treated with antibiotics and mixed feeding.

At 2-months-old, she was diagnosed with dysphagia, hypoxic-ischemic encephalopathy, neuromotor retardation, developmental coordination disorder, craniofacial dysmorphism, moderate protein-calorie malnutrition and treated with Pyritinol at the Children's Clinical Hospital in Oradea.

At 3-months-old, in the Pediatric Clinic II in Cluj-Napoca, she is presumed to have esophageal stenosis, for which a nasogastric tube for feeding was inserted.

At 4-months-old, while admitted for interstitial pneumonia in Oradea, she was diagnosed with an atrial septal defect, type ostium secundum, right to left shunt; pulmonary hypertension and paroxystic 
supraventricular tachycardia, and megaesophagus.

At 5-months-old, while admitted to the Pediatric Clinic III in Cluj-Napoca for vomiting and growth failure (Ponderal Index $=0,66)$, a metabolic genetic disorder is suspected.

At 6-months-old, she is fed by gavage, her weight is stagnant, her caloric intake is limited due to refusing food, all of which with a lack of hypoproteinemia excludes malabsorption syndrome.

From the age of 9 months, she slowly gained weight and at 1-year-old, she was genetically investigated due to severe hypotrophy.

At the age of 1 year and 2 months, an MRI showed adenohypophyseal hypoplasia and demyelination of the periventricular white matter (secondary lesions due to hypoxia).

At the age of 1 year and 3 months, she was investigated at the Universita di Roma and underwent genetic testing, which led to a presumed diagnosis of Russell-Silver Syndrome

\section{Initial assessment}

- Hypotrophy due to growth delay, with a height of $67 \mathrm{~cm}$, weight of $5,2 \mathrm{~kg}$ and head circumference of $47 \mathrm{~cm}$ (ideal for her age being a height of $81,5 \mathrm{~cm}$ and weight of $11 \mathrm{~kg}$ )

- Characteristic triangular facies, prominent supraorbital ridge, fontanelle $2 / 3 \mathrm{~cm}$, pigmented skin.

- Axial hypotonia, accentuated dorsolumbar kyphosis in the sitting position.

- Hypotonia in all four limbs, symmetrical muscular hypotrophy, dynamic knee valgus.
- From the supine position, supported from the chest by the physiotherapist, she does not raise her head.

- She does not get into a sitting position; She does not get into orthostatism without assistance.

- Walking is only possible with bilateral support; walks with a wide base of support, asymmetric, with stability and balance disorders.

\section{Kinetic objectives}

- Obtaining orthostatism.

- Improved postural control.

- Enhancing sensorimotor and functional deficits.

- Improvement of muscle tone and kinetic balance by learning balance control strategies (ankle, knee, hip strategy) and by learning controlled falls.

- Toning the muscle groups involved in breathing.

- Increasing physical training while monitoring blood glucose levels.

- Correcting her dynamic and static body posture (reverting her hyperlordosis).

\section{Results at her latest evaluation}

- Height of $80 \mathrm{~cm}$ and weight of $7000 \mathrm{~g}$.

- Normal spinal curvatures

- The upper limbs show normal muscle development and the patient can use them to achieve activities of daily living (ADL).

- The lower limbs show a muscular toning that allows the child to walk independently over long distances, to walk on rough terrain, to walk up and down a ramp, going up and down the stairs and running. 
- From the supine position, she can flex her head and neck while supporting her elbows.

- She can independently obtain orthostatism.

\section{CONCLUSIONS}

Early detection and treatment of children with RSS decisively influence recovery and future integration possibilities.Motivation for movement is very important throughout treatment. Teamwork that involves all the specialists who work with the child: recovery doctor, physiotherapist, occupational therapist and the patient's family can determine favourable developments.

During physical therapy programs, the child should practise various postures to comprehend all the different sensations that come with them.

The effectiveness and rigour of personal hygiene programs, nutrition (one hour before and after physical therapy, it is recommended to not consume anything) must be observed, and in this case, kinesiotherapy is contraindicated if it is not supported by a hypercaloric diet.

Special attention must be paid to the development of the body scheme.

In the recovery process, there is no standardized program, it varies from individual to individual, which is why we consider it important to take into account all the neuro-psycho-motor and physiological elements of each individual and the whole range of means kinesiotherapy has to offer. Physical therapy will focus on achieving psychomotor skills, especially static function, dynamic function, global coordination, manual dexterity, trunk flexibility, speed of arm movement, lower limb strength.

Achieving a correct alignment of the spine has been the key to achieving the other goals successfully and will soon allow the child's integration into a kindergarten that addresses normal children.

\section{ACKNOWLEDGEMENTS AND DISCLOSURES}

The authors state that there are no declared conflicts of interest regarding this paper.

\section{REFERENCES}

1. Tubbs RS, Wellons JC, Oakes WJ. Russell Silver syndrome and tethered spinal cord. Child's Nervous System. 2004 Jul;20(7):473-5.

2. Price SM, Stanhope R, Garrett C, Preece MA, Trembath RC. The spectrum of Silver-Russell syndrome: a clinical and molecular genetic study and new diagnostic criteria. Journal of medical genetics. 1999 Nov 1;36(11):837-42.

3. Şıklar Z, Berberoğlu M. Syndromic disorders with short stature. Journal of clinical research in pediatric endocrinology. 2014 Mar;6(1):1.

4. Prasad NR, Reddy PA, Karthik TS, Chakravarthy M, Ahmed F. A rare case of Silver-Russell syndrome associated with growth hormone deficiency and urogenital abnormalities. Indian journal of endocrinology and metabolism. 2012 Dec;16(Suppl 2):S307.

5. Yamaguchi Jr KT, Salem JB, Myung KS, Romero Jr AN, Skaggs DL. Spinal deformity in Russell-Silver syndrome. Spine deformity. 2015 Jan 1;3(1):95-7. 
Bulletin of Integrative Psychiatry O New Series OSeptember 2021 OYear XXVII ONo. 3(90)/137

(n) 6. Ranke MB, Price DA, Reiter EO, editors. Growth hormone therapy in pediatrics: 20 years of KIGS. Karger Medical and Scientific Publishers; 2007.

\section{Correspondence:}

Adina Sorina Mitrică,

Senior Kinesiotherapist County, Clinical Hospital "Saint Apostol Andrei”, Tomis Blvd 145, Constanţa, Romania, adinacozac2@gmail.com

Submission: 12 aug 2021

Acceptance: 11 sep 2021 



\section{Instructions for authors}

The Bulletin of Integrative Psychiatry publishes blind peer reviewed articles, reviews, updates, meta analyses, original papers, case reports in the following fields of research: psychiatry correlated with philosophy, ethics, meta ethics, bioethics, aesthetics, economy, sports, nutrition, law, forensic medicine, political sciences, communication science ,sociology, social assistance, anthropology, cultural anthropology, literature, religion. The journal is published quarterly in English.

Articles are submitted to the discussions in meetings of the Editorial Board, being subjected to a blind peer review evaluation from two specialists in the field.

Evaluating the scientific value and originality of the article, as well as its layout, grammar and structure and the way in which the guidelines for publication have been observed, the final publication decision is made by the editor-in- chief and the advisory board. It is also required that the article admitted for publication should represent a substantial contribution in the field, and the data included are correct and pertinent.

There are no author fees and all articles are made free access on line.

In the Declaration of Interests, authors must indicate any financial and personal relationships with other people or organizations that could influence in an incorrect way their work.

Conflict of interests can refer to financial relationships and academic competition.

Authors should not submit articles that have been published or sent for publication to other journals.

Bulletin of Integrative Psychiatry, accept for publication the following types of works (articles): reviews, updates, meta analysis, original papers, case report

Fields of research: psychiatry correlated with philosophy, ethics, metaethics, bioethics, esthetics, economy, sports, nutrition, law, forensic medicine, political sciences, communicational sciences, sociology, social assistance, anthropology, cultural anthropology, literature, religion etc.

\section{Manuscript Criteria and Information}

Manuscripts and all attached files should be submitted in electronic form and on paper.

The electronic form should be submitted, either on compact disk or by e-mail (see at end). It is preferable that two copies (in English and Romanian) of the manuscript, printed on one side of A4 paper format, single-spaced, with $2 \mathrm{~cm}$ margins, be also submitted to the same address. The manuscript should be accompanied by a cover letter including the statement on authorship responsibilities form, the statement on ethical considerations and the statement on financial disclosure (For more information please see directions on website).

\section{Authorship}

All named authors should meet the criteria for authorship as stated in the "Uniform Requirements for Manuscripts Submitted to Biomedical Journals: Writing and Editing for Biomedical Publication" issued by the International Committee of Medical Journal Editors (www.icmje.org). 
Ethical considerations

If the scientific project involves human subjects or experimental animals, authors must state in the manuscript that the protocol has been approved by the Ethics Committee of the institution within which the research work was undertaken. All authors are responsible for adhering to guidelines on good publication practice.

\section{Financial Disclosure}

The manuscript should be accompanied by a cover letter including the statement on financial disclosure. The statement on conflicts of interest will be published at the end of the paper. Please submit all requested signed documents by regular mail to the Secretariat. Scanned copies sent electronically and fax submissions are not acceptable.

\section{Corrections}

Scientific fraud is rare events; however, they have a very serious impact on the integrity of the scientific community. If the Editorial Board uncovers possible evidence of such problems it will reserves the right to take all steps it considers necessary for the elucidation of the situation, including possibility to publish errata, corrigenda, or retractions.

\section{Copyright}

The papers published in the Journal and protected by copyright. Their full or partial publication in other journal is allowed only with the written approval of the publisher.

\section{Manuscript Preparation}

- Romanian authors should send both the Romanian and English version of the article, including title, abstract and key words. Foreign authors should send the English version of the article.

- Manuscripts must be prepared in conformity to the "Uniform Requirements for Manuscripts Submitted to Biomedical Journals: Writing and Editing for Biomedical Publication" issued by the International Committee of Medical Journal Editors (www.icmje.org).

- Articles must be written in Microsoft Word, Style: Normal + Justify, Font: Times New Roman, size 12. All manuscripts must be typed single-spaced. Original source files (not PDF files), are required. In text editing, do not use spacing with spacebar, or paragraph mark, use only Enter or Tab key.

- Subheadings of the article should be left-justified, typed with capital letters, Font: Times New Roman, size 12.

- The abstracts and Key words must be written in Microsoft Word, Style: Normal + Justify, Font: Times New Roman, size 12.

- Use as few formatting commands as possible:

o input your text continuously (without breaks);

o do not use different types of fonts to highlight your text;

$\circ$ any word or phrase that you would like to emphasize should be indicated throughout the text by underlining;

○ use only the "Enter" key to indicate the end of the end of paragraphs, headings, lists etc.;

o do not use the "Space Bar" to indicate paragraphs, but only the "Tab" key

- Figures must be cited in order in the text using Arabic numerals, (e.g., fig.2). Their width should be max. $13,5 \mathrm{~cm}$. The figures have to satisfy the following conditions: 
- Black and white photographs with good contrast, with recommended size;

- Scanned photograph with a resolution of minimum 300 dpi and edited on a computer, original file (*JPG);

- Illustrations (drawings, charts) created on a computer, cited in the text, original file (*XLS, *CDR). Every figure should be accompanied by a title and a legend.

- Tables, numbered consecutively with Latin numerals (e.g., Tab. II), should have a width of max. 13,5 cm. Every table should be also accompanied by a title and a legend. The distribution of tables and figures in the text should be balanced.

- Please do not import tables or figures into the text document, but only specify their insertion in text (e.g., Table No.III insertion). They have to be sent in separate files. Files should be labeled with appropriate and descriptive file names.

- Abbreviations shall be avoid. If used, will occur preceded by the full term at their first apparition in text. A list of all used abbreviations shall be made at the end of the article,

- Separate pages: tables, graphics, pictures and schemes will appear on separate pages.

- You may use a common compression program: ARJ, RAR or ZIP.

\section{Manuscript organization}

Article title: titles should be short, specific, and descriptive, emphasizing the main point of the article. Avoid a 2-part title, if at all possible. Do not make a declarative statement in the title. Title length, including punctuation and spaces, ideally should be under 100 characters and must not exceed 150 characters.

\section{Manuscript Size}

- Original paper - 8 pages/3500 words;

- Review and update - 8 pages/3500 words;

- Case report - 4 pages/1700 words;

- Clinical notes - 3 pages/1300 words;

- Letters to editor, information scientific reunions - one page/450 words.

Author(s). First name, middle initials and surname of the authors, without any scientific, didactic or military degrees; (e.g., Mircea A Popescut, Aura Vasilescu, not Popescu M.A., Vasilescu A.).

Footnote that specifies the authors' scientific titles, professional title, name and address of their workplaces (institution and department) for each author; contact details of the corresponding author (full address, telephone number, fax number, e-mail address) and the address of the institution and department where the study has been carried out. Contact details will be published unless otherwise requested by the author.

Abstracts in in English and Romanian, should have max. 300 words. For original articles is advisable to include five paragraphs, labeled Background, Objective(s), Method(s), Result(s), and Conclusion(s).

Keywords maximum of 6 keywords (minimum of 3). Keywords should not repeat the title of the manuscript. 


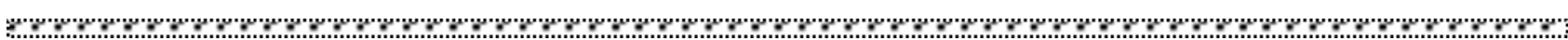

Original papers organized in:

- Introduction (no more than $25 \%$ of the text), material and methods, results, comments or discussions and acknowledgements.

- Material and methods have to be described in enough detail to permit reproduction by other teams. The same product names should be used throughout the text (with the brand name in parenthesis at the first use).

- Results should be presented concisely. Tables and figures should not duplicate text.

- Discussions should set the results in context and set forth the major conclusions of the authors.

- Information from the Introduction or Results should not be repeated unless necessary for clarity. The discussion should also include a comparison among the obtained results and other studies from the literature, with explanations or hypothesis on the observed differences, comments on the importance of the study and the actual status of the investigated subject, unsolved problems, questions to be answered in the future.

- Acknowledgements section must disclose any substantive conflicts of interest in addition to the customary recognition of non-authors who have been helpful to the work described.

References. References should be numbered consecutively in the order in which they are first mentioned in the text. Identify references in text, tables, and legends by Arabic numerals in parentheses. The reference list will include only the references cited in the text (identified by Arabic numerals in parentheses, not in square brackets and not bold). All authors should be listed when four or less; when five or more, list only the first three and add "et al" (Popescu I, Popescu I, Vasile V. et al). The name of the Journals cited in the References should be abbreviated according to ISI Journal Title Abbreviations.

It is absolutely imperative that references to be entered in the text!!

\section{Examples:}

- Reference to a journal publication:

Amura SG.: Neurotransmitter transportor: recent progress. Ann Rev Neurosci 1993; 16; 73-93.

Tonis PJ, von Sandick JW, Nieweg OE, et al.: The hidden sentinel node,in breast cancer. Eur J Nucl Med 2002; 29: 305-311

- Reference to a book:

Ashcroft FM.: Ion channels and disease, San Diego, London: Academic Press, 2000, pp. 26-52.

\section{- Reference to a chapter in an edited book:}

Pandiom MR, Fischer DA. Immunoradiometric assays. In: Scabes CG, editor. Handbook of Endocrine Research Techniques. New York, London: Academic Press, 1993, 26-52 The punctuation and the general aspect of the text format must comply with the rules mentioned above. This is a mandatory and eliminatory condition.

\section{ACKNOWLEDGMENTS AND DISCLOSURE}

Authors: an "author" is generally considered to be someone who has made substantive intellectual contributions to a published study, and biomedical authorship continues to have important academic, social, and financial implications (1). An author must take responsibility for at least one 
s component of the work, should be able to identify who is responsible for each other component, and should ideally be confident in their co-authors' ability and integrity.

We strongly encourage developing and implementing a contributor ship policy, as well as a policy on identifying who is responsible for the integrity of the work as a whole.

Disclosure: The authors must declare if they have or not a potential conflicts of interest to disclose. Acknowledgments: All contributors who do not meet the criteria for authorship should be listed in an acknowledgments section. Authors should declare whether they had assistance with study design, data collection, data analysis, or manuscript preparation. If such assistance was available, the authors should disclose the identity of the individuals who provided this assistance and the entity that supported it in the published article. Financial and material support should also be acknowledged.

\section{PEER REVIEW PROCESS}

Although the practice of peer review started 300 years ago, only since 198s the process has been active to analyze if articles sent to journals are well-written, correctly edited and represent reliable sources of information.

All manuscripts intended for publication will be subject to blind peer-review by a committee of experts which assesses the scientific and statistical correctness of articles submitted. The committee receives the manuscripts without knowing the authors' name and proposes possible changes, which will be transmitted to the authors by the medium of Editorial Board. The authors have the obligation to oversee the text in English language with the help of a professional translator.

When submitting a paper, a confirmation email is automatically sent back to the author. It contains a unique registration number used as a referral in further correspondence.

Initially, the editorial team verifies whether the manuscript complies with the editing instructions. If the paper does not meet the necessary requirements, it is rejected and the corresponding author is notified to correct the errors. If all instructions for editing have been followed accordingly, the editor selects two reviewers that will independently evaluate the paper. They have high expertise in the "peer-review" system and are well-known specialists in the field. The reviewers have all academic affiliations and may be already accredited by the Journal or specifically contacted for certain papers. Their affiliation is usually different from the one of submitting authors.

The editor sends the paper in both electronic and printed format to each reviewer with the invitation to evaluate it within 15 days. The reviewers will analyze the paper from several perspectives such as clarity, objectivity of data, scientific quality and relevance. A scale from 1 to 5 is used, where 5 is excellent and 1 is poor. The reviewers score the paper accordingly and issue a recommendation. The existence of a manuscript under review is not revealed to anyone other than peer reviewers and editorial staff. Peer reviewers remain anonymous and are expected to maintain strict confidentiality. After the review process has been completed, authors will be informed by mail of the Editor's decision.

Reviewers should inform the editor about suspected plagiarism. 
Mandatory fill and send "Cover letter for submission of manuscript" and "Declaration of Interests and disclosure form", which you can download from the website of Bulletin of Integrative Psychiatry (www.buletindepsihiatrie.ro).

\section{Ethical Considerations}

Authors of articles should sign a statement assuming the responsibility for the originality, property rights and ethical implications of their work. Authors should obtain permission or copy right to publish figures, images or tables from other journals whose material they use.

A written consent must be obtained from patients when personal information or images of patients are included in the article. Authors must state that the protocol has been approved by the Ethics Committee of the institution where the research was conducted.

\section{Address to send the manuscripts is:}

Buletin de Psihiatrie Integrativa/ Institutul de Psihiatrie "Socola" Iasi

Lecturer Alexandra Bolos: Institutul de Psihiatrie "Socola” Iasi, Șos. Bucium 36, 700282, Iasi, jud. Iasi; E-mail: contact@buletindepsihiatrie.ro 